Cite this: J. Anal. At. Spectrom., 2014, 29, 17

Received 4th November 2013

Accepted 4th November 2013

DOI: 10.1039/c3ja90068a

www.rsc.org/jaas
1

Review papers

1.2

1.3

1.4

1.4.1

1.4 .2

1.4.3

1.4.3.1

1.4.3.2

1.4 .4

1.4.5

1.5

2

2.1

2.2

2.3

2.4

2.4.1

2.4.2

2.4.3

2.4.4

2.4.5

3

3.1

3.2

3.3

3.3.1

3.3.2

3.4

3.4.1

3.4.2

Speciation

spectrometry
Sampling techniques

Sample preparation

Instrumental analysis

Atomic absorption spectrometry

Emission spectroscopy

Mass spectrometry

Inductively coupled plasma mass spectrometry

Other mass spectrometry techniques

X-ray spectrometry

Combustion and spectrometric techniques

Data analysis and quality

Water analysis

Sample preparation

Sample preconcentration and extraction

Instrumental analysis

Atomic absorption spectrometry

Inductively coupled plasma atomic emission

Inductively coupled plasma mass spectrometry

X-ray fluorescence spectrometry

Laser induced breakdown spectroscopy

Analysis of soils, plants and related materials

Review papers

Reference materials

Sample preparation

Sample dissolution and extraction

Sample preconcentration

Instrumental analysis

Atomic absorption spectrometry

Atomic emission spectrometry
${ }^{a}$ Health and Safety Laboratory, Harpur Hill, Buxton, UK SK17 9JN. E-mail: owen. butler@hsl.gsi.gov.uk

${ }^{b}$ CNR-IDPA, Universita Ca' Foscari, 30123 Venezia, Italy

${ }^{c}$ British Geological Survey, Keyworth, Nottingham, UK NG12 $5 G G$

${ }^{d}$ University of Strathclyde, Cathedral Street, Glasgow, UK G1 1XL

$\dagger$ Review coordinator.

\begin{tabular}{ll} 
3.4.3 & Atomic fluorescence spectrometry \\
3.4.4 & Inductively coupled plasma mass spectrometry \\
3.4.5 & Accelerator mass spectrometry \\
3.4.6 & Laser induced breakdown spectroscopy \\
3.4.7 & X-ray spectrometry \\
4 & Analysis of geological materials \\
4.1 & Reference materials \\
4.2 & Solid sample introduction \\
4.2.1 & Laser ablation \\
4.2.2 & Laser induced breakdown spectroscopy \\
4.3 & Sample preparation \\
4.3.1 & Sample dissolution \\
4.3.2 & Sample separation and preconcentration \\
4.4 & Instrumental analysis \\
4.4.1 & Atomic emission spectrometry \\
4.4.2 & Inductively coupled plasma mass spectrometry \\
4.4.3 & Other mass spectrometric techniques \\
4.4.3.1 & Thermal ionisation mass spectrometry \\
4.4.3.2 & Secondary ion mass spectrometry \\
4.4.3.3 & Accelerator mass spectrometry \\
4.4.4 & X-ray spectrometry \\
5 & Glossary of terms \\
6 & References \\
& \\
\hline
\end{tabular}

This is the 29th annual review of the application of atomic spectrometry to the chemical analysis of environmental samples. This Update refers to papers published approximately between September 2012 and July 2013 and continues the series of Atomic Spectrometry Updates (ASUs) in Environmental Analysis ${ }^{1}$ that should be read in conjunction with other related ASUs in the series namely: clinical and biological materials, foods and beverages; ${ }^{2}$ advances in atomic spectrometry and related techniques; ${ }^{3}$ elemental speciation; ${ }^{3} \mathrm{X}$-ray spectrometry ${ }^{4}$ and advances in the analysis of metals, chemicals and materials. ${ }^{5}$ In the field of air analysis, highlights within this review period include measuring the bioaccessible fraction of metals in particles and ongoing work in assessing the performance of optical and combustion techniques for the determination of the carbonaceous content of airborne 
particulate matter. Developments in instrumentation included new sampler designs for the collection of nanoparticles, the coupling of FFF and hydrodynamic chromatography to ICP-MS for the sizing and compositional analysis of such particles and the ongoing development of aerosol mass spectrometry. In the field of water analysis, new procedures for the detection and quantification of emerging pollutants in water such as MRI contrast agents have been developed. Instrumental developments reported include the use of molecular absorption spectrometry, by exploiting the CS-AAS technique, for measuring halogen species in water. Numerous articles involving the application of atomic spectrometry to plants, soils and related materials appeared in this review period but, as usual, most were concerned with the environmental significance of the results, rather than the methodology used to obtain them. Nevertheless, there have been some interesting developments. Both LIBS and PXRF spectrometry have been used more widely, variants such as LA-LIBS and microwave assisted LIBS have appeared, and PXRF spectrometry has been applied for the first time in the analysis of plants. Developments in geochemical analysis include the production and (re)certification of new geological RMs for bulk, isotopic and microspatial analysis. Optimisation of LA-ICP-MS techniques for the interrogation of geochemical samples continues to be reported and a number of useful instrumental review articles (AMS, ICP-MS and SIMS) have been published. Feedback on this review is most welcome and the review coordinator can be contacted using the email address provided.

\section{Air analysis}

\subsection{Review papers}

Reviews have addressed: isotopic techniques and methodologies for assessing the origins and fate of pollutants ${ }^{6}$ (71 references); on-line aerosol MS for speciation analysis ${ }^{7}$ (31 references) and the chemical analysis of single particles in ambient ultrafine aerosols ${ }^{8}$ (88 references). Consolidation of knowledge regarding emerging pollutants is most welcome, such as the review by Harrison's group ${ }^{9}$ (271 references) on nanoparticle emissions from 11 non-vehicle exhaust sources and a review on the properties, production, uses, environmental fate, toxicity and analysis of phosphorus flame retardants ${ }^{\mathbf{1 0}}$ (105 references). Studies on the bioaccessibility of metals in airborne particles have increased in number in recent years so a review $^{\mathbf{1 1}}$ (86 references) on the approaches developed for the extraction of soluble metals was timely. The review also covered analytical techniques for the determination of dissolved species in the presence of complex sample matrix, i.e., leachates, and included a useful compilation of published results for bioaccessible trace metals in airborne particles.

\subsection{Sampling techniques}

The development of personal workplace air samplers, used to monitor workers' exposure to airborne particles, continues to be a fertile area of research. The design of a new microtrap inertial impactor $^{12}$ utilised a high-density multijet plate to direct airflow and a matched mutiwell plate to collect particles by impaction.
The advantage of this system over current impactor samplers with fewer jets is a reduced pressure drop at comparable flow rates with favourable consequences for power consumption and potential for further miniaturisation. A microscale cascadeimpactor using a novel soft lithography process ${ }^{13}$ included three impaction stages with $50 \%$ cut-points experimentally determined to be $1.19,0.55$ and $0.26 \mu \mathrm{m}$, when operating at a nominal $0.5 \mathrm{~L} \mathrm{~min}^{-1}$. Particle bounce and re-entrainment were minimised by spin-coating of silicon oil onto the impaction targets. The overall particle losses were determined to be $<10 \%$ for $0.2-$ $2.5 \mu \mathrm{m}$ particles and $<12 \%$ for particles in the $0.05-0.2 \mu \mathrm{m}$ range.

For the interrogation of nanoparticles, TEM coupled with EDS offers a powerful analytical tool for the determination of size, morphology and elemental composition. Sampling airborne particles directly onto TEM grids therefore makes sense as sample preparation time can be reduced and the potential for sample alteration or contamination minimised. Two commercially available TEM porous grids that allowed particles to be collected through filtration were evaluated. ${ }^{\mathbf{1 4}}$ Collection efficiencies were $c a$. $18 \%$ for a nominal $30 \mathrm{~nm}$ size particle. A filter holder, the mini particle sampler, was specifically designed for this evaluation project to mount such grids and this new system was deemed suitable for sampling NPs in the size range 5-150 nm.

Following on from work reported in this ASU review last year on the development of field-portable FTIR systems ${ }^{15}$ for the determination of silica in coal dust, workers at $\mathrm{NIOSH}^{\mathbf{1 6}}$ have now investigated the uniformity of coal dust deposition on filters and its effect on the accuracy of FTIR analysis. As with other microbeam techniques, use of FTIR analysis entails localised spot analysis and, as such, the spatial uniformity of dust deposition can affect accuracy and measurement repeatability. Three different sampler devices were evaluated using test filters loaded with silica and coal dust reference powders. The silica content was measured by FTIR spectrometry at nine locations across the face of each filter sample. Amongst a number of observations was the major conclusion that a single measurement shot at the centre of the filter was adequate for a fieldbased method. The average bias was $c a .10 \%$ and repeatability was ca. $15 \%$.

Cascade impactor samplers are used to measure aerosol mass at different particle cuts and collected samples can further be analysed for chemical components. Concerns when using such samplers include solid particle bounce, overloading of collected particles on the impaction plate, interstage loss and clogging due to long-term or high-concentration sampling. Tests ${ }^{17}$ on a widely used system-MOUDI-showed that losses for particles $<40 \mathrm{~nm}$ in size could be $>20 \%$ and that nozzle plates with conventional step-shape nozzles could be prone to particle clogging. However, by using a lithographic technique to replace such nozzles with ones fabricated with smooth surfaces, the extent of clogging could be reduced. In addition, this new design was easier to clean between sampling exercises.

Passive samplers for collecting both gaseous and particle species from the atmosphere can be a cost-effective alternative to pumped samplers and are amenable for large-scale deployment in field sampling exercises. A disadvantage, however, is that the accuracy and precision of such devices may not meet 
sampler performance standards often prescribed for regulatory measurements. A new calcium-aluminium oxide-based absorbent ${ }^{18}$ was designed for the diffusive sampling of atmospheric $\mathrm{CO}_{2}$. Use of a range of techniques such as XRD analysis, electron microscopy and TGA showed that hydration of this absorbent was an essential part of the process of $\mathrm{CO}_{2}$ absorption and subsequent conversion to carbonate. The diffusion uptake rate was $47 \pm 3 \mathrm{~mL} \mathrm{~min}^{-1}$ and the LOD $40 \mathrm{ppm}$ for samples collected over two days at $25{ }^{\circ} \mathrm{C}$. When the samplers were deployed in triplicate in the field, the inter-sampler precision was $c a$. $6 \%$. There was good correlation (Pearson's correlation coefficient $=$ 0.879 ) between results obtained by this method and those obtained using a pumped sampler employing a reference NDIRS detection system. A passive aerosol sampler ${ }^{19}$ employed electron microscopy to measure concentrations and size distributions of airborne particulate matter. Measurement precision of this sampler, determined by deploying duplicate pairs of samplers in the field, was predominately $<20 \%$ for both $\mathrm{PM}_{2.5}>5 \mu \mathrm{g} \mathrm{m}{ }^{-3}$ and $\mathrm{PM}_{10}>20 \mu \mathrm{g} \mathrm{m} \mathrm{m}^{-3}$. A new deposition sampler ${ }^{20}$ employing industry standard $37 \mathrm{~mm}$ diameter filters could be used in different configurations such as suspension from a support with or without a protective windshield or as a suspended dust collection plate. An XRF ready option allowed sampling onto a filter cartridge assembly which could then be loaded directly into an XRF system for analysis. Initial wind tunnel tests using test aerosols of known particle size indicated that this sampler could collect representative particle size distributions.

Generation of test particle atmospheres in a laboratory environment is difficult and it is most informative to see publications describing the development and validation of aerosol test chambers. A system ${ }^{\mathbf{2 1}}$ for source characterisation and controlled human exposure to NPs generated during gas-metal arc welding had an airtight $22 \mathrm{~m}^{3}$ climate-controlled stainless steel chamber at its core. A variety of on-line measurements, e.g., using TEOM or SMPS, and offline measurements, e.g. using electron microscopy and PIXE techniques, could be made via sampling ports/samplers. Test particles were generated in a separate chamber and subsequently piped into the main chamber. Stable concentrations of atmospheric particles could be maintained for up to $6 \mathrm{~h}$ and concentrations could be varied from $<5 \mu \mathrm{g} \mathrm{m}{ }^{-3}$ to $>1000 \mu \mathrm{g} \mathrm{m}^{-3}$ by dilution with clean filtered air. When this system was used ${ }^{22}$ to evaluate NPs generated from burning of scented candles in a simulated indoor environment, additional techniques such as IC, combustion and a TOF-MS were employed. There is increased concern that workers may be at risk of adverse health effects through exposure to CNTs which are increasingly being used in industry. Researchers at NIOSH designed a CNT aerosol respirator testing facility ${ }^{23}$ for assessing the penetration of CNTs through half-mask and filtering-facepiece respirators commonly used to protect workers.

The generation of test particles within a laboratory setting can be achieved in many different ways. The most commonly used generators, spark device generators, and the theory of their operation have been reviewed ${ }^{24}$ (60 references). These generators are already widely used in semi-conductor and materials research, and health and environmental studies and can produce high-purity particles over the entire 1-100 $\mathrm{nm}$ range. The high-velocity impact ${ }^{25}$ of $\mathrm{Al}$ or $\mathrm{Cu}$ cylinders of various lengths onto a steel anvil target $(7.6 \mathrm{~mm}$ caliber, 23 or $38 \mathrm{~mm}$ in length, fired from a gas gun at velocities of up to $195 \mathrm{~m} \mathrm{~s}^{-1}$ ) resulted in a particle number distribution with a mode of $10 \mathrm{~nm}$. The goal of establishing a methodology for the production of soot particles resembling those emitted from internal combustion engines has led researchers ${ }^{\mathbf{2 6}}$ to evaluate the properties of particles produced under different operating conditions, using a commercially available and widely used combustion aerosol standard (CAST) generator. It was concluded that detailed and well-defined operational procedures were required if CAST systems were to be used to generate particles for instrument calibration.

\subsection{Sample preparation}

A closed-vessel microwave-assisted digestion method ${ }^{27}$ was evaluated for the ICP-MS determination of trace and major elements in atmospheric aerosol samples collected on commonly used quartz-fibre filters. The use of $\mathrm{HF}$ was a prerequisite in dissolving the filter media but a consequence of its use was the potential for precipitation of insoluble fluoride compounds. Three approaches were examined for minimising this unwanted reaction: evaporation of excess HF using a microwave-assisted evaporation accessory; addition of boric acid to complex free fluoride ions; and a mixture of these two procedures. The hybrid approach was deemed to be the most

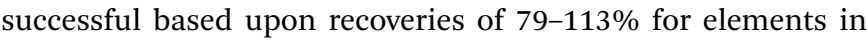
NIST SRM 1633b (constituent elements in coal fly ash) and 8098\% for elements in INCT CRM FFA-1 (elements in fine fly ash). Alternatively, a simple ultrasound-assisted extraction ${ }^{28}$ involving a $\mathrm{HNO}_{3}-\mathrm{HF}$ acid mixture has been proposed. Recoveries were $80-120 \%$ for a range of elements $(\mathrm{Ag}, \mathrm{Al}, \mathrm{As}, \mathrm{Ba}, \mathrm{Be}$, $\mathrm{Cd}, \mathrm{Co}, \mathrm{Cr}, \mathrm{Cu}, \mathrm{Fe}, \mathrm{Mn}, \mathrm{Mo}, \mathrm{Ni}, \mathrm{Pb}, \mathrm{Sb}, \mathrm{Se}, \mathrm{Sr}, \mathrm{U}, \mathrm{V}$ and $\mathrm{Zn}$ ) in four RMs, namely NIST SRMs 1633b (constituent elements in coal fly ash), 1648 (urban particulate matter), 2584 (trace elements in indoor dust) and 2710 (Montana soil). Similar recoveries were obtained when the study was replicated in a different laboratory indicating that the method was both reliable and reproducible. As a further indicator of data quality, indoor air samples collected on filters were analysed initially by EDXRF spectrometry and then subsequently by ICP-MS using this extraction method. For the six elements detectable by EDXRF spectrometry ( $\mathrm{Cr}, \mathrm{Cu}, \mathrm{Fe}, \mathrm{Ni}, \mathrm{Pb}$ and $\mathrm{Zn}$ ), there were no significant differences in values between the two measurement approaches (paired $t$-test, $p>0.2,95 \% \mathrm{CI}$ ). In summary, the authors concluded that this method was suitable for the high throughput analysis of lightly loaded air filter samples.

The bioaccessible metal fraction in urban aerosol particles may be a more informative metric than the total metal composition in assessng the potential health effects of exposure to inhaled particles. The bioaccessibility of nine elements (As, Cd, Co, Cr, Cu, Mn, Ni, Pb and $\mathrm{Zn}$ ) in both TSP and $\mathrm{PM}_{2.5}$ filter samples were measured using a SBET in vitro extraction procedure..$^{29}$ Filter aliquots were extracted $\left(1 \mathrm{~h}, 37^{\circ} \mathrm{C}\right)$ in $0.4 \mathrm{M}$ glycine (pH 1.5). Total concentrations were determined 
following $\mathrm{HNO}_{3}-\mathrm{H}_{2} \mathrm{O}_{2}$ digestion of separate filter sections using a closed-vessel microwave-assisted procedure. The mean bioaccessible fractions were $11 \%(\mathrm{Cr})$ to $65 \%(\mathrm{Cd})$ for both size fractions. The bioaccessible fractions of PGEs in airborne particulates were evaluated in two separate studies. In one,$^{30} \mathrm{a}$ procedure using a synthetic gastric juice extractant was compared with closed-vessel microwave-assisted digestion with $\mathrm{HCl}-\mathrm{HF}-\mathrm{HNO}_{3}$. The Pd and Pt bioaccesible fractions were $41 \pm$ $17 \%$ and $27 \pm 17 \%$, respectively, in TSP filter samples and $26 \pm$ $17 \%$ and $34 \pm 17 \%$, respectively, in $\mathrm{PM}_{10}$ filter samples. The second study ${ }^{31}$ was similar but simulated human lung fluids, ALF and Gamble's solution, were used. Significant amounts of up to 29,22 and $51 \%$ of $\mathrm{Pd}$, Pt and $\mathrm{Rh}$, respectively, were mobilised by ALF within 24 hours. The corresponding figures for exposure to Gamble's solution were 17, 18 and 44\%. Interestingly, when sample leaching testing was performed on NIST SRM 2557 (used auto catalyst) test samples, much lower bioaccessible values were obtained. These results underline the danger of using RMs for leaching experiments, in which, despite best intentions, matrix matching between RMs and real world samples may not be as complete as believed.

\subsection{Instrumental analysis}

1.4.1 Atomic absorption spectrometry. Two papers advocated the use of HR-CS-ETAAS for the direct solid sample analysis of $\mathrm{Ag}^{32}$ and $\mathrm{Pd}^{33}$ in airborne particulate matter collected on glass fiber filter media which were ground for analysis. The characteristic mass $M_{\mathrm{o}}$ for Ag was $4.4 \mathrm{pg}$ when measured at the main absorption line of $338.289 \mathrm{~nm}$ and the LOD ( $3 \sigma$ of the signal derived from ten atomisations of a ground blank filter) $17 \mathrm{ng} \mathrm{g}^{-1}$ equating to $0.05 \mathrm{ng} \mathrm{m}^{-3}$ in air for a sample air volume of $1440 \mathrm{~m}^{3}$. Using this optimised method, the airborne levels of $\mathrm{Ag}$ in Buenos Aires was determined to be $2-4.5 \mathrm{ng} \mathrm{m}^{-3}$. The LOD

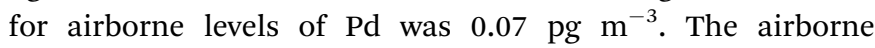
concentrations of Pd in Budapest and Istanbul were 0.3-0.9 and $0.2-0.6 \mathrm{pg} \mathrm{m}^{-3}$, respectively.

1.4.2 Emission spectroscopy. Investigation into the use of LIBS for the analysis of aerosol samples is a focus of a number of research groups. One attribute of this technique is its portability thereby providing in situ measurements. An interesting application of stand-off LIBS was an architectural survey ${ }^{34}$ of the Cathedral in Malaga. Measurements made at an average distance of $35 \mathrm{~m}$ from stone structures were consistent with the mineralogical analysis of stones. The emission profiles for $\mathrm{Al}$, $\mathrm{Ca}, \mathrm{Mg}$ and $\mathrm{Si}$ confirmed that this particular structure was almost entirely built using sandstone. In addition, the different marbles used in the construction could be classified. Moreover, identification of pollutants, e.g., $\mathrm{Mn}$ and $\mathrm{Pb}$ particles from vehicular emissions, on stone surfaces was possible, making it feasible to highlight hot-spots requiring repair and conservation. Exposure to airborne silica dust in coal mines can lead to silicosis, a potentially fatal lung disease. A LIBS system ${ }^{35}$ was evaluated as a potential portable monitoring device for the rapid in situ analysis of personal filter samples from workers. Initial studies, using filter samples spiked with reference silica, kaolin and coal dust samples, and by undertaking measurements at the Si $288.16 \mathrm{~nm}$ emission line, suggested that this approach had potential as an end-of-shift screening tool. In the hourly monitoring ${ }^{36}$ of metals (e.g., $\mathrm{Al}, \mathrm{Ca}, \mathrm{Cr}, \mathrm{Fe}, \mathrm{Pb}$ and $\mathrm{Zn}$ ) in $\mathrm{PM}_{10}$ particles during Asian dust pollution episodes, the particles were sampled through a $\mathrm{PM}_{10}$ size-selective inlet, dried and focused as a spot onto a movable nylon filter. By moving a sample spot under a Nd:YAG laser it could be interrogated for their elemental composition. This process was repeated for subsequent spots thus providing time resolved data. Elemental emission intensities were normalised to carbon (measured at $247.856 \mathrm{~nm}$ ) which could be used as an internal standard because the carbon emission from the underlying nylon filter was much larger and relatively more stable than the signal from the deposited carbonaceous particles. This approach was useful for minimising shot-to-shot variation common in laser-based systems. Metals were quantified using a calibration line established from LIBS and ICP-MS data for filter samples collected in parallel. The hourly data were successfully used to discriminate between various pollution episodes and their sources using elemental markers and employing chemometric techniques.

New AES instrumentation included: a LIBS system ${ }^{37}$ employing a low-pressure rf-plasma discharge that had the potential for enhancing sensitivities over those obtained with plasmas operating at atmospheric pressure; a LIBS system ${ }^{38}$ that used a triggering system to discharge the laser only when a particle was expected in the focal zone thereby improving the hit rate over current systems which commonly operate pulsed lasers at constant repetition rates; and a new portable dual-mode (OES and CRS) plasma spectrometer ${ }^{39}$ which had the potential advantages of a large dynamic measurement range and an ability to cross-calibrate between the two modes of operation.

\subsubsection{Mass spectrometry}

1.4.3.1 Inductively coupled plasma mass spectrometry. The multi-element capabilities of ICP-MS were exploited in a newly developed DRC-ICP-MS method ${ }^{40}$ employing a microwaveassisted digestion $\left(\mathrm{HNO}_{3}-\mathrm{HCl}-\mathrm{HF}\right.$ mixture) for the determination of 45 elements in road dust samples including PGEs (Pd, Pt and $\mathrm{Rh}$ ), 13 main group elements, 15 transition metals and 14 lanthanoids. The recoveries of PGEs from IRMM BCR CRM 723 (road dust) and NIST SRM 2556 (used auto catalyst) were 105$111 \%$. The recoveries of main group and transition elements from NIST SRM 1648a (urban particulate matter) were 85-115\%. There was excellent correlation between analysis of digests using DRC-ICP-MS and re-analysis by SF-ICP-MS $\left(r^{2}=0.9-0.99\right.$ for RMs and 0.99-1.00 for road dust samples). The authors concluded that large element sets were needed to provide the necessary data to understand better anthropogenic influences on the wider environment. One source of metals in the atmosphere is the combustion of fuels in road vehicles. Because European national emission inventories have previously shown a very high variability in elemental emission factors (mass released per kg fuel burnt), a new survey ${ }^{\mathbf{4 1}}$ analysed representative fuel samples, both diesel and petrol, from service stations in 9 nation states. Test samples were analysed using a collision cell ICP-MS system employing a HEN (ESI Apex Q). Use of a selfaspirating nebuliser with additional $\mathrm{O}_{2}$ make-up gas ensured complete combustion and thus minimised potential for carbon 
deposits on the cones. Although diesel samples could be analysed undiluted, petrol samples required dilution with Conostan Premisolv ${ }^{\mathrm{TM}}$ solvent. Organometallic oil standards were used for calibration and NIST SRMs 1634c (trace elements in fuel oil) and 1084a (wear metals in lubricating oil) used as QC materials but the recoveries were not reported. Marked differences of up to two orders of magnitude in concentrations between samples remained but the proposed revised emission factors were generally lower than previously published values.

A technique ${ }^{42}$ for the detection and characterisation of metalcontaining NPs coupled HDC, suitable for sizing NPs in the 5$300 \mathrm{~nm}$ range, to ICP-MS to provide a sensitive and selective analytical tool. Three calibration functions were required to measure NP size, number concentration and metal content, simultaneously. Reference Au NPs of various sizes were used as the model system. For water samples spiked with $60 \mathrm{~nm}$ sized $\mathrm{Au}$ NPs, the LOD was $2.2 \mathrm{ng} \mathrm{\textrm {L } ^ { - 1 }}$ (600 NPs $\left.\mathrm{mL}^{-1}\right)$. A working prototype $^{43}$ for the real-time size discrimination and elemental analysis of $\mathrm{Au}$ NPs consisted of a customised electrospray source and a differential mobility analyser to provide upstream particle size discrimination in real-time and CPC and ICP-MS instruments as downstream detectors to provide information on number density and elemental composition, respectively. A key design component in this system was the gas-exchange device for converting the air flow from the electrospray to the argon flow required to sustain the ICP-MS plasma. The Japanese research group led by Naoki Furuta, ${ }^{\mathbf{4 4}}$ continued their research into monitoring of elements in airborne particulates by direct introduction into an ICP-MS instrument. Calibrants were prepared using a desolvating USN to provide particle standards. Comparison of the results obtained with this real-time approach with those obtained for time-integrated samples collected using a more conventional filter sampling methodology gave good agreement for those elements (e.g., As and $\mathrm{Pb}$ ) with oxides that possess low melting points. In contrast, the real-time data were lower for elements (e.g., $\mathrm{Cr}$ and $\mathrm{Ni}$ ) with oxides with high melting points, indicating that such particles were not fully vaporised and ionised within the plasma. The authors suggested that this real-time approach could still be applicable if a correction factor based upon the ratio of realtime data to filter sampling data were used.

The use of quadrupole ICP-MS for isotopic measurements included the determination ${ }^{45}$ of $\mathrm{B}$ isotopes in aerosol samples as tracers of emissions from coal burning. Water-soluble B was leached from filter samples, purified and concentrated using a B-specific resin and analysed using a bracketing calibration approach with normalisation to NIST SRM 951 (boric acid standard). The mean reproducibility $(1 \sigma)$ of $3.0 \%$ for $\delta^{11} \mathrm{~B}$ was sufficient for $\mathrm{B}$ to be used as a discriminator. Isotopic data ${ }^{46}$ for $\mathrm{Nd}, \mathrm{Pb}$ and $\mathrm{Sr}$ were used in conjunction with elemental ternary diagrams to assess the relative contribution of particulate pollution from industrial point sources, such as an incinerator, a steel mill and a thermal power plant, in the air of two European cities (Kehl and Strasbourg). Suspended dust samples collected in passive samplers were digested in $\mathrm{HNO}_{3}-\mathrm{HF}$ and elemental analysis undertaken using ICP-AES and ICP-MS. For isotope ratio measurements, MC-ICP-MS was used under dry plasma conditions employing a HEN equipped with membrane desolvator. This combination of isotope tracers data with element triangle plots made it possible to identify specific point sources of pollution. The direct measurement ${ }^{47}$ of $U$ isotope ratios in single $10-20 \mu \mathrm{m}$ U-doped glass particles used $n s$ LA coupled to MC-ICP-MS. The analysis of 28 glass reference particles, measured under optimised conditions, yielded an average bias of $<0.6 \%$ from certified values for ${ }^{234} \mathrm{U} /{ }^{238} \mathrm{U}$ and ${ }^{235} \mathrm{U} /{ }^{238} \mathrm{U}$. Results for the ${ }^{236} \mathrm{U} /{ }^{238} \mathrm{U}$ isotope ratio deviated by $<2.5 \%$ from certified values. The calculated expanded measurement uncertainties $(k=2)$ were $2.6,1.4$ and $5.8 \%$ for ${ }^{234} \mathrm{U} /{ }^{238} \mathrm{U},{ }^{235} \mathrm{U} /{ }^{238} \mathrm{U}$ and ${ }^{236} \mathrm{U} /{ }^{238} \mathrm{U}$, respectively.

1.4.3.2 Other mass spectrometry techniques. New measurement tools for nuclear safeguards will require new RMs to allow comparability of measurements by commonly used techniques such as LA-ICP-MS, SIMS and TIMS. To address this, IRMM, in collaboration with ITU, initiated a study ${ }^{48}$ to investigate the feasibility of preparing and characterising a U-particle RM, certified for isotopic abudances and for U-mass per particle. To assist this process an improved ID-TIMS methodology was developed by IRMM to quantify the U-mass in single particles. Monodisperse U-oxide test particles were prepared by ITU using an aerosol-generation technique capable of producing particles of well-characterised size and isotopic composition. Experimental results demonstrated that it was possible to measure the U-mass per particle to a relative expanded uncertainity of $c a$. $10 \%(k=2)$. The authors concluded that this enhanced method will be a valuable tool to assist in the certification of future RMs. It was possible ${ }^{49}$ to distinguish between different valences states such as $\mathrm{UO}_{2}, \mathrm{U}_{3} \mathrm{O}_{8}$ and $\mathrm{UO}_{3}$ on surface layers and through depth profiles of U-oxide particles by interrogating the ion distributions measured by TOF-SIMS.

Developments and improvements in gas-phase $M S$ included a new isotope ratio method ${ }^{50}$ for the high-precision measurement of ${ }^{17} \mathrm{O} /{ }^{16} \mathrm{O}$ and ${ }^{18} \mathrm{O} /{ }^{16} \mathrm{O}$ in $\mathrm{CO}_{2}$ to assist in tropospheric studies. The method was based on isotopic exchange equilibrium between $\mathrm{H}_{2} \mathrm{O}$ and $\mathrm{CO}_{2}$ in sealed glass ampoules followed by water fluorination to produce $\mathrm{O}_{2}$. Dual inlet IRMS measurements of the $\delta^{17} \mathrm{O}$ and $\delta^{18} \mathrm{O}$ of $\mathrm{O}_{2}$ in $c a .70 \mu \mathrm{mol}$ of $\mathrm{CO}_{2}$ allowed $\delta^{17} \mathrm{O}$ values to be obtained with very high precision $(0.01-0.3 \%$ o $)$. In a rapid extractive ESI-MS method ${ }^{51}$ for the quantification of trace radioactive ${ }^{129} \mathrm{I}$ in ambient air, gaseous ${ }^{129} \mathrm{I}_{2}$ was initially converted into ${ }^{129} \mathrm{I}^{-}$by passing it through an excess of $\mathrm{Na}_{2} \mathrm{SO}_{3}$. By adding an excess of ${ }^{127} \mathrm{I}_{2}$ into the solution, this ${ }^{129} \mathrm{I}^{-}$was coverted into a tri-iodate ion complex $\left(\mathrm{I}_{3}{ }^{-}\right)$. Quantification was based upon measurement of the characteristic ${ }^{129} \mathrm{I}^{-}$fragment. The calibration curve had good linearity over a relatively wide range of $0.01-1000 \mathrm{ppbv}\left(r^{2}=0.991\right)$, the LOD was $4.5 \mathrm{ppt}$ and the RSD was $4-13 \%$. The method was successfully applied to the detection of trace amounts of ${ }^{129} \mathrm{I}_{2}$ released in a simulated nuclear leakage accident.

Real-time measurements using aerosol $M S$, aided by the increased availability of new instrumentation, are providing more information on the origins and fate of particles in the atmosphere. Particulates containing trace elements emitted from vehicles are the focus of increasingly stringent air quality regulations but, to date, the emission rates and physiochemical 
properties of such particles are not well characterised, largely as a result of difficulties in making such measurements. A newly developed instrument, ${ }^{52}$ the soot-particle aerosol mass spectrometer, employed a continuous $1064 \mathrm{~nm}$ laser beam to vaporise all particles, including the refractory ones, which were subsequently ionised by electron impact and analysed by HRaTOF-MS. In contrast, commercially available aerosol MS systems that employ thermal desorption and electron impact ionisation methods can only quantify species that readily vaporise at up to $600{ }^{\circ} \mathrm{C}$. The new soot-particle instrument also had a conical vaporiser used in more established aerosol MS systems so that only non-refractory components could be measured if the laser were switched off. The new instrument was considered a powerful tool for meeting future requirements for measurements at increasingly lower levels. The limitation ${ }^{53}$ of a HR-aTOF-MS system that employed thermal desorption and electron impact ionisation for the on-line near-real-time detection of trace elements in airborne particles was that only elements with low melting and boiling points (e.g., As, $\mathrm{Cu}, \mathrm{Zn}$ ) could be detected. With a nominal 5 minute sampling interval, the average LOD was $c a .0 .3 \mathrm{ng} \mathrm{m}^{-3}(3 \sigma)$. In order to assess whether aerosol MS could be used as a quantitative tool, concentration data obtained were compared to those obtained by offline analysis of particles collected at the same times and locations using alternative methodologies. Two offline approaches were used: $12 \mathrm{~h}$ time-integrated $\mathrm{PM}_{2.5}$ filter samples collected using a high volume air sampler, subsequently digested for ICP-AES and ICP-MS analysis; and $6 \mathrm{~h}$ time-integrated $\mathrm{PM}_{0.07-0.34}, \mathrm{PM}_{0.34-1.15}, \mathrm{PM}_{1.15-2.5}$ filter samples collected using the IMPROVE DRUM sampler for PIXE analysis. Not unsurprisingly, the degree of correlation and agreement between the three measurement approaches varied depending upon the element in question, reflecting inherent limitations in each of the analytical approaches. The authors suggested that further intercomparison exercises, under controlled conditions, would be required to understand more fully the differences but that aerosol MS showed promise for the real-time detection of trace elements in air.

1.4.4 X-ray spectrometry. The calibration and performance aspects of $X$-ray techniques for characterisation of airborne particulate matter continue to attact attention. Initial studies ${ }^{54}$ with a unit constructed at the Atominstitut in Vienna for pipetting $\mathrm{nL}$ droplets onto flat surfaces, e.g., quartz reflectors and wafers, for TXRF analysis suggested that the process was repeatable and that precise spatial patterns could be deposited on different sample carriers. More specifically, the system was able to produce calibrant standards for the quantification of aerosols collected by impactor samplers. Further developments are eagerly awaited. Historically, XRF techniques have been commonly used to analyse filter samples in a non-destructive manner, thus allowing further testing to be carried out. However, the validity of this approach ${ }^{55}$ was questioned when it was observed that the EDXRF analysis under vacuum of particulate matter collected on commonly used quartz and Teflon filters led to mass losses of particulate matter, ionic compounds, VOCs and water. Although losses of $\mathrm{NH}_{4}{ }^{+}$and $\mathrm{NO}_{3}{ }^{-}$species have been previously reported, this was the first time that losses of $\mathrm{Ca}^{2+}, \mathrm{Cl}^{-}, \mathrm{Mg}^{2+}$ and $\mathrm{Na}^{+}$species had been observed. Further work to understand the mechanism of this mass loss will require additional measurements of, e.g., organic/elemental carbon and water contents. Analysis in an inert atmosphere, rather than under vaccum, may alleviate the extent of the losses but could result in a decrease in sensitivity, particularly for lighter elements.

Novel but intriguingly simplistic applications of XRF for analysis of airborne particulates included the use $\mathrm{e}^{56}$ of a fieldportable XRF spectrometer to determine if desert varnish rock samples contained a record of recent air pollution. A major component of desert varnish, a coloured coating found on rocks in arid environments, is windblown clay. As the concentrations of $\mathrm{As}, \mathrm{Cr}, \mathrm{Pb}$ and $\mathrm{Zn}$, elements commonly found in fly ash, were significantly higher in samples collected downwind from two power plants than in unvarnished substrate rock, it was concluded that desert varnish could indeed be utilised as a passive environmental monitor to investigate recent air pollution (over the last 20-30 years). The potential $^{57}$ of using commercially available carbon adhesive tabs, typically used to mount samples for SEM analysis, in TXRF analysis was tested by sprinkling small quantities of particles (ca. $0.5 \mathrm{mg}$ ) onto these carbon substrates mounted on quartz reflectors. Good agreement with certified values was obtained for a number of powdered CRMs including NIST SRM 1648 (urban particulate matter). For quantification, a chosen certified element was taken as an internal standard. For unknown particulate samples, elements were normalised to the most abundant element so only elemental concentration ratios and not absolute concentrations could be measured. This procedure was advocated for the analysis of atmospheric fall-out particulate matter by swabbing surfaces to collect settled dust.

Solid-state speciation analysis gives an insight into the chemical composition of airborne particles. The XAS analysis ${ }^{58}$ of airborne particulate matter, vehicle brake lining and brake pad wear residues showed that brake pads contain appreciable levels of $\mathrm{Sb}$, typically $1-2 \%(\mathrm{~m} / \mathrm{m})$, mostly as $\mathrm{Sb}^{\mathrm{III}}$ derived from the use of stibnite $\left(\mathrm{Sb}_{2} \mathrm{~S}_{3}\right)$ as a lubricant to reduce vibrations and to improve friction stability. The other major form was $\mathrm{Sb}^{\text {III }}$ derived from $\mathrm{Sb}_{2} \mathrm{O}_{3}$. However, the finding that the majority of wear residues, airborne particles and suspended road dust contained $\mathrm{Sb}_{2} \mathrm{O}_{4}$, an admixture of $\mathrm{Sb}^{\mathrm{III}}$ and $\mathrm{Sb}^{\mathrm{V}}$ oxides, supported the findings from thermogravimetic experiments that during braking brake pads may indeed reach temperatures high enough to induce oxidation. The authors concluded that $\mathrm{Sb}$ could be used as a tracer of motor vehicle emissions in source apportionment studies. The XAS technique is indeed powerful and is increasingly being used in diverse air pollution applications such as the speciation and bioaccumulation of $S$ in camphor tree leaves ${ }^{59}$ and $\mathrm{Zn}$ speciation in flue dust arising from the generation of waste during the production of carbon steel in blast furnaces. ${ }^{60}$ The HR-PIXE analysis ${ }^{61}$ of aerosols collected in Budapest clearly identified the major $\mathrm{Cl}$ component as $\mathrm{NaCl}$. Readers are directed to our companion Update for further information on developments and applications in reviews of X-ray spectrometry. ${ }^{4}$ 
1.4.5 Combustion and spectrometric techniques. New instrumentation is being developed to measure the carbon content in airborne particles that can impact greatly upon both climate and human health. A major contributor to aerosols in the workplace is DEEE which WHO have recently classified as a Group One carcinogen. A new real-time personal monitor ${ }^{62}$ measured the elemental carbon content of DPM captured on a Teflon filter. The instrument worked on the principle of light extinction, a combination of light absorption and scattering, using a laser at $650 \mathrm{~nm}$. In the case of DPM collected on a filter, absorption was the dominant process. A calibration function was generated by exposing the instrument to DEEE in a controlled chamber alongside filter samples which were subsequently analysed using a reference combustion method (NIOSH 5040). For each data pair, the optical density, determined by taking the inverse log of the transmission (instrumental voltage reading), was plotted against the elemental carbon result obtained by the combustion method to derive a linear calibration plot $\left(r^{2}=0.98\right)$ over the range $20-400 \mu \mathrm{g} \mathrm{m}^{-3}$. For a 15 min integration period, the LOD was $10 \mu \mathrm{g} \mathrm{m}^{-3}$. The instrument was not prone to interferences from humidity or oil mists. Potential light scattering effects due to other particles could be minimised by selectively sampling DPM over larger sized interferent particles through the use a $1 \mu \mathrm{m}$ size-selective sampler inlet. Although rarely present in the workplace nowadays, cigarette smoke could cause a positive bias in results. This instrument is currently being tested in underground mines, where worker exposure to DEEE can be a concern. Another instrument, ${ }^{63}$ the multi-wavelength absorbance analyser, has been developed to measure light absorption by ambient air particulate matter collected on filters and hence to derive the black and brown carbon contents. This system used switchable low-power laser diodes at 405, 635 and $850 \mathrm{~nm}$ wavelengths thereby offering the possibility to apportion black and brown/ organic carbon sources. Whilst the laser beam was collimated to illuminate only a small $\left(c a .1 \mathrm{~mm}^{2}\right)$ area of the filter, the instrument could automatically scan up to $2 \times 2 \mathrm{~cm}^{2}$ in about $10 \mathrm{~min}$. A 16-position filter wheel allowed unattended operation. Results correlated well with those obtained using other established photometric techniques (MAAP and a polar photometer) and with elemental carbon results obtained using a TOT method following the EUSAAR_2 protocol.

Evaluation of the analytical steps within TOT methods is another fertile area of interest. A step-wise solvent extraction method $^{64}$ for characterising carbonaceous aerosols allowed organic material to be separated into distinct fractions. Three punches taken from each filter were extracted with solvents of increasing polarity. The first was extracted in hexane (100\%), the second in hexane-methylene chloride ( $1: 1$ by volume) and the third by a mixture of hexane-methylene chloride-acetone ( $1: 1: 1$ by volume). In summary, the method fractionated organic aerosol into extractable and non-extractable OC and then further separated the extractable OC into three fractions defined as non-polar, low-polar and high-polar OC. It is hoped that this new methodology could assist atmospheric scientists to gain a better insight into the formation of secondary organic aerosols for which knowledge of precursors, production pathways and atmospheric evolution is lacking. The outcome of a study $^{65}$ on the effects of different thermal treatments on radiocarbon measurements of OC and EC fractions in the atmospheric aerosol was suggested improvements to existing thermal protocols. One such improvement was the addition of a thermal step at high temperature in a helium atmosphere, after the traditional $\mathrm{O}_{2}$ precombustion step, to remove more fully the refractory fraction of OC. By doing so, the potential for carry over of charred OC into the EC determination step was minimised. A study ${ }^{6}$ was undertaken to ascertain the effect of increasing Fe content in laboratory-produced soot aerosol on its compostion, structure and thermo-chemical properties. The temperature-programmed oxidation profiles showed a main peak ascribed to the evolution of $\mathrm{CO}_{2}$ and a shoulder peak which was assigned to the combustion of iron carbides which became more pronounced as the concentration of Fe increased. The temperature of maximum $\mathrm{CO}_{2}$ emission was found to decrease exponentially with increasing Fe content. Such a finding casts doubt on the feasibility of commonly used thermooptical technniques for the quantification of OC and EC in carbonaceous particles if they are substantially contaminated with inorganic compounds, given that the distinction between the carbon forms using thermal techniques requires an operationally defined combustion temperature split-point.

\subsection{Data analysis and quality}

Evaluation of methodologies and instrumental techniques through interlaboratory comparisons is recognised as a valuable tool amongst measurement scientists. The divergent sampling techniques for respirable dust and the analyses for crystalline silica are an important issue amongst industrial occupational hygienists. In a comprehensive comparison study, ${ }^{67}$ the workplace atmosphere multi-sampler, a rotating device in which 12 samplers could be exposed to the same dust environment concurrently, was used to compare the performance of six respirable dust samplers. The samplers were exposed to airborne dusts in four workplace settings (enamel production, sand extraction, foundry and brickworks) and the resultant filter samples analysed in seven participating laboratories using FTIR or XRD spectrometries.

It is possible for particles to deposit on surfaces in air samplers rather than fully on the filters. An acid-soluble internal capsule digested with the filter has been proposed as a possible solution to the incomplete sampling of airborne particles. An interlaboratory study ${ }^{68}$ with 10 participants evaluated the suitability of cellulosic capsule inserts in the determination of trace elements in airborne samples. Prototype inserts were spiked with: aqueous solutions of $\mathrm{Pb}, \mathrm{Pb}$-containing soil RMs or aerosol samples (As, Cd, Co, Cr, Cu, Fe, Pb, Mn and $\mathrm{Ni}$ ) generated using a desolvated nebuliser system. For these elements evaluated, the interlaboratory precision and mean recoveries were similar to those that could be expected if only filter samples were digested and analysed. As such this extra cellulose material should not present undue analytical complications but it remains to be seen whether such inserts can be produced commercially. 
In a simple method ${ }^{\mathbf{6 9}}$ for generating matched filter sets with known $O C$ and EC contents, carbon black particles were dispersed in water and nebulised, dried and desolvated in a test chamber to provide a reference EC particle aerosol. A saturated alginic acid solution was used as the starting material for preparing an OC-containing aerosol. Analysis in seven participating laboratories using the NIOSH 5040 combustion method gave a laboratory repeatability of $<10 \%, 11 \%$ and $12 \%$ RSD for TC, OC and EC, respectively. Within-laboratory repeatability was $<12 \%$. This relatively simple generation system was considered suitable for method-performance studies.

Comparisons of instrumental techniques for measuring the same chemical moieties are interesting to read. Aerosols of ultrafine $\mathrm{TiO}_{2}$ particles ${ }^{70}$ with an agglomerate mean diameter of $67 \mathrm{~nm}$ were loaded (3-578 $\mu \mathrm{g})$ onto PTFE filters and analysed independently using FTIR, LIBS and portable XRF procedures. The LODs $(3 \sigma)$ were $108,0.03$ and $11.8 \mu \mathrm{g}$, respectively, for the three procedures. The greatest dynamic range was given by the portable XRF instrumentation. In summary, XRF spectrometry could be a useful field measurement tool but further tests are required to test its performance on real matrix-containing samples. Robust methods to detect and characterise engineered NPs in environmental samples are urgently needed. The combination of ICP-MS with a size separation method holds promise in this context. Hence, the comparison ${ }^{71}$ of the HDC and AF4 techniques coupled to ICP-MS for detection, quantification and characterisation of NPs was welcome. The LODs, resolution and recoveries for both techniques were determined using Au NPs. The AF4 system was capable of separating mixtures of 5, 20, 50 and $100 \mathrm{~nm}$ particles with greater resolution than the HDC system, particularly in the smaller size range. Higher sample recoveries were noted for the HDC system (7796\%) than for the AF4 system (4-89\%). The LOD for both techniques was $c a .5 \mu \mathrm{g} \mathrm{L} \mathrm{L}^{-1}$. An additional benefit of HDC over A4F was that it has a capability of separating a dissolved-sample signal from a NP signal.

\section{Water analysis}

\subsection{Sample preparation}

As noted in last year's review, ${ }^{\mathbf{1}}$ the determination of $\mathrm{Hg}$ in natural waters remains a challenge due to preservation and stability problems. In order to investigate the stability and behaviour of $\mathrm{Hg}^{2+}$ spiked at natural levels in water samples, Guevara and Horvat ${ }^{72}$ irradiated an enriched ${ }^{196} \mathrm{Hg}^{2+}$ solution to produce a ${ }^{197} \mathrm{Hg}^{2+}$ radiotracer solution that was used to spike filtered and unfiltered marine, coastal lagoon, lake, river and rain waters at 3 to $13 \mathrm{ng} \mathrm{L^{-1 }}$ with and without acidification (1\% $\mathrm{v} / \mathrm{v} \mathrm{HCl}$ ). Subsequent storage was at room temperature or at $5{ }^{\circ} \mathrm{C}$. The ${ }^{197} \mathrm{Hg}^{2+}$ was stable for over 10 days in unfiltered and unacidified marine and lake waters but $20 \%$ of the spike was lost, probably to the walls of the container (the authors did not specify), from the particulate and dissolved phases of river and lagoon waters. In refrigerated samples, the ${ }^{197} \mathrm{Hg}^{2+}$ partitioned between the dissolved and solid fractions as above but reached equilibrium more slowly. The ${ }^{197} \mathrm{Hg}^{2+}$ spike in samples acidified to $1 \% \mathrm{v} / \mathrm{v} \mathrm{HCl}$ was stable at room temperature and at $5{ }^{\circ} \mathrm{C}$ when stored in PTFE or borosilicate glass bottles, but significant (20$30 \%$ ) losses occurred at all temperatures when the samples were stored in polyethylene bottles. The authors did not speculate on the fate of the lost mercury and did not carry out speciation analysis, so unfortunately we do not know if species interconversion occurred.

\subsection{Sample preconcentration and extraction}

Review articles published this year examined preconcentration methods from environmental matrices including waters. Of particular interest was a review ${ }^{73}$ (52 references) of recent developments in SPE of elemental species from aqueous solutions. Two reviews focussed on the use of CNTs as SPE sorbents. One concentrated on their use prior to atomic spectrometric detection of trace elements ${ }^{74}$ (140 references) and the other more specifically on the chemical modification of $\mathrm{CNTs}^{75}$ (78 references). Given the explosion of interest in liquid microextraction techniques, a review of DLLME coupled with atomic absorption spectrometry ${ }^{76}$ (126 references) was timely. Tables 1 and 2 summarise the most significant developments for analyte preconcentration prior to water analysis in this Update period.

\subsection{Speciation}

A review on the speciation of $\mathrm{As}, \mathrm{Cr}, \mathrm{Hg}, \mathrm{Sb}, \mathrm{Se}$ and $\mathrm{Sn}$ by coupled techniques $^{77}$ (79 references) included analysis of air, drinking water and soil matrices.

In a field-separation-based method for the speciation analysis of arsenic, ${ }^{78} \mathrm{As}^{\mathrm{V}}$ was selectively retained on an anionexchange resin and the eluent containing other cationic or neutral species collected. The $\mathrm{As}^{\mathrm{V}}$ was then eluted with 5\% $\mathrm{HNO}_{3}$ and the As content of both eluents determined by ICP-SFMS operating in medium resolution mode. The method accuracy was assessed by analysis of NIST SRM 1640 (natural water). In another offline method, ${ }^{79}$ the $A s^{\mathrm{III}}$ in drinking water and snow was complexed with APDC and retained on polymeric microbeads. The adsorbed As was eluted with $0.25 \mathrm{M} \mathrm{HNO}_{3}$ and quantified by ETAAS. The enrichment factor was 86 and the LOD for As ${ }^{\text {III }} 10 \mathrm{ng} \mathrm{L}^{-1}$. The method was validated by carrying out spiking experiments (recovery varied from 96-100\%) and analysis of water RM SEM 2011 from a Turkish national QA scheme.

Non-chromatographic methods ${ }^{\mathbf{8}}$ for the speciation analysis of $\mathrm{Cr}$ in natural waters have been reviewed (87 references). Addition $^{81}$ of the ionic liquid 1-butyl-3-methylimidazolium tetrafluoroborate ([C4MIM]BF4) to water samples improved the DDTC extraction of $\mathrm{Cr}^{\mathrm{VI}}$ complexes during hollow-fibre liquidphase-extraction. The $\mathrm{Cr}^{\mathrm{VI}}$ in the eluate was determined by FAAS. The improvement in enrichment factor from 50 in the absence of ionic liquids to 175 resulted in a LOD of $0.7 \mathrm{ng} \mathrm{mL}^{-1}$. Results for IERM CRM GSBZ5027-94 (environmental water) were in good agreement with the certified values. The dye dimethyl indocarbocyanide, an ion pairing agent ${ }^{82}$ that complexes $\mathrm{Cr}^{\mathrm{VI}}$ under acid conditions, was used in a colorimetric method for the determination of $\mathrm{Cr}^{\mathrm{VI}}$ by ETAAS. The complex was back extracted into toluene from the sample and 
Table 1 Preconcentration methods using liquid phase extraction for the analysis of water

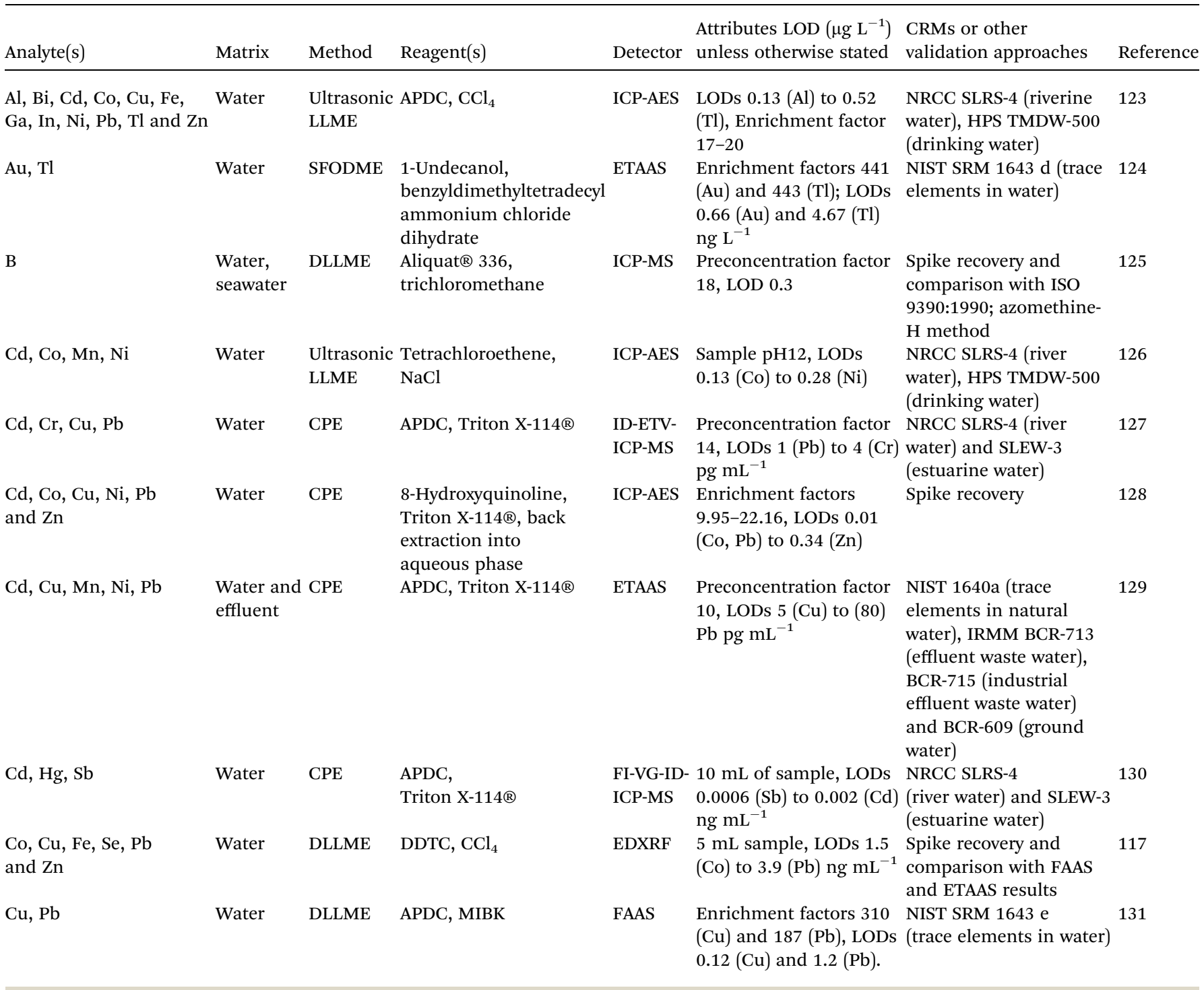

the $\mathrm{Cr}$ determined by ETAAS. The LOD was $0.25 \mu \mathrm{g} \mathrm{L} \mathrm{L}^{-1}$ for a 3 $\mathrm{mL}$ water sample. Both coprecipitation and DLLME were used ${ }^{83}$ in the determination of total $\mathrm{Cr}$ and $\mathrm{Cr}^{\mathrm{VI}}$ in water, effluent and soils. The total $\mathrm{Cr}$ concentration was determined by FAAS after oxidation with $\mathrm{Ce}\left(\mathrm{SO}_{4}\right)_{2}$ in $\mathrm{H}_{2} \mathrm{SO}_{4}$ and coprecipitation with APDC. The $\mathrm{Cr}^{\mathrm{VI}}$ was complexed with APDC and extracted by DLLME before quantification and the $\mathrm{Cr}^{\mathrm{III}}$ was determined by difference. The enrichment factor for a $40 \mathrm{~mL}$ sample was 400 for the DLLME extraction and 100 for the coprecipitation approach. The LODs were $0.037\left(\mathrm{Cr}^{\mathrm{VI}}\right)$ and $2.13 \mu \mathrm{g} \mathrm{L} \mathrm{L}^{-1}$ (total $\mathrm{Cr}$ ). The method was validated by recovery of a spike from drinking water and the determination of total $\mathrm{Cr}$ in the NRCCRM CRM GBW-07309 (stream sediment).

Chromatographic methods for the determination of halogen species continue to receive attention. A method for fluorine speciation analysis ${ }^{84}$ used molecular absorption spectrometry (CS-AAS) to detect F via the stable GaF molecule at $211.248 \mathrm{~nm}$.
Offline RP LC with a $\mathrm{C}_{8}$ column and a water-methanol $(1+1)$ mobile phase separated the two model compounds trifluorobenzoic acid and 5-fluoroindol-5-carboxyilic acid. The method LOD was $c a .1 \mathrm{ng} \mathrm{mL} \mathrm{mL}^{-1}$ (100 pg absolute) and species identification was verified by ESI-MS. The authors postulated that this method approach could be suitable for the identification and quantification of unknown fluorinated organic compounds in environmental water samples. A new method ${ }^{85}$ using the ion pairing agent tetraethylammonium hydroxide allowed the separation of the iodine species $\mathrm{I}^{-}, \mathrm{IO}_{3}{ }^{-}, 3$-iodotyrosine and 3,5-diiodotyrosine in a single chromatographic run and was tested on seawater and seaweed samples. The LODs using an ICP-MS detector were $0.061\left(\mathrm{IO}_{3}{ }^{-}\right)$to 0.24 (3,5-diiodotyrosine) $\mu \mathrm{g} \mathrm{L} \mathrm{L}^{-1}$ and the recoveries $90-110 \%$. The coupling of ion exchange chromatography with ICP-MS for the inorganic speciation analysis of $\mathrm{Br}$ and $\mathrm{I}$ in only $0.3 \mathrm{~mL}$ of Antarctic ice ${ }^{86}$ gave LODs of 5-9 $\mathrm{pg} \mathrm{g}^{-1}$ for the individual species. 
Table 2 Preconcentration methods using solid phase extraction for the analysis of water

\begin{tabular}{|c|c|c|c|c|c|c|c|}
\hline Analyte(s) & Matrix & Substrate & $\begin{array}{l}\text { Substrate coating or } \\
\text { modifying agent }\end{array}$ & Detector & $\begin{array}{l}\text { Attributes LOD } \\
\left(\mu \mathrm{g} \mathrm{L}^{-1}\right) \text { unless } \\
\text { otherwise stated }\end{array}$ & $\begin{array}{l}\text { CRMs or other } \\
\text { validation } \\
\text { approaches }\end{array}$ & Reference \\
\hline $\mathrm{Cd}$ and $\mathrm{Pb}$ & Water & $\begin{array}{l}\text { Oxidised } \\
\text { MWCNT }\end{array}$ & APDC & TXRF & $\begin{array}{l}\text { LODs } 1.0(\mathrm{Cd}) \text { and } 2.1 \\
(\mathrm{~Pb}) \mathrm{ng} \mathrm{mL}^{-1}, 20 \mathrm{~mL} \\
\text { sample }\end{array}$ & Spike recovery & 133 \\
\hline $\mathrm{Cd}, \mathrm{Co}, \mathrm{Cu}, \mathrm{Pb}, \mathrm{Zn}$ & $\begin{array}{l}\text { Seawater } \\
\text { and urine }\end{array}$ & $\begin{array}{l}\text { PVC packed } \\
\text { beads }\end{array}$ & & ICP-MS & $\begin{array}{l}\text { LOD } 0.7(\mathrm{Co}) \text { to } 7.0 \\
(\mathrm{~Pb}) \mathrm{ng} \mathrm{L}^{-1}, \\
\text { Enrichment factor of } 10\end{array}$ & $\begin{array}{l}\text { NRCC SLEW-3 } \\
\text { (estuarine water), } \\
\text { NASS-2 (seawater) } \\
\text { and NIST SRM } \\
\text { 2670a (human } \\
\text { urine) }\end{array}$ & 134 \\
\hline $\begin{array}{l}\mathrm{Co}, \mathrm{Cr}, \mathrm{Cu}, \mathrm{Mn}, \mathrm{Ni} \\
\text { and } \mathrm{Zn}\end{array}$ & Water & $\begin{array}{l}\text { Oxidised } \\
\text { MWCNT }\end{array}$ & $\begin{array}{l}\text { Electrochemically } \\
\text { assisted sorption }\end{array}$ & EDXRF & $\begin{array}{l}\text { LODs } 1(\mathrm{Cr} \text { and } \mathrm{Cu}) \text { to } \\
8(\mathrm{Zn}) \mathrm{ng} \mathrm{mL} \mathrm{mL}^{-1} 100 \mathrm{~mL} \\
\text { sample }\end{array}$ & $\begin{array}{l}\text { Spike recovery, } \\
\text { comparison } \\
\text { with ICP-AES }\end{array}$ & 136 \\
\hline Cs & $\begin{array}{l}\text { Estuarine and } \\
\text { coastal waters }\end{array}$ & $\begin{array}{l}\text { Separation } \\
\text { using an } \\
\text { AG50W-8X ion } \\
\text { exchange resin }\end{array}$ & $\begin{array}{l}\text { Adsorption onto } \\
\text { ammonium } \\
\text { molybdophosphate }\end{array}$ & ICP-MS & $\begin{array}{l}\text { LOD } 1.0 \mathrm{ng} \mathrm{L}{ }^{-1}, 20 \mathrm{~mL} \\
\text { sample volume }\end{array}$ & $\begin{array}{l}\text { NRCC SLEW-3 } \\
\text { (estuarine water), } \\
\text { CASS-4 (near } \\
\text { shore seawater) } \\
\text { and NASS-5 } \\
\text { (seawater) even } \\
\text { though not } \\
\text { certified for Cs }\end{array}$ & 137 \\
\hline REEs & Seawater & $\begin{array}{l}\text { TSK }^{\mathrm{TM}} \text { Polymer } \\
\text { beads }\end{array}$ & MWCNT & ICP-MS & $\begin{array}{l}\text { LOD } 0.01(\mathrm{Lu})-0.16(\mathrm{Ce}) \\
\text { pg } \mathrm{mL}^{-1}, 100 \mathrm{~mL} \text { sample }\end{array}$ & $\begin{array}{l}\text { Spike recovery } \\
\text { and comparison } \\
\text { with another } \\
\text { method }\end{array}$ & 140 \\
\hline${ }^{99} \mathrm{Tc}$ & Seawater & Eichrom Teva & $\begin{array}{l}\mathrm{Fe}(\mathrm{OH})_{2} \\
\text { coprecipitation }\end{array}$ & ICP-MS & $\begin{array}{l}\text { LOD } 11.5 \mathrm{pg} \mathrm{m}^{-3} \\
\text { for a } 200 \mathrm{~L} \text { sample } \\
\text { (equivalent } \\
\text { to } 7.5 \mathrm{mBg} \mathrm{m}^{-3} \text { ) }\end{array}$ & $\begin{array}{l}\text { Comparison } \\
\text { with standard } \\
\text { method }\end{array}$ & 141 \\
\hline
\end{tabular}

The determination of gadolinium-based MRI contrast agents in biological and environmental samples remains a hot topic with a review ${ }^{87}(79$ references) and two new significant articles being published recently. Detection of three unknown species in sewage sludge and waste water ${ }^{88}$ indicated that species transformation can occur during anaerobic sludge treatment. The presence of the proprietary MRI agents ${ }^{89}$ DotaremA $\AA$ and GadovistaA® in water samples and river plants $5 \mathrm{~km}$ downstream of treatment works near Berlin was confirmed by coupling HILIC with ICP-MS and comparing retention times with those of standards. This finding supports concerns that certain emerging pollutants may not be fully captured in traditional water treatment processes.

The fractionation of trace elements in water has become more feasible with the ever increasing proliferation of SEC and FFF instruments. The transport and fate of REEs ${ }^{90}$ and 16 other trace elements ${ }^{91}$ in Alaskan rivers and the extent of their binding to organic and iron-rich nanocolloids was studied by directly coupling FFF to ICP-MS. It was noted that the distribution of these elements within these fractions was dependent on seasonal variations. The trace elements associated with marine dissolved organic matter have been characterised ${ }^{92}$ by SEC 
followed by AEC. Using SEC it was demonstrated that marine dissolved organic matter, following ultra-filtration with a 10000 Da cut off filter, ranged from 6.5-16 kDa. The AES-UV analysis (absorbance at $205 \mathrm{~nm}$ ) of this mass fraction revealed the presence of 4 sub-fractions. With an elemental ICP-MS detector it was demonstrated that $\mathrm{Sr}$ and $\mathrm{Zn}$ containing complexes were associated with the first fraction, Mn was bound to the second and Co was detected in the third fraction.

\subsection{Instrumental analysis}

2.4.1 Atomic absorption spectrometry. Improvements in the use of AAS have been reported. The use of the slotted quartz tube as an atom trap ${ }^{93}$ has been resurrected by some workers for the preconcentration of $\mathrm{Bi}$ on the surface of the quartz tube before release of the trapped atoms with $50 \mu \mathrm{L}$ of methyl ethyl ketone. The use of the slotted tube resulted in a 2.9-fold improvement in sensitivity over an AAS system without this slotted tube, but by trapping on the tube a 256-fold improvement in sensitivity was

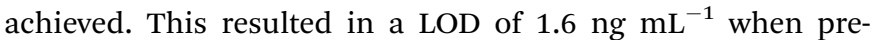
concentrating a nominal $36 \mathrm{~mL}$ sample. The same research group ${ }^{94}$ then modified this method for the determination of $\mathrm{Sb}$. The optimal conditions of a nominal $25 \mathrm{~mL}$ sample volume and the use of MIBK as the releasing solvent resulted in a 369-fold sensitivity enhancement and a LOD of $3.9 \mu \mathrm{g} \mathrm{L}^{-1}$. Use of quartz atom traps improved the LODs in the CVG of Ag. ${ }^{95,96}$ In the first paper, ${ }^{95}$ the LOD of $0.7 \mathrm{ng} \mathrm{mL}^{-1}$ for $\mathrm{Ag}$ following trapping for $120 \mathrm{~s}$ was a significant improvement to that $\left(10 \mathrm{ng} \mathrm{mL}{ }^{-1}\right)$ for a similar system without this integration step. In the second paper, ${ }^{96}$ the LOD of $0.11 \mathrm{ng} \mathrm{mL}^{-1}$ with $150 \mathrm{~s}$ trapping was better than that $\left(1 \mathrm{ng} \mathrm{mL}^{-1}\right)$ for CVG using a multi-atomiser. The best combination of chemical modifiers ${ }^{97}$ for the ETAAS determination of $\mathrm{As}, \mathrm{Cr}, \mathrm{Cu}$ and $\mathrm{Mn}$ in thermal spring waters was a ternary mixture of Ni, Pd and citric acid. Results for NIST SRM 1643e (trace elements in water) were in good agreement with certified values. The use of continuum source ETAAS $^{98}$ to measure Br gave an absolute LOD of $78 \mathrm{pg}\left(7.8 \mu \mathrm{g} \mathrm{L}^{-1}\right.$ for a $10 \mu \mathrm{L}$ injection). Bromine was detected as $\mathrm{CaBr}$ at the molecular absorption line of $625.315 \mathrm{~nm}$ after in situ formation in the pyrolytic graphite tube in the presence of an excess of $\mathrm{Ca}$ and $\mathrm{Zr}$ used as a permanent modifier. Careful selection of the absorption bands (less sensitive for high concentrations to more sensitive for low concentrations) made a linear working range of $10 \mu \mathrm{g} \mathrm{L}^{-1}$ to $1 \mathrm{~g} \mathrm{~L}^{-1}$ possible. The method was considered suitable for the determination of $\mathrm{Br}^{-}, \mathrm{Br}$-containing whirlpool disinfectant agents and polybrominated flame retardants in waters.

2.4.2 Inductively coupled plasma atomic emission spectrometry. Some novel uses of the ICP technique have been reported. A review ${ }^{99}$ (67 references) of current methods for the determination of chlorine in inorganic substances compared ICP-AES methods for the determination of $\mathrm{Cl}$ species $\left(\mathrm{Cl}, \mathrm{Cl}^{-}\right.$ and $\mathrm{ClO}_{4}{ }^{-}$) in aqueous media to the traditionally used titrimetric and chromatographic methods. In an interesting variation $^{\mathbf{1 0 0}}$ of the procedure that uses $\mathrm{K}_{2} \mathrm{Cr}_{2} \mathrm{O}_{7}$ for the determination of COD in waste waters, the sample refluxing step was initiated using a microwave-assisted reaction. The resultant $\mathrm{Cr}^{\mathrm{III}}$ generated by the reduction of the $\mathrm{Cr}_{2} \mathrm{O}_{7}{ }^{-}$was determined by FIICP-AES rather than the more traditional spectrophotometric endpoint. The linear range was $2.78-850 \mathrm{mg} \mathrm{O}_{2} \mathrm{~L}^{-1}$ with an LOD of $0.94 \mathrm{mg} \mathrm{O}_{2} \mathrm{~L}^{-1}$ and the results obtained correlated well with those obtained using the standard method. A miniaturised analytical CCD-AES system ${ }^{\mathbf{1 0 1}}$ for the cold vapour determination of $\mathrm{Hg}$ in water was modified to use a gold filament preconcentration system to increase sensitivity. The LOD of $0.02 \mathrm{ng} \mathrm{L}^{-1}$ was sufficient for the determination of $\mathrm{Hg}$ in natural waters. Recoveries of $101 \pm 2 \%(n=5)$ for $\mathrm{Hg}$ in IRMM CRM ERM®CA615 (Groundwater) were obtained.

2.4.3 Inductively coupled plasma mass spectrometry. Two review papers surveyed the use of ICP-MS analysis in the wider environmental (198 references) ${ }^{\mathbf{1 0 2}}$ and life sciences arenas (42 references). ${ }^{103}$ More specifically, in the second review, the determination of radionuclides in drinking water using ICP-MS techniques was compared against traditional radiometric techniques. A review of recent advances in vapour generation coupled with atomic spectrometry ${ }^{\mathbf{1 0 4}}$ (119 reference) covered the non-chromatographic speciation analysis of $\mathrm{As}, \mathrm{Bi}, \mathrm{Cd}, \mathrm{Ge}, \mathrm{Hg}$, $\mathrm{Ni}, \mathrm{Pb}, \mathrm{Sb}, \mathrm{Se}, \mathrm{Sn}$ and Te in environmental samples including waters.

On account of its sensitivity, ICP-MS is well placed to meet regulatory monitoring requirements for emerging pollutants likely to be imposed in the future. Over 88 and $69 \%$ of Gd and Pt, respectively, discharged in hospital waste water was not removed $^{\mathbf{1 0 5}}$ by a waste water treatment plant and was consequently discharged into the river Seine. The ETV-ICP-MS LOD ${ }^{\mathbf{1 0 6}}$ was $0.12 \mu \mathrm{g} \mathrm{L}^{-1}$ when Au was used as a modifier in the determination of $\mathrm{Hg}$ in production waters arising from crude oil extraction processes. The average spike recovery was $106 \%$ for a production water sample which had been spiked with a Biorad Level 1 urine control material to produce a realistic saline matrix simulant. Reduction in argon consumption ${ }^{\mathbf{1 0 7}}$ to a mere $1.5 \mathrm{~L} \min ^{-1}$ as a move to reduce the cost of regulatory measurements was achieved with a novel low-flow ion source/ sampling cone geometry. Even at these low flow rates, there was sufficient analytical sensitivity as judged by the good recoveries obtained for NIST SRM 1643e (trace elements in water).

In a $H G-I C P-M S$ procedure for the simultaneous separation, preconcentration and determination of $\mathrm{As}, \mathrm{Bi}$ and $\mathrm{Sn}$ in waters, ${ }^{108}$ the analytes were retained on a functionalised silica column prior to quantification. Under optimum conditions of a sample loading flow rate of $1.9 \mathrm{~mL} \mathrm{~min}^{-1}$, a $0.5 \%(\mathrm{~m} / \mathrm{v}) \mathrm{NaBH}_{4}$ solution and a carrier gas flow rate of $0.98 \mathrm{~L} \mathrm{~min}^{-1}$, the enrichment factors ranged from $2.5(\mathrm{Sn})$ to 7.0 (Bi) and the LODs from $0.142(\mathrm{Sn})$ to $0.002(\mathrm{Bi}) \mu \mathrm{g} \mathrm{\textrm {L } ^ { - 1 }}$. Results for NWRI CRMs TMDA-54.4 and TM-24.3 (both fortified lake waters) were in good agreement with certified values. The volatile generation of $\mathrm{Cd}^{109}$ and $\mathrm{Pb}^{110}$ species was improved 15 - and 17-fold, respectively, by the addition of $\mathrm{K}_{3} \mathrm{Cr}(\mathrm{CN})_{6}$ and $\mathrm{K}_{3} \mathrm{Mn}(\mathrm{CN})_{6}$, to the $\mathrm{NaBH}_{4}$ reductant prior to ICP-MS detection.

The use of isotope dilution analysis in intercomparison exercises can generate data with a high degree of precision. An exact-matching ID-ICP-MS approach ${ }^{\mathbf{1 1 1}}$ was used for the determination of $\mathrm{Cd}, \mathrm{Ni}$ and $\mathrm{Pb}$ in a NRCC candidate RM SIM-QM-S2 (trace elements in drinking water). Exact matching was 
achieved by carrying out an initial analysis of the water using an external calibration approach to ascertain elemental concentrations in the test sample and then adding equal quantities of enriched isotopes to prepare 1:1 spiked solutions. Such ratios are optimal for counting statistics and for achieving the best possible measurement precisions. Results were in good agreement with values generated by other NMIs as part of an intercomparison exercise involving this candidate material.

The use of ICP-MS for isotopic analysis continues to be reported. As part of an interlaboratory analysis ${ }^{112}$ of CRM IAEA-443 (natural and artificial radionuclides in seawater from the Irish sea), the MC-ICP-MS results for ${ }^{239} \mathrm{Pu},{ }^{240} \mathrm{Pu}$, and ${ }^{241} \mathrm{Pu}$ activities and activity ratios were in good agreement with the radiometric data from 12 other laboratories. Such studies demonstrate the usefulness of ICP-MS as an alternative to traditional but slower radiometric techniques. The use of high-efficiency cones and desolvating nebulisers allowed the ${ }^{143} \mathrm{Nd} /{ }^{144} \mathrm{Nd}$ ratio to be determined on trace levels (1-5 ng) of $\mathrm{Nd} .^{113}$ Used in conjunction with a high-yield column preconcentration step, the long term measurement precision of the ${ }^{143} \mathrm{Nd} /{ }^{144} \mathrm{Nd}$ ratio was $( \pm 0.000016,2 \mathrm{SD})$, comparable to that of TIMS analysis. An anion-exchangeresin-based clean-up method ${ }^{114}$ for the measurement of $\delta^{34} \mathrm{~S}$ required only $2 \mu \mathrm{g}$ of sample and allowed a method precision of $0.24-0.34 \%(2 \sigma)$ to be achieved. This precision was comparable to that achieved using a previously reported cation-exchange clean-up methodology which, however, required $500 \mu \mathrm{g}$ of sample.

2.4.4 X-ray fluorescence spectrometry. A number of papers advocated the use of XRF techniques for water analysis. The use of SR-TXRF spectrometry ${ }^{\mathbf{1 1 5}}$ to determine trace element concentrations in Brazilian groundwater seems to this reviewer to be using a sledge hammer to crack a nut but there may be some merit to this approach as sample preconcentration was not required. The passive sample collection method DGT ${ }^{\mathbf{1 1 6}}$ was used with EDXRF to determine the labile concentrations of Co, $\mathrm{Cu}, \mathrm{Mn}, \mathrm{Ni}, \mathrm{Pb}$ and $\mathrm{Zn}$ in river water. The DGT samplers were analysed directly and gave results similar to those obtained by the SR-TXRF analysis of filtered samples from the same rivers. The use of DLLME extraction and dried spot EDXRF spectrometry $^{\mathbf{1 1 7}}$ for the determination of $\mathrm{Co}, \mathrm{Cu}, \mathrm{Fe}, \mathrm{Ni}, \mathrm{Pb}, \mathrm{Se}$ and $\mathrm{Zn}$ in nominal $5 \mathrm{~mL}$ water samples gave LODs of between 1.5 (Co) and $3.9(\mathrm{~Pb}) \mathrm{ng} \mathrm{mL}^{-1}$. An alternative procedure, ${ }^{118}$ used to extract Se from aqueous samples, involved the use of MWCNTs in dispersive SPME mode. Mean spike recoveries were $97 \%$ and the LOD using EDXRF was $0.06 \mathrm{ng} \mathrm{mL}^{-1}$.

2.4.5 Laser induced breakdown spectroscopy. Although the use of LIBS for water analysis remains hampered by the lack of sensitivity, hardware commonly used elsewhere in atomic spectrometry such as $\mathrm{USN}^{119}$ or $\mathrm{HG}^{120}$ have now been combined with LIBS in an attempt to boost sensitivity. Alternative approaches advocated the use of absorbents such as printing ${ }^{\mathbf{1 2 1}}$ or filter paper ${ }^{\mathbf{1 2 2}}$ in an attempt to preconcentrate water samples. Papers were soaked in the sample, dried and then ablated. By preconcentrating a $40 \mathrm{~g}$ sample, LODs for $\mathrm{Cr}$ and $\mathrm{Pb}$ of 18 and $75 \mu \mathrm{g} \mathrm{L}^{-1}$ were achievable.

\section{Analysis of soils, plants and related materials}

\subsection{Review papers}

Reviews of analytical methods for the determination of specific analytes included a critical evaluation ${ }^{\mathbf{1 4 2}}$ of techniques for the measurement of $\mathrm{Se}$ in mushrooms (53 references); a summary ${ }^{\mathbf{1 4 3}}$ of methods for the determination of Re in various sample matrices including soils and plants (65 references); and overviews of radiochemical and ICP-MS procedures for measuring $\mathrm{Th}^{\mathbf{1 4 4}}$ (129 references) and ${ }^{239} \mathrm{~Np}^{\mathbf{1 4 5}}$ (227 references) in environmental samples.

Reviews on specific sample types and applications included the use of chemometrics in authentication of herbal medicines ${ }^{\mathbf{1 4 6}}$ by chromatographic, genetic and spectroscopic methods (196 references); the speciation and fractionation of trace elements in tea infusions ${ }^{147}$ to assess bioaccessibility (60 references); and the capabilities and limitations ${ }^{148}$ of INAA, XRF spectrometry, ICP-AES, ICP-MS and AAS in plant ionomics research (290 references).

\subsection{Reference materials}

A brown rice flour CRM (NMIJ CRM 7531-a) was certified ${ }^{\mathbf{1 4 9}}$ containing $0.280,0.308,4.34,11.7,27.6$ and $31.8 \mathrm{mg} \mathrm{kg}^{-1}$ As, $\mathrm{Cd}, \mathrm{Cu}, \mathrm{Fe}, \mathrm{Mn}$, and $\mathrm{Zn}$, respectively.

\subsection{Sample preparation}

3.3.1 Sample dissolution and extraction. Rezic ${ }^{\mathbf{1 5 0}}$ presented a comparison of digestion and extraction methods for over 20 elements in cellulosic fibre materials (cotton, flax and hemp) as part of an assessment of the suitability of these materials as biosorbents. Microwave-assisted digestion of $0.5 \mathrm{~g}$ samples with $10 \mathrm{~mL}$ of $7 \mathrm{M} \mathrm{HNO}_{3}$ gave better accuracy than dry ashing or open-vessel digestion when used in the analysis of CRM IAEA-V9 (cotton cellulose); whilst ultrasound-assisted extraction in dilute mixed mineral acid solution recovered higher concentrations of analytes than liquid solid extraction or microwaveassisted extraction from fibres that had been steeped in a multielement solution overnight. For the determination of $\mathrm{P}$ in soils, Ivanov et al. ${ }^{151}$ recommended digestion with $60 \% \mathrm{HClO}_{4}$ instead of aqua regia in either the ISO 11466 or EPA Method 3052 procedures because the aqua regia method underestimated $P$ values for soil CRMs. In the determination of phytoavailable $\mathrm{P}$ extracted either in $0.04 \mathrm{M}$ calcium lactate at $\mathrm{pH} 3.5$ (the Egner Riehm soil test) or in $0.5 \mathrm{M}$ sodium bicarbonate at $\mathrm{pH} 8.5$ (method ISO 11263:2002), ICP-MS yielded higher concentrations than colorimetry. The relative differences were greater in soils with lower P concentrations. The determination of Ti in environmental studies is gaining importance as a means of estimating concentrations of engineered $\mathrm{TiO}_{2}$ nanoparticles in the environment. In the analysis of a range of materials ${ }^{\mathbf{1 5 2}}$ (stream sediment, bentonite, kaolinite and humic acid spiked with anatase, brookite and rutile), a novel muffle-furnace-based $\mathrm{KOH}$ fusion method yielded much higher Ti recoveries than microwave-assisted digestion. For example, results obtained 
when Method EPA 3051A was applied to pure samples of the $\mathrm{TiO}_{2}$ polymorphs were $<10 \%$ of theoretical values, whilst recoveries of $c a$. $90 \%$ could be obtained with fusion.

Microwave-assisted digestion with a $5: 4 \mathrm{HNO}_{3}-\mathrm{H}_{2} \mathrm{O}_{2}$ mixture gave better precision, ${ }^{153}$ but similar recoveries, to those obtained by either aqua regia or reverse aqua regia digestion in the determination of 20 analytes in plants by ICP-AES. Disposable, screw-capped polypropylene tubes ${ }^{\mathbf{1 5 4}}$ were used as a cheaper alternative to PTFE vessels in the digestion of sediments with $30 \% \mathrm{HNO}_{3}+5 \% \mathrm{HF}$. Recoveries similar to EPA Method 3052 were obtained for 26 elements, but the approach was unsuitable for Rb, REEs, Th, U or Zr.

Microwave-assisted EDTA extraction ${ }^{155}$ was a viable alternative to aqua regia extraction for the estimation of pseudototal $\mathrm{Cd}$, $\mathrm{Cu}, \mathrm{Mn}$ and $\mathrm{Pb}$ concentrations in selected soil and compost samples, but gave poor recoveries for $\mathrm{As}, \mathrm{Ba}, \mathrm{Be}, \mathrm{Co}, \mathrm{Cr}, \mathrm{Ni}, \mathrm{V}$ and $\mathrm{Zn}$. Unfortunately, even for the analytes successfully determined, the method may not prove transferable to other types of substrate. Microwave-assisted extraction with EDTA did provide $^{\mathbf{1 5 6}}$ the basis for a successful IC-ICP-MS method for the determination of $\mathrm{Cr}^{\mathrm{VI}}$ in solid samples including soil and welding dust. The analyte was extracted quantitatively with $50 \mathrm{mM}$ EDTA at pH 10 in only 10 minutes $\left(5 \mathrm{~min}\right.$ at $90{ }^{\circ} \mathrm{C}+5$ min at $100{ }^{\circ} \mathrm{C}$ ). Application of a double spike ID procedure showed that species interconversion - the bane of Cr speciation measurement - was inhibited by the formation of a stable $\mathrm{Cr}^{\mathrm{III}}$ EDTA complex.

A ultrasound-assisted extraction $\operatorname{method}^{157}$ for the determination of $S$ in mine tailing by ICP-AES - optimised by the use of a two-level, three-factor, full factorial design - involved sonication of $0.1 \mathrm{~g}$ samples for 20 minutes at $80^{\circ} \mathrm{C}$ in $1 \mathrm{~mL} \mathrm{HCl}+1 \mathrm{~mL}$ $\mathrm{HNO}_{3}$. Sonication ${ }^{158}$ for $15 \mathrm{~min}$ in $0.05 \mathrm{M}$ EDTA solution followed by quantification by ICP-AES was the basis of a fast screening method for estimation of mobile and potentially mobile $\mathrm{Cu}, \mathrm{Pb}$ and $\mathrm{Zn}$ in sediment samples.

Sequential extraction protocols generally specify the use of airdried samples. However, evidence has emerged that this may underestimate metal availability in flooded field conditions. Researchers in China ${ }^{\mathbf{1 5 9}}$ applied the BCR procedure to soils from rice paddies, extracting one portion of each sample at field moisture capacity under $\mathrm{N}_{2}$ and another after air drying. A significant shift of $\mathrm{Cd}, \mathrm{Cr}, \mathrm{Cu}$ and $\mathrm{Ni}$ (but not $\mathrm{Pb}$ ) from acid exchangeable and reducible to residual forms occurred on drying. Huang et al. ${ }^{\mathbf{1 6 0}}$ spiked soils with ${ }^{202} \mathrm{Hg}$ and then used ICP-MS to measure the ${ }^{202} \mathrm{Hg} /{ }^{200} \mathrm{Hg}$ isotope ratio in the fractions obtained from an eight-step modified Tessier procedure. After two weeks equilibration at room temperature, the tracer was recovered predominantly in the first four fractions: watersoluble, exchangeable, and associated with fulvic and humic acids. Kozak and Niedzielski ${ }^{\mathbf{1 6 1}}$ adapted their reactor manifold previously used for water analysis to perform in situ extraction of water-leachable, exchangeable and $2 \mathrm{M} \mathrm{HCl}$-leachable forms of $\mathrm{As}$ and $\mathrm{Sb}$ in sediment, with quantification by on-line HG-AAS.

Interest has continued in improving physiologically-based extraction tests to assess human bioaccessibility of elements following ingestion. A round-robin study ${ }^{162}$ compared no fewer than 17 different procedures for assessment of the bioaccessible content of up to 24 elements in NIST SRM 2710 (Montana soil). No preferred method emerged, but several gave results consistent with in vivo testing for As (swine and mouse) and $\mathrm{Pb}$ (swine only). The $\mathrm{pH}$ of the extractant(s) was found to have a strong influence on results. A modified version ${ }^{163}$ of the European Standard Toy Safety Protocol EN-71 (sample : extractant ratio $1: 2000$ ) extracted similar amounts of As, $\mathrm{Cd}, \mathrm{Cr}, \mathrm{Cu}, \mathrm{Ni}, \mathrm{Pb}$ and $\mathrm{Zn}$ as the well-established SBET method (0.4 M glycine at pH 1.5) from NIST SRMs 2710 and 2711 (both Montana soils) and 2583 and 2584 (both indoor dusts). The modified EN-71 extraction was therefore recommended for use as a simple and rapid soil screening test.

3.3.2 Sample preconcentration. Analyte preconcentration procedures continue to be developed because they remove potential interferents and allow workers who have access only to techniques such as FAAS to improve their LODs substantially. Methods for the analysis of soils, plants or related materials, or those developed for other sample matrices that used soil or plant CRMs for validation, are summarised in Tables 3-5.

A combination of preconcentration approaches ${ }^{83}$ was used successfully for Cr speciation in soil extracts and water by FAAS. The $\mathrm{Cr}^{\mathrm{VI}}$ concentration was determined following DLLME using APDC, carbon tetrachloride and ethanol as chelating agent, extraction solvent and disperser solvent, respectively. The total Cr concentration was determined by coprecipition following oxidation of the sample with $0.02 \% \mathrm{Ce}\left(\mathrm{SO}_{4}\right)_{2}$ in $0.07 \mathrm{M} \mathrm{H}_{2} \mathrm{SO}_{4}$. The $\mathrm{Cr}^{\mathrm{III}}$ concentration was estimated by difference. A four-step procedure $^{\mathbf{1 6 4}}$ reduced interference from $\mathrm{Mo}$ and $\mathrm{Sn}$ in the determination of Cd in rice and sediments by ICP-MS. The steps were: thiourea SPE for removal of the majority of matrix elements; coprecipitation with $\mathrm{Mg}(\mathrm{OH})_{2}$ to eliminate Mo; acid dissolution of the precipitate; and strong anion exchange SPE to remove Sn.

\subsection{Instrumental analysis}

3.4.1 Atomic absorption spectrometry. A thermal desorption AAS method ${ }^{\mathbf{1 6 5}}$ used a commercial total $\mathrm{Hg}$ analyser for rapid identification of $\mathrm{Hg}$ species in solid samples. The procedure was applied successfully to soil and sediment samples and CRMs BCR CRM 142 R (light sandy soil), RTC CRM 021 (sandy loam) and NRCC MESS-3 and PACS-2 (both marine sediments).

Developments in $A A S$ included a method for the determination of $\mathrm{Ag}$ that introduced a new design ${ }^{95}$ of CVG integratedatom-trap. A 2 min in situ preconcentration gave a 143-fold improvement in sensitivity over conventional FAAS and an LOD of $0.7 \mu \mathrm{g} \mathrm{L}^{-1}$. A method ${ }^{\mathbf{1 6 6}}$ for the determination of $\mathrm{Cd}$ in soil extracts combined high-speed self-reversal background correc-

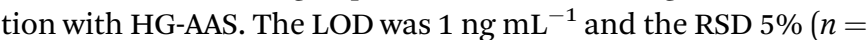
10). Results were statistically similar to those obtained by ETAAS using a $\mathrm{Pd} / \mathrm{MgNO}_{3}$ matrix modifier. Li et al. ${ }^{\mathbf{1 6 7}}$ more than doubled both sensitivity and linear range for the determination of $\mathrm{Cu}$ and $\mathrm{Zn}$ in plants by coating the inner wall of a slotted quartz tube atomiser with $\mathrm{SiO}_{2}$ nanoparticles. Recoveries of analytes from NIST SRMs 1515 (apple leaves) and 1573 (tomato leaves) were in the range $95-102 \%$. 
Table 3 Preconcentration methods involving liquid-phase extraction used in the analysis of soils, plants and related materials

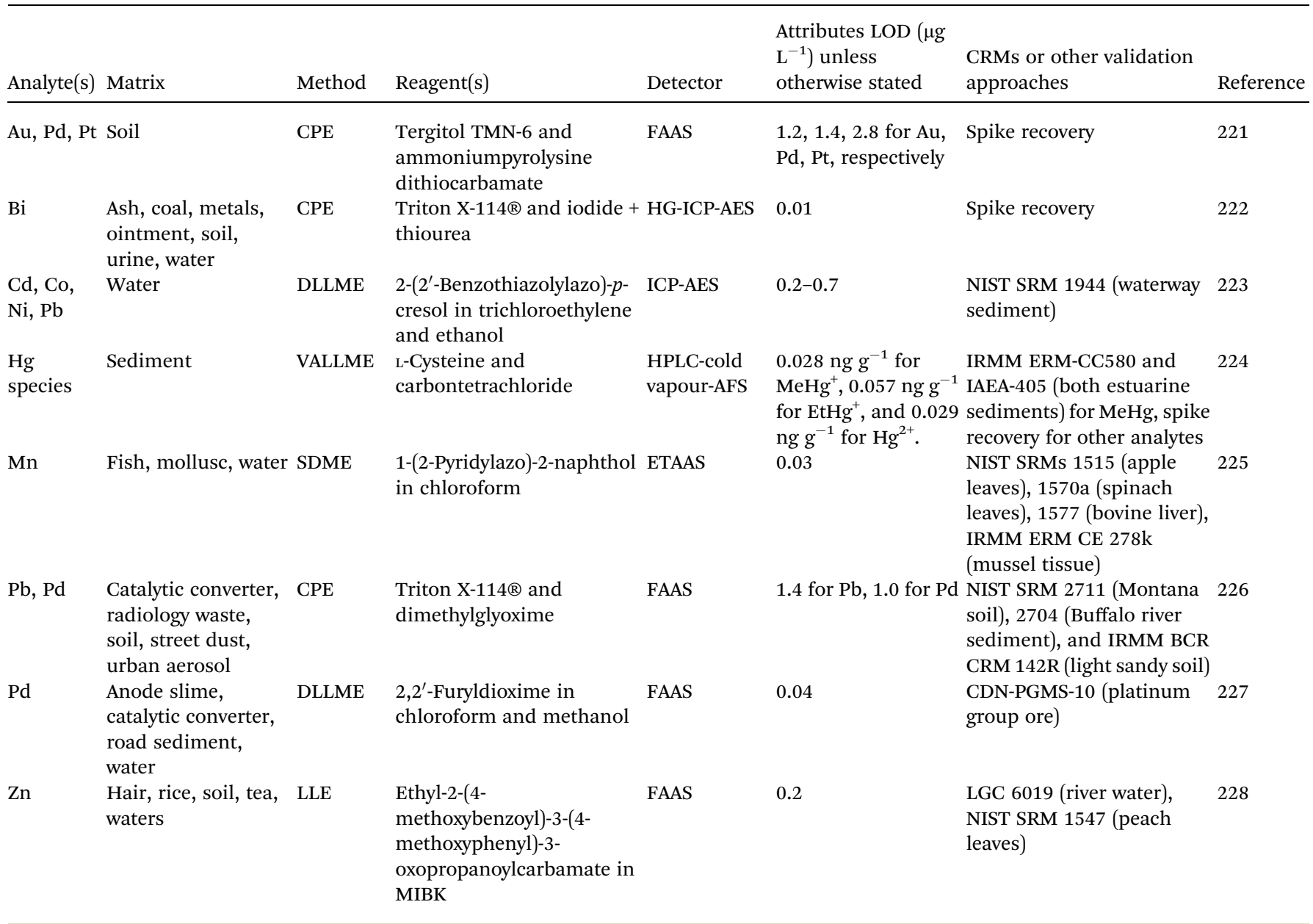

Developments in ETAAS included a new chemical modifier ${ }^{168}$ of $6 \mu \mathrm{g} \mathrm{Pb}+1600 \mu \mathrm{g}$ citric acid that overcame chloride interference in the determination of $\mathrm{Ag}$ in aqua regia digests of soils, sediments and sludges, and a procedure ${ }^{169}$ for the simultaneous determination of $\mathrm{As}, \mathrm{Cd}, \mathrm{Cu}, \mathrm{Cr}, \mathrm{Ni}, \mathrm{Pb}$ and $\mathrm{Tl}$ in sediment digests and extracts, optimised via a $3^{3}$ Box-Behnken factorial design. Interest in slurry sample introduction continued. One reported method $^{\mathbf{1 7 0}}$ used Ir as a permanent modifier in the measurement of $\mathrm{Cd}$ and $\mathrm{Pb}$ in medicinal plants. Another ${ }^{171}$ used dimethylglyoxime-impregnated activated carbon to preconcentrate Co and Ni from plant CRMs prior to introduction to the graphite tube as a carbon slurry. Although good recoveries were obtained (105-114\% for Co and $95-100 \%$ for $\mathrm{Ni}$ ), before the sorbent could be added the samples had to be digested in $\mathrm{HNO}_{3}$ and the digests taken to near dryness, reconstituted in de-ionised water, and adjusted to $\mathrm{pH} 7$ with sodium hydroxide. This is a disadvantage relative to conventional slurry sample introduction that can be applied directly to solid samples.

Table 4 Preconcentration methods involving precipitation used in the analysis of soils, plants and related materials

\begin{tabular}{|c|c|c|c|c|c|c|}
\hline Analyte(s) & Matrix & Carrier & Detector & $\begin{array}{l}\text { Attributes LOD } \\
\left(\mu \mathrm{g} \mathrm{L}^{-1}\right) \text { unless } \\
\text { otherwise stated }\end{array}$ & $\begin{array}{l}\text { CRMs or other validation } \\
\text { approaches }\end{array}$ & Reference \\
\hline $\begin{array}{l}\mathrm{Cd}, \mathrm{Co}, \mathrm{Cr}, \mathrm{Cu}, \mathrm{Fe}, \mathrm{Mn}, \\
\mathrm{Ni}, \mathrm{Pb}\end{array}$ & Food, soil & Holmium hydroxide & AAS & & $\begin{array}{l}\text { IRMM BCR CRM 141R } \\
\text { (calcareous loam soil), CRM } \\
025-050 \text { (soil) }\end{array}$ & 229 \\
\hline $\mathrm{Cd}, \mathrm{Co}, \mathrm{Pb}, \mathrm{Zn}$ & $\begin{array}{l}\text { Baby food, dried } \\
\text { eggplant, water }\end{array}$ & $\begin{array}{l}\text { Mo(VI)- } \\
\text { diethyldithiocarbamate }\end{array}$ & FAAS & $1.1-2.2$ & $\begin{array}{l}\text { NWRI TMDW-500 (drinking } \\
\text { water) }\end{array}$ & 230 \\
\hline Cr species $^{a}$ & Soil, water & Copper-violuric acid & FAAS & 1.2 & Spike recovery & 231 \\
\hline
\end{tabular}

${ }^{a}$ Coprecipition of $\mathrm{Cr}^{\mathrm{III}}$, then reduction with sulfuric acid and ethanol, determination of total $\mathrm{Cr}$, and estimation of $\mathrm{Cr}^{\mathrm{VI}}$ by difference. 
Table 5 Preconcentration methods involving solid phase extraction used in the analysis of soils, plants and related materials

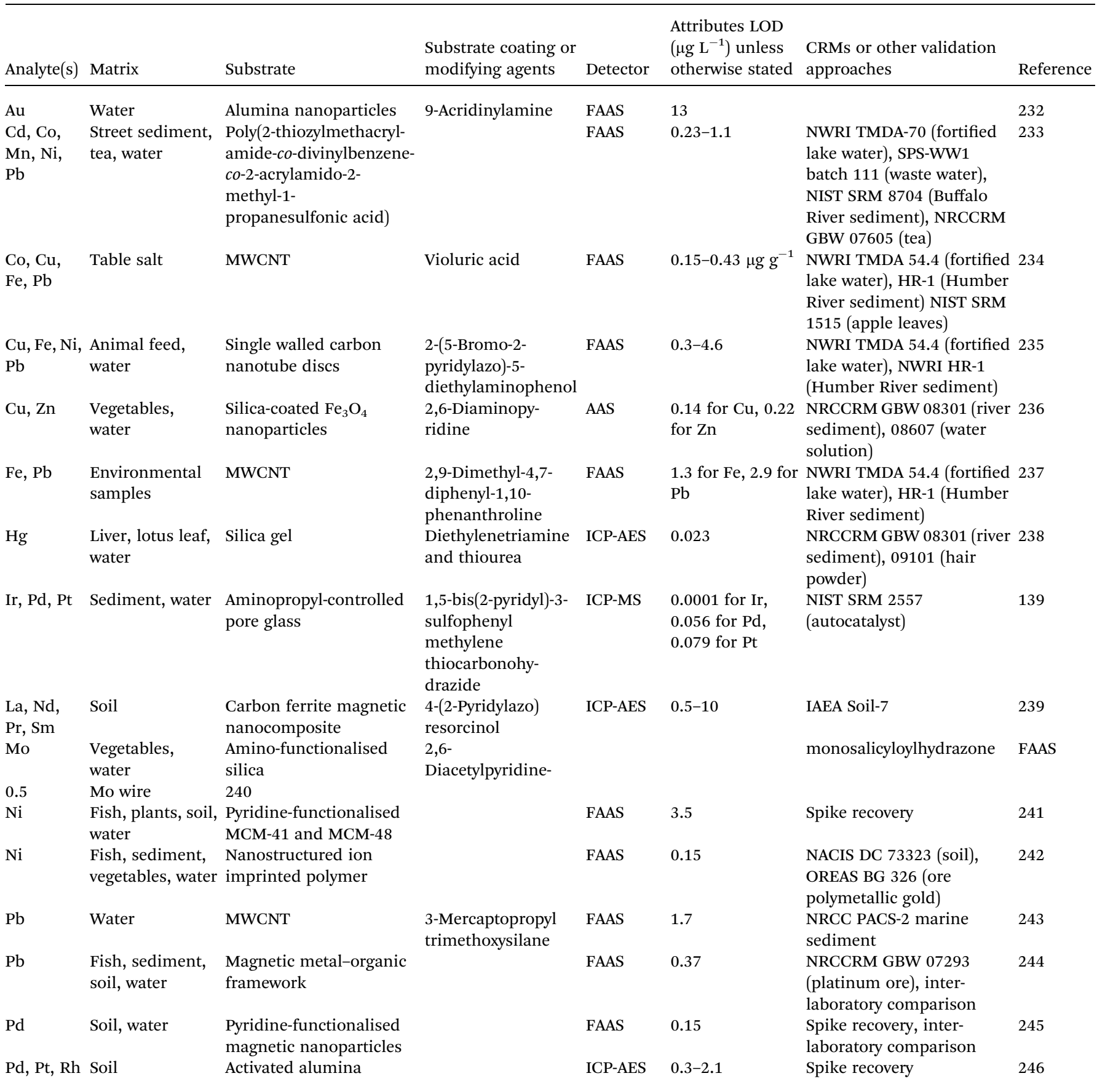

High-resolution continuum-source AAS has seen use with both flame and electrothermal atomisers. Researchers in Romania ${ }^{172}$ developed a fast sequential method for determination of $\mathrm{Ag}, \mathrm{Cd}$, $\mathrm{Co}, \mathrm{Cr}, \mathrm{Cu}, \mathrm{Ni}, \mathrm{Pb}$ and $\mathrm{Zn}$ in soil digests by HR-CS-FAAS. This was shown by the Bland and Altman statistical method to have accuracy, precision and LODs statistically similar to those obtained using ICP-AES. Researchers in Brazil, who have long championed CS-AAS, reported methods for the determination of $\mathrm{Cr}^{173}$ and $\mathrm{Pb}^{174}$ in medicinal plants by HR-CS-ETAAS with direct solid sampling. Both procedures yielded accurate results, at the $95 \%$ confidence level, for analysis of RMs including NIST
SRM 1515 (apple leaves), 1547 (peach leaves) and 1575a (pine needles). The use of wavelength-integrated absorbance and/or summation of absorbance at different lines enhanced ${ }^{175}$ sensitivity in the determination of $\mathrm{B}, \mathrm{P}$ and $\mathrm{S}$ in plant digests by HRCS-FAAS.

3.4.2 Atomic emission spectrometry. Use of a flow-blurring $\circledast$ multiple nebuliser ${ }^{176}$ increased analyte transport into the plasma by $>40 \%$ relative to a standard sample introduction system and also meant that an internal standard $\left(1 \mathrm{mg} \mathrm{L}^{-1} \mathrm{In}\right)$ could be mixed with samples and standards in the spray chamber, thereby reducing interference from $\mathrm{Ca}, \mathrm{K}, \mathrm{Mg}$ and $\mathrm{Na}$ in the 
determination of As and Se by ICP-AES. Recovery of As from BCR CRM 280R (lake sediment) was $96 \%$ compared with $116 \%$ with a conventional nebuliser. The LODs were $c a .50 \mu \mathrm{g} \mathrm{L}^{-1}$ for both analytes compared with $91 \mu \mathrm{g} \mathrm{L}^{-1}$ for As and $130 \mu \mathrm{g} \mathrm{L}^{-1}$ for Se when using a conventional nebuliser.

In contrast, lower plasma loading and sample consumption was achieved ${ }^{177}$ in the development of a high-temperature, singlepass spray chamber (also called a torch-integrated sample introduction system, see Section 3.4.4). Combined with segmented sample injection into an air carrier gas and single point standard addition, it was used in the ICP-AES analysis of marine samples including CRMs GBW 07313 and ISS-A1 (both marine sediment). Matrix interferences from $\mathrm{Al}, \mathrm{Ca}, \mathrm{K}$ and $\mathrm{Na}$ on the analytes $\mathrm{Ag}, \mathrm{Al}, \mathrm{Cd}, \mathrm{Mn}$ and $\mathrm{Zn}$ were reduced.

Mulitvariate optimisation using two-level factorial design ${ }^{\mathbf{1 7 8}}$ allowed development of a method for the determination of mercury by FI-cold vapour-ICP-AES with a LOD of $0.11 \mu \mathrm{g} \mathrm{L}^{-1}$. The recovery was 99\% for NIST SRM 2704 (Buffalo River sediment) and 98\% for CRM IAEA 085 (human hair).

3.4.3 Atomic fluorescence spectrometry. A new method ${ }^{179}$ for the speciation of $S b$ in vegetables by HPLC-HG-AFS involved ultrasound-assisted extraction with $10 \mathrm{mM}$ EDTA at $\mathrm{pH} 2.5$. It gave the highest yield ( $70 \%$ of the total Se present) of all the extraction reagents tested. This extractant was compatible with the HPLC mobile phase used and, importantly, prevented oxidation of $\mathrm{Sb}^{\mathrm{III}}$ to $\mathrm{Sb}^{\mathrm{V}}$. The LODs were $0.07,0.08$ and $0.9 \mu \mathrm{g}$ $\mathrm{L}^{-1}$ for $\mathrm{Sb}^{\mathrm{III}}, \mathrm{Sb}^{\mathrm{V}}$, and trimethyl $\mathrm{Sb}^{\mathrm{V}}$, respectively.

A simplified method ${ }^{\mathbf{1 8 0}}$ for determination of mercury species in sediments by HPLC-cold vapour-AFS used $0.1 \%$ mercaptoethanol microwave-assisted extraction. Results similar to certified values were obtained for $\mathrm{MeHg}^{+}$in CRMs ERM-C580 and IAEA 405 (both estuarine sediments). The LODs were 0.5, 1.1 and $0.5 \mathrm{ng} \mathrm{g}^{-1}$ for $\mathrm{MeHg}^{+}, \mathrm{EtHg}^{+}$and $\mathrm{Hg}^{2+}$, respectively.

3.4.4 Inductively coupled plasma mass spectrometry. Grotti et al. ${ }^{\mathbf{1 8 1}}$ optimised a torch-integrated total-consumption sample introduction system for ICP-MS. Using a chamber temperature of $150{ }^{\circ} \mathrm{C}$, a nebuliser gas flow rate of $0.7 \mathrm{~L} \mathrm{~min}^{-1}$, a sheathing gas flow rate of $0.35 \mathrm{~L} \mathrm{~min}^{-1}$ and a sample uptake rate of $20 \mu \mathrm{L} \mathrm{min}{ }^{-1}$, the apparatus was between 2 and 8 times more sensitive than a conventional micronebuliser and mini spray chamber system for the measurement of 30 analytes. Results for a set of CRMs, including NIST SRM 1570a (spinach leaves), were in good agreement with certified values ( $t$-test at 95\% probability).

The accuracy of the determination of lanthanides in plants by ICP-MS was improved ${ }^{\mathbf{1 8 2}}$ by the removal of silica and fluoride by volatilisation as $\mathrm{SiF}_{4}$ and $\mathrm{BF}_{3}$ after microwave digestion of the sample. The low recoveries obtained if this was omitted were attributed to the formation of tiny silica particles that could act as analyte sorbents and interfere with ion production.

Claverie et al. ${ }^{183,184}$ developed a LA-ICP-MS method with a fast spinning platform on which samples and standards, prepared as lithium metaborate fused beads, were ablated alternately. The standard was spiked with Gd isotopically enriched in ${ }^{157} \mathrm{Gd}$, whilst the sample was spiked with Gd of natural isotopic abundance. Differences in ablation rates between the two materials could therefore be calculated from analysis of the mixed aerosol. In one set of experiments ${ }^{\mathbf{1 8 3}}$ the two glasses were mounted symmetrically about the spin axis; in another ${ }^{\mathbf{1 8 4}}$ they were positioned on the platform such that it was possible to ablate either only the sample or, by moving the laser farther offaxis, an increasing proportion of standard, thus performing incell standard additions. The approach was used successfully to determine $\mathrm{Ba}, \mathrm{Cu}, \mathrm{Ni}, \mathrm{Sr}, \mathrm{Pb}$ and $\mathrm{Zn}$ in glass, rock, sediment and soil SRMs.

The excellent review of hyphenated techniques involving ICPMS (89 references) presented by Maher et al. ${ }^{\mathbf{1 8 5}}$ predominantly concerned HPLC-ICP-MS but also covered HPLC-HG-ICP-MS, cryogenic trapping ICP-MS, and GC-ICP-MS. Example applications were discussed, challenges highlighted, and recommendations for future work provided. Articles featuring HPLC-ICP-MS published since 1978 were reviewed by Shoaib and Al-Swaidan ${ }^{77}$ (79 references).

Various procedures involving chromatographic separation coupled to ICP-MS have been reported for specific analytes. A gradient elution HPLC-ICP-MS method ${ }^{\mathbf{1 8 6}}$ successfully separated organoarsenic feed additives and other As species present in the $0.5 \mathrm{M} \mathrm{H}_{3} \mathrm{PO}_{4}$ extracts of soil and sediment from the vicinity of pig farms in China. Complementary SEC-ICP-MS and CZE-ICP-MS methods ${ }^{\mathbf{1 8 7}}$ were developed and applied to the characterisation of low-, medium- and high-molecular weight complexes of cadmium with glutathione and phytochelatins in model solutions and extracts of thale cress (Arabidsopsis thaliana). Gadolinium-based contrasting agents ${ }^{89}$ used in MRI were detected in river water and aquatic plants near Berlin by hydrophilic interaction chromatography ICP-MS. Application of a variety of techniques ${ }^{\mathbf{1 8 8}}$ including HPLC-ICP-MS gave a comprehensive characterisation of low molecular weight $(<5 \mathrm{kDa})$ selenometabolites in rice, wheat and maize grown on soils naturally rich in Se. A speciation method ${ }^{\mathbf{1 8 9}}$ involving online preconcentration IC-ICP-MS gave LODs for both selenite and selenate in Se deficient soils of $<10 \mathrm{pg}$.

3.4.5 Accelerator mass spectrometry. Several AMS facilities reported new or enhanced analytical capabilities during the review period. The Centre for Isotopic Research on Cultural and Environmental Heritage in Italy ${ }^{\mathbf{1 9 0}}$ used a new beam line dedicated to actinide measurement for analysis of soils from around the Garigliano power plant, which is currently undergoing decommissioning. The Gliwice Absolute Dating Methods Centre in Poland ${ }^{\mathbf{1 9 1}}$ improved its sample throughput for radiocarbon measurement to around 400 targets per year. The Xi'an AMS Centre in China ${ }^{\mathbf{1 9 2}}$ demonstrated that its methods for measurement of ${ }^{129}$ I can be applied to sequential extracts of soil to aid understanding of I migration in loess profiles. The research group at the Vienna Environmental Research Accelerator in Austria ${ }^{193}$ developed a method to measure ${ }^{239} \mathrm{Pu},{ }^{240} \mathrm{Pu}$, ${ }^{241} \mathrm{Pu},{ }^{242} \mathrm{Pu}$ and ${ }^{244} \mathrm{Pu}$ on a single target. This allowed more precise assessment of the origin of $\mathrm{Pu}$ in environmental samples than was previously possible.

3.4.6 Laser induced breakdown spectroscopy. A comprehensive ${ }^{\mathbf{1 9 4}}$ review of LIBS (312 references) explained the fundamentals of the technique, described specific approaches including double pulse and fs LIBS and summarised applications in a range of fields. Another review ${ }^{195}$ (84 references) 
provided an authoritative overview of developments and applications of LIBS relevant to the analysis of plants. Together with animal and microbial samples, plants were also the subject of a wider review ${ }^{196}$ of the biological applications of LIBS.

The first application of LA-LIBS to soil analysis has been published. ${ }^{197}$ In this technique, the processes of solid sample ablation and generation of the LIBS plasma for analyte measurement are performed separately, allowing each to be optimised independently, although both can be performed with the same laser following beam-splitting. The LA-LIBS and conventional LIBS procedures were compared for the measurement of $\mathrm{K}$ in soils spiked with $\mathrm{N}-\mathrm{P}-\mathrm{K}$ fertiliser. Superior linearity was obtained with LA-LIBS $\left(r^{2}=0.861 c f . r^{2}=\right.$ 0.665). Although acceptable results were obtained for only $\mathrm{Ca}$, $\mathrm{Fe}, \mathrm{K}$ and $\mathrm{Mg}$ in the analysis of 65 soil samples with known concentrations of $\mathrm{Ca}, \mathrm{Fe}, \mathrm{K}, \mathrm{Mg}, \mathrm{Mn}$ and $\mathrm{Na}$, there is considerable scope for further development of the approach.

Another interesting innovation was the application of microwave-assisted LIBS to soil analysis. ${ }^{198}$ The LIBS signal intensity could be increased markedly by application of microwave radiation to extend plasma emission lifetime. The sensitivity for measurement of $\mathrm{Cu}$ was thereby increased 23-fold and concentrations as low as $30 \mathrm{mg} \mathrm{kg} \mathrm{kg}^{-1}$ could be measured. Additional analytes such as $\mathrm{Ag}$, undetectable using conventional LIBS analysis, could be detected.

Applications of LIBS to plant analysis included the development of a method ${ }^{\mathbf{1 9 9}}$ for measurement of $\mathrm{Cu}$ in algae by standard additions, and a detailed investigation ${ }^{200}$ of how laser fluence and focusing affected the determination of $\mathrm{Al}, \mathrm{B}, \mathrm{Ca}, \mathrm{Cu}$, $\mathrm{Fe}, \mathrm{K}, \mathrm{Mg}, \mathrm{Mn}, \mathrm{P}$ and $\mathrm{Zn}$ in pellets of plant material. Best results were obtained when the Q-switched Nd:YAG laser (1064 nm) was operated at $50 \mathrm{~J} \mathrm{~cm}^{-1}$ with a spot size of $750 \mu \mathrm{m}$.

Research has continued to improve the performance of LIBS for analysis of soils. Methods have been reported for the determination of $\mathrm{Pb},{ }^{201} \mathrm{Zn},{ }^{202}$ and $\mathrm{Ca}, \mathrm{Cu}$ and $\mathrm{Zn},{ }^{203}$ all with LODs $<50$ $\mathrm{mg} \mathrm{kg}^{-1}$. Repeatedly firing the laser at the same spot on a soil sample enhanced ${ }^{\mathbf{2 0 4}}$ both signal intensity and signal-to-background ratio for $\mathrm{Fe}, \mathrm{K}, \mathrm{Mn}$ and $\mathrm{Ti}$, potentially improving LODs. Frydenvang et al. ${ }^{205}$ developed a novel approach for determining elemental ratios that combined the fundamental mathematical framework of calibration-free LIBS with empirical calibration using 22 CRMs, including NIST SRMs 2709 (San Joaquin soil), 2710 (Montana soil - highly elevated trace elements) and 2711 (Montana soil - moderately elevated trace elements). The usefulness of $\mathrm{ANNs}^{\mathbf{2 0 6}}$ in overcoming matrix effects and nonlinear response in LIBS was clearly illustrated when a transportable instrument was deployed at a former mining site in France. A separate ANN model was built for each analyte, if necessary incorporating lines for other elements to improve the prediction. Results obtained for $\mathrm{Al}, \mathrm{Ca}, \mathrm{Cu}$ and $\mathrm{Fe}$ agreed well with those obtained using ICP-AES.

3.4.7 X-ray spectrometry. Applications of $\mu$-SR-XRF spectrometry $^{207}$ to study the distribution of biologically important elements in environmental matrices, including plants and soils, were reviewed (80 references).

Plessow $^{\mathbf{2 0 8}}$ highlighted some major problems in the analysis of soil by XRF spectrometry for $\mathrm{B}, \mathrm{Cl}$ and $\mathrm{F}$. Fluorescence intensities changed dramatically over time, usually increasing over replicate analyses, but occasionally decreasing, depending on the nature of the sample. He attributed this to radiolysis, suggesting that irradiation could mobilise the analytes, which could then either move into the analytical zone, or through it and be lost to the vacuum. Difficulties in the application of PIXE to soil and other thick insulating samples ${ }^{\mathbf{2 0 9}}$ due to charge build-up, which contributes to the Bremsstrahlung background, were overcome by use of an electron flood gun and beam profile monitor. The utility of the approach was demonstrated by analysis of CRM IAEA Soil 7. Wovkulich et al. ${ }^{210}$ ran soil column experiments in a synchrotron beam line. Both $\mu$-XRF and $\mu$-XANES spectrometries were used to measure changes in As concentration and speciation following treatment of the soil with oxalic acid, a potential reagent for use in the remediation of As-contaminated soil. Malherbe and Claverie ${ }^{\mathbf{2 1 1}}$ presented the intriguing possibility of using a commercially available high-resolution WDXRF spectrometer for direct determination of $\mathrm{Cr}$ speciation in solid samples, including soils, based on differences in $K_{\beta}$ transition profiles between $\mathrm{Cr}^{0}$, $\mathrm{Cr}^{\mathrm{III}}$ and $\mathrm{Cr}^{\mathrm{VI}}$.

In the analysis of plants, Paltridge et al. confirmed the suitability of EDXRF spectrometry for measuring Fe and $\mathrm{Zn}$ in rice and pearl millet ${ }^{212}$ and $\mathrm{Fe}$, Se and $\mathrm{Zn}$ in wheat ${ }^{213}$ and recommended wider use of the technique to assess nutrient status in biofortification programmes. Other workers used $\mu$-SR-XRF to image and quantify $\mathrm{Fe}$ in tomato roots ${ }^{\mathbf{2 1 4}}$ and to investigate the distribution of macronutrients and micronutrients in Dioscorea balcanica. ${ }^{215}$ A rather unusual study ${ }^{216}$ combined ultrasoundassisted extraction with TXRF spectrometry for the measurement of $\mathrm{Ca}, \mathrm{Cr}, \mathrm{Cu}, \mathrm{Fe}, \mathrm{K}, \mathrm{Mn}, \mathrm{Ni}, \mathrm{P}, \mathrm{Pb}$ and $\mathrm{Zn}$ in medicinal plants, spices and herbs. The optimised procedure involved 15 min sonication of $10 \mathrm{mg}$ finely ground sample in $1 \mathrm{~mL}$ of $10 \%$ $\mathrm{v} / \mathrm{v} \mathrm{HNO}_{3}+10 \% \mathrm{v} / \mathrm{v} \mathrm{HCl}+10 \% \mathrm{v} / \mathrm{v} \mathrm{HF}$, followed by centrifugation to separate residual solid and drying of $10 \mu \mathrm{L}$ of the supernatant onto a quartz sample carrier for analysis.

As noted in our sister review, ${ }^{4}$ developments and applications of PXRF spectrometry continue to be reported. Bosco ${ }^{217}$ summarised presentations delivered at the James L Waters Symposium at Pittcon in 2012 and provided a fascinating insight into the commercial evolution of the technique. Researchers in Brazil $^{218}$ proposed a new method to correct for the effects of moisture in the analysis of soil based on the low energy background under the Ti $K_{\alpha}$ peak. More significantly, two groupsone in Australia and one in the UK-almost simultaneously reported the 'first' application of PXRF spectrometry to the analysis of plants. McLaren et al. ${ }^{\mathbf{2 1 9}}$ determined $\mathrm{Ca}, \mathrm{Co}, \mathrm{Cr}, \mathrm{Fe}$, $\mathrm{K}, \mathrm{Mn}, \mathrm{Ni}, \mathrm{P}, \mathrm{S}, \mathrm{Si}$ and $\mathrm{Zn}$ in agricultural plants from New South Wales whereas Reidinger et al. ${ }^{220}$ focussed on the measurement of $\mathrm{P}$ and $\mathrm{Si}$.

\section{Analysis of geological materials}

\subsection{Reference materials}

Current interest in developing suitable RMs for microanalytical and isotopic analysis was highlighted in a review ${ }^{\mathbf{2 4 7}}$ of papers published in 2011 containing analytical data for geochemical and 
environmental RMs and CRMs. The on-line version, containing all the references and supporting information in appendices, is particularly valuable because it is fully integrated with the GeoReM database (http://georem.mpch-mainz.gwdg.de), thereby providing the geoanalyst with access to information on approximately 2600 RMs. The IGGE has reported ${ }^{248}$ certified and indicative values for 18 oxides and elements in four new chromium ore CRMs with $\mathrm{Cr}_{2} \mathrm{O}_{3}$ contents between 17.6 and $57.8 \% \mathrm{~m} / \mathrm{m}$.

The increased use of microanalytical techniques in recent years has fuelled the demand for suitable reference glasses. Two soda lime reference glasses (BAM-S005-A and BAM-S005-B), initially prepared as standards for bulk analysis by techniques like XRF spectrometry, were assessed for their suitability as glass standards for microanalysis using EPMA, LA-ICP-MS and SIMS. ${ }^{249}$ All major and 33 trace elements were homogeneously distributed at the $\mu \mathrm{m}$ scale in both glasses but $\mathrm{Cl}, \mathrm{Cr}$, Cs, Mo and $\mathrm{Ni}$ were not. Information values for major elements on the original certificate were confirmed by EPMA, while LA-ICP-MS data for 18 trace elements were within the uncertainties of the certified concentrations; no explanation for the lack of agreement with the certified values for $\mathrm{Ba}, \mathrm{Ce}, \mathrm{Pb}$ and $\mathrm{Sr}$ could be given. New LA-ICP-MS data for a further 22 trace elements were presented and will enhance the utility of these materials. The paucity of commercially available RMs for the determination of $\mathrm{Au}$ and the PGEs in sulfides by LA-ICP-MS prompted a comparative study ${ }^{250}$ of some PGE-bearing sulfide materials employed as in-house RMs in various laboratories around the world. A new nickel sulfide RM (NiS-3) was developed and used to calibrate LA-ICP-MS measurements of the five in-house sulfide RMs. Gold and PGE concentrations were not homogeneously distributed in all the RMs tested. Calibration against different RMs did not produce consistent results for all elements, highlighting the importance of the widespread availability of well-characterised sulfide RMs.

More RMs for isotope studies are required to facilitate easy comparison between data sets. Although NIST SRM 3108 (Cd solution), certified for its Cd concentration, is not an isotopic RM per se, a round-robin intercalibration ${ }^{251}$ of various in-house Cd reference solutions involving seven laboratories demonstrated that it fulfilled all reasonable criteria for its adoption as a zero-delta $\mathrm{RM}$, pending the certification of another material as a proper isotopic RM for Cd. Similarly, there is no universally accepted zero-delta RM for the Mo stable isotope system, making it difficult to compare results generated in different laboratories using different analytical approaches. In an inter-laboratory calibration ${ }^{252}$ of various in-house Mo standard solutions, the $\delta^{98}$ Mo values differed by up to $0.37 \%$, significantly exceeding the typical reproducibility of the determinations. Data from this study facilitated a rigorous assessment of previously published Mo isotope data. Mutually consistent $\delta^{98}$ Mo data for NIST SRM 3134 (Mo solution) supported the proposal by Greber et al. ${ }^{253}$ that the Mo-isotope community should adopt this material as the zero-delta RM. Greber $e t$ al. also refined the working values for Mo concentrations in NIST glass RMs SRM 610 and 612, using an ID double-spike technique, and advocated their use as solid standards, as they have identical and homogeneous ${ }^{98} \mathrm{Mo} /{ }^{95} \mathrm{Mo}$ ratios at a test portion of $0.02 \mathrm{~g}$. Despite its significantly different ablation behaviour, Darling et al. ${ }^{254}$ found that NIST SRM 610 was effective in correcting for instrumental mass fractionation during in situ $\mathrm{Pb}$ isotope analysis of a range of $\mathrm{Fe}-$ $\mathrm{Ni}-\mathrm{Cu}-\mathrm{Zn}$ sulfides from the Sudbury impact structure using $193 \mathrm{~nm}$ LA-MC-ICP-MS. Although matrix-dependent melting and condensate accumulation around the sulfide ablation pits may have reduced the sensitivity of the measurements, they did not result in any detectable isotopic fractionation.

Twelve natural monazites were analysed to find a suitable RM with homogeneous Sm-Nd composition and concordant U-Th$\mathrm{Pb}$ age to act as a standard for in situ microanalysis. ${ }^{255}$ From determinations of trace element concentrations by quadrupole ICP-MS and of isotope ratios by LA-MC-ICP-MS, with some check data for Nd-Sm isotopes by ID-TIMS, two monazites were found to be sufficiently homogeneous to act as potential standards.

\subsection{Solid sample introduction}

4.2.1 Laser ablation. A succinct summary ${ }^{256}$ of advances in laser sampling over the past few years concluded that the benefits expected of femtosecond LA systems, compared to ns systems, have only been partially realised thus far. The wider availability of fs LA systems should facilitate future research into fs ablation processes. For those new to this field, a comprehensive review ${ }^{257}$ (157 references) of recent developments and future prospects for fs LA-ICP-MS should prove valuable. It addressed the fundamentals of laser-solid interactions during ablation and the characteristics of various LA systems. Most of the examples of fs LA-ICP-MS applications, including depth profiling and geochemical analysis, confirmed that the use of fs LA can greatly reduce elemental fractionation, matrix effects and the need for matrix-matched standards, compared to the use of $n s$ LA. The advantages of UV over IR wavelengths for ns LA systems are well documented; however, these benefits were not so conclusive in studies using fs systems. In line with previous work, Kimura and Chang ${ }^{258}$ reported reduced laser-induced matrix effects using a $200 \mathrm{~nm}$ fs laser rather than a $193 \mathrm{~nm} n s$ excimer laser for the determination of 44 major and trace elements in silicate glasses by SF-ICPMS. Velasquez et al..$^{259}$ confirmed that data of similar quality could be obtained for $\mathrm{Au}$ and $\mathrm{Cu}$ concentrations in natural sulfides by NIR fs LA coupled to quadrupole ICP-MS, irrespective of whether NIST silicate glasses or sulfide RMs were used as calibrators. In a study ${ }^{260}$ of Th-U ratios in titanite by fs LA-MC ICP-MS, ablations were carried out at wavelengths of 800 $\mathrm{nm}$ (NIR) and $265 \mathrm{~nm}$ (UV) using a Ti-sapphire-based laser system. Elemental fractionation was significantly less using the UV single spot ablation mode compared to NIR spot analyses, but precision was limited by the lower ion signals achievable. Differences in U-Th fractionation were also observed between different titanite materials, e.g., glass and minerals, even when their compositions were nearly identical, indicating that the calibration standard needed to be matched both in terms of composition and crystal structure. 
Several new investigations have provided insights into causes of elemental fractionation in LA-ICP-MS. When silicate glasses were ablated with a $193 \mathrm{~nm}$ excimer laser in a single-volume ablation chamber, ${ }^{261}$ differential responses of volatile and refractory elements (relative to ${ }^{43} \mathrm{Ca}$ ) at different ablation sites were found to be correlated with the local helium gas velocity at the position of analysis. This fractionation was thought to be related to the different behaviour of these elements during condensation after ablation, as well as interaction between condensate and the carrier gas. In contrast, ablation within a two-volume sample chamber, designed to produce a uniform helium flow regime throughout the ablation cell, showed little evidence of this type of elemental fractionation. Flamigni et $a .^{262}$ used 2D optical emission spectrometry and quadrupole ICP-MS to investigate the processes involved in the vaporisation of laser-produced aerosols and particles within the ICP. They demonstrated a shift of a few mm along the axial channel in the onset and maximum positions of atomic emission, depending on whether the aerosols were produced from the ablation of silicate glasses or of metals. These shifts arose from the aerosol penetrating to different depths along the ICP axial channel, depending on its composition, resulting in varying ion extraction efficiencies through the vacuum interface. Although further work is required, these findings may influence the design of future LA-ICP-MS systems.

Hardware modifications for improving the analytical performance of LA-ICP-MS included the development of a signalsmoothing device, ${ }^{263}$ which consisted of a copper cylinder (internal volume $c a .94 \mathrm{~cm}^{3}$ ) filled with steel wire and placed between the ablation cell and the ICP torch. This device produced smooth signals at laser repetition rates as low as 1$2 \mathrm{~Hz}$ without any detrimental effect on the signal decay time and was successfully used for $\mathrm{U}-\mathrm{Pb}$ dating of zircons. The development of a spinning ablation cell platform enabled ID $^{183}$ and standard addition ${ }^{\mathbf{1 8 4}}$ techniques to be implemented with LA-ICP-MS. Two samples were placed close together in a sample holder on a rotating platform in the ablation cell and ablated using a stationary laser beam, allowing quasi-simultaneous ablation of the materials. Isotope dilution ${ }^{\mathbf{1 8 3}}$ was performed on four NIST SRMs, two soils and two sediments, prepared as lithium borate fusions spiked with a natural Gd solution. By ablating an isotopically spiked glass, containing known amounts of ${ }^{135} \mathrm{Ba},{ }^{157} \mathrm{Ga},{ }^{206} \mathrm{~Pb},{ }^{86} \mathrm{Sr}$, and ${ }^{67} \mathrm{Zn}$, alongside each sample on the spinning platform, a homogeneous aerosol was produced after a period of equilibration. The main advantage of this method was the possibility of analysing a large number of samples with the same isotopically spiked glass RM, which could be reused after polishing to remove previous ablations. The spinning platform was employed in a similar manner to determine $\mathrm{Ba}, \mathrm{Cu}, \mathrm{Ni}, \mathrm{Pb}, \mathrm{Sr}$ and $\mathrm{Zn}$ concentrations in geological materials by standard addition. ${ }^{\mathbf{1 8 4}} \mathrm{A}$ glass RM, prepared by spiking lithium borate flux with a multielement solution containing the elements of interest and a solution of ${ }^{157} \mathrm{Gd}$, was mounted alongside the fused sample in an off-axis alignment so that it was possible to increase the proportion of standard in the aerosol mix by performing the ablation further from the axis of rotation. The validity of the proposed method for the direct and fast analysis of solid samples of different matrices by standard additions using a single standard sample was demonstrated using NIST SRMs. A new design ${ }^{264}$ of skimmer and sample cones with addition of nitrogen to the central gas flow enhanced signal intensities for LA-MC-ICP-MS measurements. This modification was utilised for the in situ determination of Hf isotope ratios in zircons using Faraday detectors, for which large ions beams are necessary for precise and accurate results.

Laser ablation ICP-MS is now considered an essential tool for analysing individual fluid inclusions. The main limitation in determining $\mathrm{Br}$ and $\mathrm{Cl}$ by LA-ICP-MS is their high first ionisation energies, which result in low signal intensities. Using wellcharacterised natural scapolite standards, Hammerli et al. ${ }^{\mathbf{2 6 5}}$ routinely achieved LODs of $8 \mu \mathrm{g} \mathrm{g}^{-1}$ for $\mathrm{Br}$ and $500 \mu \mathrm{g} \mathrm{g}^{-1}$ for $\mathrm{Cl}$ during multi-element analysis of individual fluid inclusions by quadrupole ICP-MS coupled to a $193 \mathrm{~nm}$ ArF excimer laser. Corrections for polyatomic interferences on the $\mathrm{Br}$ signal were required, particularly when analysing K-bearing minerals, with measurements at mass ${ }^{81} \mathrm{Br}$ recommended in preference to ${ }^{79} \mathrm{Br}$. In most fluid inclusion analysis by LA-ICP-MS, microthermometric measurements are used to provide an absolute concentration for one major element, usually $\mathrm{Na}$, which is then applied as an internal standard to the LA-ICP-MS data. Recently, concerns have been voiced about the thermodynamic and numerical models used to estimate the absolute concentration of the internal standard from the microthermometric data, particularly for complex fluids containing salts other than $\mathrm{NaCl}$. Microthermometric measurements of two phase transitions allowed Schlegel et al. ${ }^{\mathbf{2 6 6}}$ to quantify absolute concentrations of $\mathrm{CaCl}_{2}$ and $\mathrm{NaCl}$ in $\mathrm{Ca}-\mathrm{Na}$ dominated brine inclusions. Using this approach, accurate $\mathrm{Na}$ concentrations for internal standardisation of LA-ICP-MS data could be obtained irrespective of the host mineral, e.g., quartz or calcium-rich minerals like fluorite or carbonate. Leisen et al. ${ }^{267}$ presented an improved method for calculating cation concentrations in quartz-hosted fluid inclusions of low to moderate salinity. When combined with a signal processing protocol, this enabled them to estimate analytical uncertainties for each major and trace element determined in a single inclusion. The method was validated against concentrations in materials previously analysed by LIBS or crush-leach methods, and was applied as part of a wider strategy ${ }^{\mathbf{2 6 8}}$ involving microthermometry and LA-ICP-MS for the determination of $\mathrm{Br}, \mathrm{Cl}$ and $\mathrm{Na}$ concentrations in individual fluid inclusions of variable size and bulk salinity. The calculated uncertainty on $\mathrm{Cl} / \mathrm{Br}$ and $\mathrm{Na} / \mathrm{Br}$ ratios was found to be between 30 and $38 \%$, regardless of the salinity of the inclusion.

The application of LA-ICP-MS to $\mathrm{U}-\mathrm{Pb}$ geochronology continues to be a major growth area. Nemchin et al. ${ }^{269}$ summarised the state-of-the-art capability of LA-ICP-MS and SIMS for resolving age variations in $\mathrm{U}$ and Th-bearing minerals at the $\mu \mathrm{m}$-scale. A review ${ }^{\mathbf{2 7 0}}$ of the development of LA-ICP-MS for U-Pb dating of accessory minerals illustrated how recent advances have increased the precision and accuracy of such analysis. Included was a typical workflow for the in situ analysis of assessory minerals in standard $30 \mu \mathrm{m}$ polished thin sections by $193 \mathrm{~nm}$ ArF excimer LA-ICP-MS. Data reduction was performed 
using Iolite ${ }^{\mathrm{TM}}$ and VizualAge $\mathrm{T}^{\mathrm{TM}}$. The latter is a new software tool $^{271}$ developed for reducing and visualising U-Pb geochronology data obtained by LA-ICP-MS. In addition, it provides computational tools to correct for the presence of common lead. In a recent zircon dating study, ${ }^{272}$ systematic differences observed in ${ }^{206} \mathrm{~Pb} /{ }^{238} \mathrm{U}$ data obtained by LA-ICP-MS and TIMS were related to differences in radiation damage in the RM and samples. Annealing unknown and reference zircons to the same state prior to analysis appeared to overcome this problem. A modified protocol ${ }^{273}$ based on single shot LA-ICP-MS, with semiautomated data reduction and robust error propagation, offered rapid sample throughput for analysing detrital zircon and monazite grains without compromising data quality. The time taken to analyse 120 sample grains and associated RMs was reduced from $c a .2 \mathrm{~h}$ using conventional LA protocols with continuous laser pumping to $20 \mathrm{~min}$, with only a modest increase in uncertainity from $2 \%$ to $4 \%$. Significant matrix effects were encountered during in situ $\mathrm{U}-\mathrm{Pb}$ dating of titanite $\mathrm{e}^{274}$ by $193 \mathrm{~nm}$ LA coupled to quadrupole ICP-MS. Consistent ages were obtained when titanite RMs rather than zircons were used for external calibration.

The suitability of various RMs for LA-ICP-MS multi-element analysis of Roman and late Iron Age glasses ${ }^{275}$ was evaluated. Standards from the Corning Museum of Glass were considered to be more appropriate for this purpose than the NIST SRM 600 series of glass RMs in terms of their matrix composition and concentration range of trace elements, but the former were not as well characterised as the NIST ones in terms of element concentrations and their homogeneity. Quantification was achieved by adopting a strategy developed by previous workers, in which an average response factor for each analyte was calculated from a set of glass RMs. Comparison of individual response factors obtained from different standards provided an indication of any standard that suffered from specific issues, so that any deemed unsuitable could be discarded. Calibration using sets of response factors produced more accurate results than single-point calibrations and enabled the quantification of trace elements in glasses with very different compositions. As an alternative to the glass RMs currently available, Ulrich and Kamber $^{276}$ proposed the use of natural obsidian glass as an inexpensive and abundant QC material for LA-ICP-MS analysis of silicates and oxides. The obsidian samples were homogeneous at the $40 \mu \mathrm{m}$ scale for many trace elements including REEs. Silicon was recommended as the internal standard for these matrices.

The suitability of carbon as the internal standard for biological and medical applications has long been a matter of debate. A fundamental study ${ }^{277}$ on the ablation behaviour of carbon revealed a matrix-dependent partitioning of carbon into gaseous species and particles, whereas trace elements were exclusively transported in the particulate phase. Calcium carbonate powder and diamonds used as cutting tool tips were included in the 12 common carbon matrices examined.

4.2.2 Laser induced breakdown spectroscopy. Recent developments in LIBS instrumentation and analytical performance are covered in a sister Update. ${ }^{3}$ Much of the current research into geological applications of LIBS has been directed towards improving the performance of the ChemCam instrument on the Mars Science Laboratory Curiosity rover. ${ }^{278,279}$ The possibility of developing a LIBS instrument for in situ $\mathrm{K}-\mathrm{Ar}$ geochronology for Mars has also been explored. ${ }^{280}$ A laboratorybuilt portable LIBS instrument ${ }^{281}$ was used to identify tephra layers in lacustrine sediments and fossilisation processes in ammonites. An optimised calibration procedure for determining elemental ratios by LIBS, as advocated by Frydenvang et al. ${ }^{205}$ was better than empirical methods at coping with matrix effects. Their procedure was a hybrid between an empirical approach, based on calibration curves using 22 NIST and USGS RMs spanning a wide range of rock compositions, and the mathematical framework of the theoretical calibrationfree LIBS method often employed.

\subsection{Sample preparation}

4.3.1 Sample dissolution. Although the principles of green chemistry $^{282}$ can be applied to every step of the analytical process, techniques that involve in situ measurements with little or no sample preparation or dissolution, e.g., LIBS and PXRF spectrometry, can be considered to be the most environmentally friendly. However, there is still scope to simplify the reagents and digestion conditions used in methods where complete sample digestion is a prerequisite. Thus, a dissolution procedure ${ }^{283}$ employing ammonium bifluoride $\left(\mathrm{NH}_{4} \mathrm{HF}_{2}\right)$ was developed for the ICP-MS multielement analysis of rocks. Ultrapure $\mathrm{NH}_{4} \mathrm{HF}_{2}$, prepared using a standard PFA sub-boiling distillation system, has a higher boiling point than mineral acids such as $\mathrm{HF}, \mathrm{HNO}_{3}$ and $\mathrm{HCl}$ so digestions could be carried out at higher temperatures than usual, facilitating the decomposition of refractory mineral phases. Digestion $(2-3 \mathrm{~h}$ at $230{ }^{\circ} \mathrm{C}$ ) with $200 \mathrm{mg}$ of $\mathrm{NH}_{4} \mathrm{HF}_{2}$ in a screw top Teflon vial was sufficient to digest $50 \mathrm{mg}$ of the USGS RM GSP-2 (granodiorite), one of the more challenging samples to dissolve because of its $550 \mu \mathrm{g} \mathrm{g}^{-1} \mathrm{Zr}$ content. This was six times faster than a conventional acid digestion in a high pressure PTFE bomb at $190^{\circ} \mathrm{C}$. In addition, the $\mathrm{NH}_{4} \mathrm{HF}_{2}$ digestion was not hampered by the formation of insoluble fluorides, making it an effective, simple, economical and comparatively safe method of dissolution. A new simple design of sub-boiling still ${ }^{284}$ may be of interest to many geochemical laboratories. It consisted of two Teflon bottles connected at right angles, with one acting as the feed bottle and heated by IR radiation on its upper surface, and the other in a cold water bath acting as the condenser and receiver. Compared to commercially available stills with a similar performance, this still was easy and inexpensive to construct, had a smaller footprint, much larger yield (up to 500 $\mathrm{mL}$ of mineral acid per day) and lower energy consumption.

In a systematic reassessment of the optimum conditions for high pressure digestion of felsic rocks in $\mathrm{HF}-\mathrm{HNO}_{3}$ acids, Zhang et al. ${ }^{285}$ concluded that the use of $\mathrm{HF}$ alone was more effective in dissolving refractory phases, such as zircon, than the use of a mixture of $\mathrm{HF}$ with other minerals acids. It was recommended that a test portion of $\leq 100 \mathrm{mg}$ of ultrafine powder $(<30 \mu \mathrm{m}$ nominal particle size) be taken to prevent the formation of 
insoluble fluorides even though this might result in unrepresentative subsampling.

4.3.2 Sample separation and preconcentration. A review ${ }^{286}$ of methods for the dissolution of geological materials for the determination of REEs by ICP-MS presented the strengths and weaknesses of both alkali fusion and acid digestion procedures. Alkali fusions are preferred by many laboratories because they are relatively rapid and digest totally the resistant accessory minerals, but they result in a solution with high TDS content. Singh et $a .^{287}$ compared two fusion procedures for the dissolution of zircon prior to the measurement of the REEs, Th and U: one based on sodium peroxide and the other using a $3+1$ mixture of $\mathrm{KHF}_{2}$ and NaF. Unfortunately, certified values were unavailable for both of the two zircons analysed, although data from both methods were comparable with each other and any available published data. The TDS of the final solution was, in fact, not a problem as the sensitivity of modern ICP-MS instruments allows such solutions to be analysed at high dilutions.

For samples with low REE content or matrix components that cause severe polyatomic interferences, separation and preconcentration of REEs prior to analysis is desirable; the determination of the REEs and Th at $\mathrm{ng} \mathrm{kg}^{-1}$ levels in ultramafic rocks being one such case. Preconcentration methods are often based on ion-exchange resins, as in that developed by Sun et al. ${ }^{288}$ in which anion exchange and inorganic co-precipitation were used to separate and preconcentrate REEs from a HF$\mathrm{HNO}_{3}$ digest treated with boric acid to prevent the formation of insoluble fluorides. In a novel approach, Fedyunina et al. ${ }^{289}$ used a chelating sorbent, Pol-DETATA (cross-linked polystyrene grafted with diethylene-triaminetetraacetate groups), to extract REEs from lithium metaborate fusions of rock CRMs. Because Pol-DETATA sorbs metals ions other than the REEs, 5-sulfosalicylic acid was added as a masking agent to minimise the retention of $\mathrm{Fe}$, which would otherwise reduce REE sorption. Flow injection of $50 \mu \mathrm{L}$ of eluate in $1 \mathrm{M} \mathrm{HNO}_{3}$ into the ICP-MS instrument was deemed a reasonable compromise between maximising analytical sensitivity and minimising the risk of corrosion of the interface. Data obtained were within $15 \%$ of the reference value for most REEs in the four CRMs analysed. The authors claimed that the method was faster, required less reagent and provided lower LODs than more conventional preconcentration methods based on ion-exchange or extraction chromatography.

\subsection{Instrumental analysis}

4.4.1 Atomic emission spectrometry. A review ${ }^{256}$ of recent developments in geochemical analysis by ICP-AES confirmed that most advances have focussed on improved sample pretreatment, sample introduction and calibration. The determination of $U$ isotopes by ICP-AES was particularly novel although unlikely to replace ICP-MS as the technique of choice for these measurements. In a modified sample introduction system ${ }^{290}$ for ICP-AES, the heater/condenser of a commercial USN system was replaced with a pre-evaporation tube and sheathing device. On leaving the USN, the aerosol was heated to $400{ }^{\circ} \mathrm{C}$ by IR heating before entering the ICP. The increased amount of water vapour introduced by this configuration improved the plasma excitation conditions and robustness such that analysis of geological samples could be carried out by simple calibration, without matrix-matching, using an argon emission line as the internal standard. A 10-25 fold improvement in sensitivity and LODs, compared to conventional pneumatic nebulisation, was reported. Volatile elements such as B and $\mathrm{Hg}$, normally lost in the heating phase of a conventional USN, could also be determined.

4.4.2 Inductively coupled plasma mass spectrometry. Several noteworthy reviews of recent developments in ICP-MS are available. A summary of improvements in ICP-MS hardware ${ }^{256}$ covered developments in ion detectors, TOF and MattauchHerzog designs of ICP-MS instruments, the concept of distanceof-flight MS and the introduction of the first commercial ICP triple-quadrupole mass spectrometer. The update ${ }^{3}$ on atomic spectrometry described new approaches to sample preparation for isotope ratio measurements by ICP-MS, as well as novel instrument features and applications. Baxter et al. ${ }^{291}$ published a detailed tutorial (184 references) on fundamental aspects of isotope abundance ratio measurements by SF-ICP-MS. A more general overview ${ }^{102}$ focussed on progress in coupling different separation techniques to ICP-MS for quantitative analysis in environmental and life sciences. It is always instructive to view the history of ICP-MS developments through the eyes of one of its leading practitioners; Longerich's perspective ${ }^{292}$ is relevant to anyone engaged in geochemical analysis.

While quadrupole ICP-MS is firmly established as a routine workhorse for elemental determinations, improvements in isotope ratio measurements by MC-ICP-MS continue to support advances in geochemical research. The emphasis is often on novel methods for chemical separation and purification to improve the accuracy of isotope ratio measurements. A one-step separation $^{293}$ of $\mathrm{Mg}$ from matrix elements using AG50W-X8 cationexchange resin in a purification process taking about $5 \mathrm{~h}$ gave recoveries of $\geq 97 \%$ for $\mathrm{Mg}$ whereas $\leq 0.2 \%$ of the matrix components were recovered. The total procedural blank of $<3 \mathrm{ng}$ $\mathrm{Mg}$ was considered to be negligible. Magnesium isotope measurements were made by MC-ICP-MS under cool plasma conditions using a high-sensitivity skimmer cone (X-cone) to maximise signal intensity and to reduce background interferences. Although the samples contained significant Ca concentrations, $\mathrm{Ca}: \mathrm{Mg}$ ratios of up to $100: 1$ had little impact on the measured $\mathrm{Mg}$ isotope data. The accuracy of the procedure was confirmed through the analysis of seven rock RMs. The analytical precision was $0.03-0.09 \%$ o $(2 \sigma)$. In a method for the isolation of $\mathrm{Sb}$ from stibnite ores, ${ }^{294}$ care was taken not to change the oxidation state which could influence the $\mathrm{Sb}$ isotope ratio. After aqua regia digestion, separation was achieved using a combination of cation-exchange chromatography on Dowex AG50-X8 resin and AEC on Amberlite IRA 743 resin. Indium was used to correct for instrument-induced mass bias during measurements of ${ }^{123} \mathrm{Sb} /{ }^{121} \mathrm{Sb}$ by MC-ICP-MS at medium resolution $(R=4000)$. Variations in Sb isotope ratios in stibnite ores of $0.1 \%$, compared to a measurement reproducibility of $0.01 \%$, demonstrated the potential of this method for provenance studies of Roman glasses. Lithium isotope ratios ${ }^{295}$ in three RMs were measured by MC-ICP-MS after a three-step separation 
technique employing cation-exchange chromatography on AG50W-X8, with $2.8 \mathrm{M} \mathrm{HCl}, 0.15 \mathrm{M} \mathrm{HCl}$ and $0.5 \mathrm{M} \mathrm{HCl}$ in $30 \%$ ethanol as eluants at each of the three stages. The precision of the technique $( \pm 0.72-1.04 \%, 2 \sigma)$ was similar to that obtained by other MC-ICP-MS laboratories.

A method ${ }^{296}$ for the simple and rapid determination of $O s$ and $R e$ isotope ratios by MC-ICP-MS was based on Carius tube digestion and sparging introduction of Os. Measurement times were reduced significantly by employing four channeltron multi-ion counters for simultaneous measurement of the Os isotopes. Because the amplification efficiencies of the multi-ion counters differed from one another and varied with time, Os isotope ratios were corrected using the sample-standard bracketing method. Rhenium isotopes were measured by means of eight Faraday cups with solution nebulisation via a USN. The method was sufficiently sensitive to determine Re-Os isotope systematics in samples such as chert with low concentrations. Precisions for ${ }^{187} \mathrm{Os} /{ }^{188}$ Os ratios for RMs JMS-2, JCh-1 (GSJ sedimentary rock RMs) and DROsS (Durham Romil Os solution) were $0.35-0.71,1.56-3.31$ and $0.99-1.28 \%$ RSD, respectively, depending on the ion intensities. These precisions were considered to be adequate for reconstructing changes in marine Os isotope compositions. Lawley and Selby ${ }^{297}$ proposed a room-temperature chemical separation technique using $\mathrm{HF}$ to isolate ultrafine $(<50 \mu \mathrm{m})$ molybdenite grains for Re-Os geochronology. Exposure to HF had no effect on the Re-Os molybdenite systematics. The procedure allowed the determination of reproducible ages for ultrafine samples that were unsuitable for Re-Os determinations using traditional physical mineral separation techniques.

Kramchaninov et al. ${ }^{298}$ sought to refine the procedure for $\mathrm{Sr}$ isotope measurements by $M C-I C P-M S$ to achieve performance data to rival those obtainable by TIMS. By correcting for mass bias effects using a combination of normalisation to zirconium isotope ratios and standard-sample bracketing, they obtained precisions of $\pm 0.015- \pm 0.05 \%$ for ${ }^{88} \mathrm{Sr} /{ }^{86} \mathrm{Sr}$, depending on sample composition. These precisions were better than those reported previously by similar protocols based on MC-ICP-MS but worse than those achievable by double spike TIMS $( \pm 0.02 \%)$. The advantages cited were greater productivity (56 times higher) and the ability to measure ${ }^{88} \mathrm{Sr} /{ }^{86} \mathrm{Sr}$ and ${ }^{87} \mathrm{Sr} /{ }^{86} \mathrm{Sr}$ simultaneously with high precision. However, at least $95 \% \mathrm{Sr}$ recovery from the chromatographic column was essential for accurate results. Building on earlier work using a heated torch integrated spray chamber, Paredes et al. ${ }^{299}$ demonstrated that it was possible to measure $\mathrm{Sr}$ isotope ratios at a continuous liquid flow rate of $<10 \mu \mathrm{L} \mathrm{min}{ }^{-1}$ with a repeatability of $c a .40 \mathrm{ppm}$ on the ${ }^{87} \mathrm{Sr} /{ }^{86} \mathrm{Sr}$ ratio measured in NIST SRM 987 (strontium carbonate). This figure of merit was similar to that (30-50 ppm) previously reported for liquid flows rates 5 to 10 times higher. The new instrumental setup allowed a sheathing gas to be introduced and included a semi-automated FI sample-delivery system to minimise manipulation of small sample volumes.

Several new procedures for the measurement of $N d$ isotopes by $M C-I C P-M S$ have been published. Huang et al. ${ }^{113}$ employed a combination of high-sensitivity cones and a new generation desolvator (Aridus II or APEX-IR), together with column chemistry based on Eichron LN resin, to achieve optimal conditions for $\mathrm{Nd}$ isotope determination in a variety of sample matrices with low $\mathrm{Nd}$ content, including carbonates and seawater. The long-term precision of \pm 0.000016 (2SD) for ${ }^{143} \mathrm{Nd} /{ }^{144} \mathrm{Nd}$ in a sample size of $c a .1 .25 \mathrm{ng} \mathrm{Nd}$, was a factor of 5 better than that for existing MC-ICP-MS methods using $<2 \mathrm{ng}$ $\mathrm{Nd}$. Their column separation chemistry provided yields $(>92 \%)$ similar to those of more traditional multi-step separations but was simpler and more rapid, with negligible procedural blanks. As a practical alternative to ID-TIMS, Sanchez-Lorda et al. ${ }^{\mathbf{3 0 0}}$ proposed an MC-ICP-MS procedure for determining ${ }^{143} \mathrm{Nd} /{ }^{144} \mathrm{Nd}$ and ${ }^{147} \mathrm{Sm} /{ }^{144} \mathrm{Nd}$ ratios on solutions of silicate rocks without resorting to ID or separating $\mathrm{Nd}$ and $\mathrm{Sm}$ from each other. The LREEs were separated from matrix elements with yields of $\geq 97 \%$ by cation-exchange on Dowex AG50W followed by extraction chromatography on Eichrom TRU resin. Oxide formation, a major cause of mutual fractionation of $\mathrm{Nd}$ and Sm in the ICP, was minimised by introducing the sample into the ICP via a commercially available two-step desolvation system. After correction for instrumental mass bias effects and isobaric interferences, the overall reproducibility for ${ }^{147} \mathrm{Sm} /{ }^{144} \mathrm{Nd}$ was $0.2-0.7 \%$ RSD. Although this performance cannot compete with that achievable by TIMS (typically $0.1 \%$ $\mathrm{RSD}$ ), the precision and accuracy were sufficient for many geological applications. Interestingly, the within-run uncertainty of 0.000014 for ${ }^{143} \mathrm{Nd} /{ }^{144} \mathrm{Nd}$ in a depleted basalt (GSJ JB2), was similar to the long-term precision reported by Huang et $a .^{113}$ In a study of isotopic fractionation of $\mathrm{Ce}$ and $\mathrm{Nd}$ in geological samples by MC-ICP-MS, Ohno and Hirata ${ }^{301}$ employed a similar two-step separation scheme to isolate the LREEs before further purification on an Ln Spec column to separate $\mathrm{Ce}$ and $\mathrm{Nd}$. Mass discrimination effects were corrected by means of an external correction technique based on an exponential law, using ${ }^{149} \mathrm{Sm} /{ }^{147} \mathrm{Sm}$ and ${ }^{153} \mathrm{Eu} /{ }^{151} \mathrm{Eu}$ ratios to correct the isotope data for $\mathrm{Ce}$ and $\mathrm{Nd}$, respectively. The reproducibilities of the measurements for ${ }^{142} \mathrm{Ce} /{ }^{140} \mathrm{Ce}$, ${ }^{146} \mathrm{Nd} /{ }^{144} \mathrm{Nd}$ and ${ }^{148} \mathrm{Nd} /{ }^{144} \mathrm{Nd}$ were $0.08 \%$ o (2SD, $\left.n=25\right), 0.06 \%$ (2SD, $n=39$ ) and $0.12 \%$ o (2SD, $n=39$ ), respectively. With this level of precision it was possible to demonstrate that the Ce and $\mathrm{Nd}$ isotope ratios in two igneous and two sedimentary rocks were the same, within analytical uncertainty, whereas the ratios for both elements were significantly higher in a carbonate RM.

The $100^{\text {th }}$ anniversary of the publication of "Age of the Earth" in 1913 by Arthur Holmes, the first person to use radioactivity to date rocks, has been marked by various conferences and review articles on isotope geochronology and its future. An issue of Elements (volume 9, number 1) dedicated to this theme contained perspectives on various aspects of modern geochronology by some of the leading practitioners in the field. In his review of the evolution of $\mathrm{U}-\mathrm{Pb}$ geochronology as a robust dating technique, Corfu ${ }^{302}$ focussed on the causes and implications of discordance between the ${ }^{206} \mathrm{~Pb} /{ }^{238} \mathrm{U}$ and ${ }^{207} \mathrm{~Pb} /{ }^{235} \mathrm{U}$ decay systems. Although targeted at the nuclear industry, a guide $^{303}$ to the fundamental concepts and recent applications of $\mathrm{U}$ chronometry may also be of interest to some geochemists.

An article on high precision geochronology $y^{304}$ highlighted the continuing efforts of the EARTHTIME community (http:// 
www.earth-time.org) to identify and mitigate inter-laboratory biases through group inter-calibration experiments. Important developments in the application of $\mathrm{U}-\mathrm{Pb}$ dating to speleothems were discussed by Woodhead and Pickering. ${ }^{305}$ Although the mechanisms for the transport and incorporation of $\mathrm{Pb}$ and $\mathrm{U}$ in speleothem calcite remain a matter of debate, LA-ICP-MS and autoradiography were considered ideal screening methods for reconnaissance studies. ${ }^{\mathbf{3 0 6}}$ On the basis of exploratory studies already undertaken, this is likely to be a major growth area in the next decade as the potential palaeoclimatic information contained within selected speleothems offers insights in many fields of research.

\subsubsection{Other mass spectrometric techniques}

4.4.3.1 Thermal ionisation mass spectrometry. The analytical capabilities of the current generation of TIMS instruments have renewed the debate ${ }^{256}$ over the best strategies for achieving the lowest uncertainties and best accuracy for geological applications, as well as choice of the most appropriate RM.

As noted in Section 4.3.2, double spike TIMS is the method of choice when the best precision for $N d$ isotope determinations is required. Wakaki and Tanaka ${ }^{307}$ refined this procedure by including internal normalisation and an iterative calculation procedure to improve precision and to minimise possible systematic bias during data analysis. The average ${ }^{143} \mathrm{Nd} /{ }^{144} \mathrm{Nd}$ ratio for GSJ JNdi-1 (neodymium oxide) was $0.512106 \pm$ 0.000010 (2SD, $n=44$ ). Significant mass-dependent isotope fractionation occurred during the analysis of commercial highpurity Nd oxide reagents and the La Jolla RM, relative to JNdi-1, suggesting that these data should always be normalised to JNdi1 rather than the La Jolla RM, which is often used for this purpose. By replacing the $10^{11} \Omega$ resistors in the feedback loop with $10^{12} \Omega$ resistors to reduce the noise in the Faraday cup current amplifiers, Koornneef et $a .^{308}$ achieved a two-fold improvement in the analytical precision on ${ }^{143} \mathrm{Nd} /{ }^{144} \mathrm{Nd}$ and ${ }^{87} \mathrm{Sr} /{ }^{86} \mathrm{Sr}$ ratio measurements. Their data suggested that it should be possible to resolve the variability in the fourth decimal place for $\mathrm{Nd}$ and $\mathrm{Sr}$ isotope ratios in geological samples as small as $100 \mathrm{pg}$. The $10^{12} \Omega$ resistors were expected to provide a similar improvement in S/Ns when used in MC-ICP-MS detection systems, although any limitations imposed by the slower response time of the $10^{12} \Omega$ resistors would need to be investigated. Normally, the determination of ${ }^{143} \mathrm{Nd} /{ }^{144} \mathrm{Nd}$ and ${ }^{147} \mathrm{Sm} /{ }^{144} \mathrm{Nd}$ ratios by TIMS requires purified $\mathrm{Nd}$ and $\mathrm{Sm}$ fractions to be loaded onto different filaments because of severe isobaric interferences, making the procedure lengthy and laborious. Li et al. ${ }^{309}$ proposed a new method, using a mixed ${ }^{152} \mathrm{Sm}-{ }^{148} \mathrm{Nd}$ spike rather than the traditional ${ }^{149} \mathrm{Sm}-{ }^{150} \mathrm{Nd}$ spike, in which both ratios and concentrations of $\mathrm{Nd}$ and $\mathrm{Sm}$ were measured simultaneously on the same filament loading. Measurements of ten silicate rock CRMs confirmed that neither precision nor accuracy of the results had been compromised.

One of the major problems in the measurement by TIMS of boron isotope ratios in organic-rich natural samples, such as fossil carbonates, is interference from isobaric ions from the organic matter. Characterisation of natural biocarbonates ${ }^{\mathbf{3 1 0}}$ confirmed these isobaric interferences originated from organic compounds with an acylamino group $\left(-\mathrm{CO}_{2}-\mathrm{NH}_{2}\right)$. However, total elimination of organic matter by pretreating the samples is still a considerable challenge. A method ${ }^{311}$ for the determination of $\mathrm{B}$ isotope composition of tourmalines employed $\mathrm{K}_{2} \mathrm{CO}_{3}$ fusion and a three-column ion-exchange procedure to achieve full recovery of $\mathrm{B}$ prior to measurement by positive ionisation TIMS and MC-ICP-MS. Although the $\delta^{11} \mathrm{~B}$ values obtained by the two techniques were generally in good agreement, some discrepancies observed for a couple of samples were thought to be due to interferences from isobaric ions formed from trace organic matter during ion-exchange. Thus, it would appear that MC-ICP-MS may be preferred over TIMS for organic-rich samples.

Experiments $^{312}$ were performed to assess whether an approach to $\mathrm{U}-\mathrm{Pb}$ dating of monazite involving multi-step chemical abrasion plus TIMS could reveal complexities in either age or composition that might be masked by single-step analysis. It was recommended that high temperature annealing should not be used for monazite because the annealing induced recrystallisation that affected the style of dissolution and produced age and composition data that were more variable than those for unannealed samples. Instead, slow partial dissolution of monazite in weak acid proved suitable for obtaining consistent information on complex samples.

An investigation ${ }^{313}$ into the suitability of various commercial silica gels as emission activators for the ionisation of $\mathrm{Pb}$ in TIMS concluded that the emitter produced by Sigma-Aldrich was an excellent alternative to Merck silica gel, which is no longer manufactured.

4.4.3.2 Secondary ion mass spectrometry. An authoritative overview of the current state of SIMS technology formed part of a more wide-ranging review ${ }^{256}$ of recent developments in geochemical analysis. Applications of SIMS to geochronology, palaeoclimate studies and quantification of volatile elements were highlighted, together with the increased popularity of NanoSIMS due to its capability for high-spatial-resolution imaging. The main applications of NanoSIMS within the Earth sciences continue to be imaging and isotope ratio determinations on presolar grains. For a detailed account of the technical aspects and application of NanoSIMS in cosmochemistry and biogeochemistry, a critical review (170 references) by Hoppe et $a .^{314}$ is recommended.

The increased capabilities of SIMS have resulted in more research projects using the technique to resolve variations in the growth of biocarbonate structures at the $\mu \mathrm{m}$ scale. Vetter et al. ${ }^{315}$ conducted experiments in which planktonic foraminifera were grown at a constant temperature and transferred every $12 \mathrm{~h}$ between unmodified seawater and seawater with modified $\mathrm{Ba} /$ $\mathrm{Ca}$ and $\delta^{18} \mathrm{O}$ chemistry to produce time-resolved bands of shell calcite with predictable geochemistries. Elemental $(\mathrm{Ba} / \mathrm{Ca})$ data were obtained by LA-ICP-MS and cross-correlated with $\delta^{18} \mathrm{O}$ measurements by SIMS with a $3 \mu \mathrm{m}$ spot and average precision of $0.6 \%$ (2 SD). The finding that $\mathrm{Ba}$ and $\delta^{18} \mathrm{O}$ tracers were incorporated into the shell calcite synchronously demonstrated the power of SIMS, in combination with high resolution LA-ICPMS, to measure chemical variations in daily growth increments in the fossil record. NanoSIMS ${ }^{316}$ was used to study the skeletal structures of a coral exposed to ${ }^{86} \mathrm{Sr}$-enriched seawater at 
intervals of $48 \mathrm{~h}$ interspersed with 5 days of growth under normal seawater conditions. Images of the ${ }^{86} \mathrm{Sr} /{ }^{44} \mathrm{Ca}$ ratio in the skeleton formed during the experiment allowed the growth rate of components of the coral skeleton to be calculated.

New approaches to $U-P b$ geochronology by SIMS have taken advantage of the high spatial resolution that can be achieved. Schmitt and $\mathrm{Zack}^{\mathbf{3 1 7}}$ used an $\mathrm{O}_{2}{ }^{+}$primary ion beam coupled with surficial $\mathrm{O}_{2}$ gas deposition (so-called $\mathrm{O}_{2}$ flooding) for $\mathrm{U}-\mathrm{Pb}$ dating of rutile. Natural and synthetic rutiles were conductive under $\mathrm{O}_{2}{ }^{+}$bombardment so higher sputter rates were possible than by conventional SIMS with a $\mathrm{O}_{2}{ }^{-}$beam, without incurring detrimental effects due to sample charging. Both $\mathrm{Pb}-\mathrm{Pb}$ and $\mathrm{U}-$ $\mathrm{Pb}$ ages generated were accurate to within $<1 \%$ for Early Paleozoic to Archean rutile, without evidence of any significant bias due to crystal orientation. The coupling of two new approaches enabled Ault et al. ${ }^{318}$ to analyse zircons too small to be dated by standard SIMS and TIMS methods. Automated mineralogy was used instead of mineral separation to identify rapidly sub-20 $\mu \mathrm{m}$ zircons in a single thin Section. A modified SIMS protocol then preferentially collected secondary ions emitted from a domain a few $\mu \mathrm{m}$ in size within the $c a .20 \mu \mathrm{m}$ diameter analysis pit. In this manner, in situ $\mathrm{U}-\mathrm{Pb}$ data were acquired for zircons grains with dimensions of $<10 \mu \mathrm{m}$.

Other novel geological applications of SIMS included high precision in situ measurements of $\mathrm{Mg}$ isotopes in meteoritic materials ${ }^{319}$ using $30-40 \mu \mathrm{m}$ analytical spots. The data reduction procedure was critical for achieving the level of precision required, typically $\pm 5 \mathrm{ppm}$. By modelling factors such as Faraday cup background drift and instrumental fractionation induced by the sample matrix, the fully corrected $\mathrm{Mg}$ isotopic data attained the levels of precision and accuracy needed to establish the chronology of events in the early solar system based on the decay of ${ }^{26} \mathrm{Al}$ to ${ }^{26} \mathrm{Mg}$. Following an evaluation of methods for correcting the significant instrumental mass fractionation observed during in situ determination of oxygen isotopes in magmatic glasses, ${ }^{320}$ a simple correction scheme based on the $\mathrm{SiO}_{2}$ content of appropriate standards spanning a compositional range from basalt to rhyolite was recommended. Using this method, the $\delta^{18} \mathrm{O}$ values of a range of glass RMs were reproduced to within $\pm 0.4 \%$ of their nominal value. An unusual approach $^{321}$ to the quantification of abundant volatile elements $(\mathrm{Cl}, \mathrm{F}$ and $\mathrm{H})$ in apatites by SIMS was based on the stoichiometric constraint that the sum of the volatile elements must closely approach $100 \%$ occupancy of their collective structure sites. The main advantage of this procedure is that it does not require any independently known homogeneous RMs. Whitehouse $^{322}$ demonstrated the potential of SIMS for high spatial resolution measurements of all four $\mathrm{S}$ isotopes in sulfides. In addition, two sulfides from SW Greenland and Minas Gerais, Brazil were shown to be sufficiently homogenous to be used as secondary RMs to monitor the accuracy of $\Delta^{33} \mathrm{~S}$ measurements by SIMS.

The use of TOF-SIMS for quantitative analysis of geological materials is still in its infancy. Marques et al. ${ }^{323}$ studied a single melt inclusion in a single phenocryst to evaluate the advantages and limitations of this technique for elemental and isotopic determinations. Two basalt glass RMs (USGS BCR-1 and GSJ JB-
2) with similar matrix composition and physical properties to the melt inclusion were used for quantification. The composition of an ore-metal sublimate on the wall of an exposed vapour bubble inside the melt inclusion could be determined as well as the composition of its host clinopyroxene. Results for the melt inclusion and the clinopyroxene were close to those obtained previously by EPMA and LA-ICP-MS. Values for B, Cl, Li, O and S isotope ratios in the two glass RMs differed significantly from literature values so the authors concluded that more research was necessary to establish whether these discrepancies related to sample heterogeneity at the nanoscale or to analytical factors such as matrix effects in SIMS analysis.

4.4.3.3 Accelerator mass spectrometry. A review of advances in $A M S^{256}$ noted that the focus of current geochemical applications has shifted from extraterrestrial materials to tectonics and climate research, and hot topics now include archaeometry and anthropology. The precision and accuracy of cosmogenic ${ }^{3} \mathrm{He}$ measurements by AMS are dependent on the passive He blank from the extraction apparatus. A new high temperature single vacuum furnace ${ }^{324}$ was capable of extracting He from minerals such as apatite, pyroxene and olivine with virtually $100 \%$ recovery. After heating at $1450{ }^{\circ} \mathrm{C}$ for $20 \mathrm{~min}$, the blanks of $3.7 \times$ $10^{-21}$ mole for ${ }^{3} \mathrm{He}$ and $1.1 \times 10^{-15}$ mole for ${ }^{4} \mathrm{He}$ were an order of magnitude better than those of a conventional double vacuum furnace. Large accelerators are normally necessary to separate ${ }^{36} \mathrm{Cl}$ from its stable isobar ${ }^{36} \mathrm{~S}$ but these measurements can now be performed with modern $5 \mathrm{MeV}$ AMS instruments using gas stripping to produce the highest quality beams. A protocol ${ }^{325}$ for the accurate determination of ${ }^{36} \mathrm{Cl}$ included ID for stable $\mathrm{Cl}$ measurement and separation from ${ }^{36} \mathrm{~S}$ on a relatively small automated spectrometer using $30 \mathrm{MeV}$ ions. Improvements in AMS measurement precisions and low $\mathrm{Pt}$ machine backgrounds contributed to the first reported observation that the ${ }^{198} \mathrm{Pt} /{ }^{195} \mathrm{Pt}$ ratio in two presolar nanodiamonds $\mathrm{s}^{326}$ from the Allende meteorite may be enhanced by $6-7 \%$. Although they require verification, these results may shed light on nucleosynthesis processes taking place in the parent star.

Ten laboratories participated in the first international interlaboratory comparison ${ }^{327}$ for the measurement of the longlived radionuclide ${ }^{10} \mathrm{Be}$. The results for three samples $\left({ }^{10} \mathrm{Be} /{ }^{11} \mathrm{Be}\right.$ $=10^{-12}-10^{-14}$ ) were made traceable to NIST SRM 4325 (beryllium chloride solution) to avoid discrepancies from the use of different calibration materials. Multi-variate statistical analysis of the data indicated that participating AMS facilities fell into two distinct groups, with maximum discrepancies of $6-31 \%$ depending on the absolute ${ }^{10} \mathrm{Be} /{ }^{11} \mathrm{Be}$ value. Various issues were discussed openly in the paper because the laboratories had waived their right to anonymity. Unfortunately, NIST SRM 4325 is no longer available, so another material of the same metrological quality is required in the very near future. Instead of following the common practice of adding stable ${ }^{9} \mathrm{Be}$ as a carrier during sample preparation prior to ${ }^{10} \mathrm{Be}$ AMS measurements, researchers at ETH Zurich advocated ${ }^{328}$ a two-step leaching procedure for the measurement of ${ }^{10} \mathrm{Be} /{ }^{11} \mathrm{Be}$ in marine sediments without the addition of ${ }^{9} \mathrm{Be}$ carrier. An elaborate procedure was necessary to separate authigenic Be from detrital Be while keeping contamination from ${ }^{9} \mathrm{Be}$ to a minimum. In a 
procedure $^{329}$ for measuring ${ }^{10} \mathrm{Be}$ in small amounts of sediments, 1-10 mg of sediment were spiked with several hundred $\mu \mathrm{g}$ of ${ }^{9} \mathrm{Be}$ carrier. The ${ }^{10}$ Be values obtained by this method agreed within $3-5 \%$ with values previously determined on much larger $200 \mathrm{mg}$ samples at the same AMS facility at the University of Tokyo. Efficient extraction and purification of quartz from rocks, soils and sediments are essential for in situ AMS measurement of cosmogenic nuclides such as ${ }^{26} \mathrm{Al}$ and ${ }^{10} \mathrm{Be}$ in the determination of surface exposure ages, erosion rates and burial ages. The use of hot phosphoric acid, ${ }^{330}$ which preferentially dissolved silicates but not quartz, was considered an alternative to the usual procedure involving repetitive etching in dilute HF. This method was particularly effective at recovering quartz from samples with very low quartz abundance or with cryptocrystalline silica, e.g., greywacke and chert.

4.4.4 X-ray spectrometry. For up-to-date information on instrumental developments and applications of X-ray techniques, the Update on $\mathrm{XRF}^{4}$ should be consulted. A review ${ }^{331}$ (203 references) of synchrotron photon-based techniques focussed on the main methodological developments and trends in their use for the characterisation of ancient and historical materials.

Polarised-beam EDXRF instruments are routinely used for the determination of major and trace elements in a wide range of materials including soils and sediments ${ }^{\mathbf{3 2}}$ and chert artefacts. ${ }^{333}$ Redus and Huber ${ }^{334}$ suggested that a suitable figure of merit for comparison of EDXRF instruments would be the time required to achieve a given statistical uncertainty and they demonstrated how this could be used to select the optimum detector and spectrometer configuration for a specific application. A comparison ${ }^{335}$ of EDXRF detectors concluded that CdTe detectors generally gave better precision and accuracy for $\mathrm{K}$ lines greater than 20 or $25 \mathrm{keV}$ but that high resolution silicon drift detectors were superior at lower energies. For applications requiring accurate measurement of high $Z$ elements in complex matrices, instruments with a combined or dual detector system provided both high resolution and high efficiency.

The popularity of XRF core scanning for obtaining elemental data from sediment cores has increased, particularly for applications such as paleoclimate studies in which relative rather than absolute element concentrations are required. The capabilities of a new core scanner, ${ }^{336}$ with a resolution of $0.8 \mathrm{~mm}$, were compared with ICP-AES and ICP-MS analysis after acid digestion of discrete samples collected at $1 \mathrm{~mm}$ intervals on a $5 \mathrm{~m}$ marine sediment core. Scanning was suitable for obtaining an overview on the chemical patterns along the core and so identifying the most appropriate sampling locations to take discrete samples for ICP analysis to address specific paleoclimatic questions. Errors calculated by the core scanner software were underestimated, especially at high count rate, so it was recommended that the XRF data should always be compared with quantitative data from discrete samples for calibration purposes. Hennekam and de Lange ${ }^{337}$ noted the measurement variability caused by different thicknesses of the water film underneath the plastic foil during XRF core scanning and suggested ways of correcting for this.

Recent applications of PXRF devices, in use for over a decade, included mudrock chemostratigraphy in drill cores, ${ }^{338}$

characterisation of stoneware ceramics ${ }^{339}$ and the provenacing of glass beads. ${ }^{340}$ The user-friendly nature of the technique means that handheld and portable bench-top instruments are regularly employed in activities such as mineral prospecting, ore-grade evaluation and contaminated land surveys by operators with very limited knowledge of the underlying spectrometry. A cautionary tale in relation to the use of PXRF devices in mineral exploration ${ }^{341}$ was highlighted in a study commissioned by the Canadian Mining Industry Research Organisation (CAMIRO), in which the performance of three handheld and two benchtop models were evaluated. No reliance could be placed on preset factory calibrations so recalibration of portable instruments with well-charactersied RMs was recommended. The CAMIRO Phase I report, which is available at http:// www.appliedgeochemists.org, gives a detailed picture of the performance of this type of instrumentation and should be essential reading for anyone interested in using PXRF instrumentation.

\section{Glossary of terms}

$2 \mathrm{D}$

A4F

AAS

AEC

AES

AFS

ALF

ANN

AMS

APDC

ASU

aTOF-MS

BAM

BCR

CCD

CDN

CI

CNT

COD

CPC

CPE

CRM

CRS

CS

CVG

CZE

DDTC

DEEE

DGT

DLLME

DPM

DRC

EC

ED
Two-dimensional

Asymmetrical flow field flow fractionation

Atomic absorption spectrometry

Anion exchange chromatography

Atomic emission spectrometry

Atomic fluorescence spectrometry

Artificial lysosomal fluid

Artifical neural network

Accelerator mass spectrometry

Ammonium pyrrolidine dithiocarbamate

Atomic spectrometry update

Aerosol time of flight mass spectrometry

Federal Institute for Materials Research and Testing

(Germany)

Community Bureau of Reference (of the European

Community) now IRMM

Charge coupled detector

CDN Resource Laboratories Ltd (Canada)

Confidence interval

Carbon nanotube

Chemical oxygen demand

Condensation paricle counter

Cloud point extraction

Certified reference material

Cavity ringdown spectroscopy

Continuum source

Chemical vapour generation

Capillary zone electrophoresis

Diethyldithiocarbamate

Diesel engine exhaust emission

Diffusion gradient in thin films

Dispersive liquid liquid microextraction

Diesel particulate matter

Dynamic reaction cell

Elemental carbon

Energy dispersive 


\begin{tabular}{|c|c|c|c|}
\hline EDS & Energy dispersive spectrometry & LREE & Light rare earth element \\
\hline EDTA & Ethyldiaminetetraacetic acid & MAAP & Multiangle absorption photometer \\
\hline EDXRF & Energy dispersive X-ray fluorescence & MC & Multicollector \\
\hline EN & European standard & MIBK & Methyl isobutyl ketone \\
\hline EPA & Environmental Protection Agency (USA) & MOUDI & Micro orifice uniform deposition impactor \\
\hline EPMA & Electron probe microanalyser & MRI & Magnetic resonance imaging \\
\hline ERM & European Reference Material & MS & Mass spectrometry \\
\hline ES & Electrospray & MWCNT & Multiwalled carbon nanotube \\
\hline ESI-MS & Electrospray ionisation mass spectrometry & NACIS & National Analysis Centre for Iron and Steel (China) \\
\hline ETAAS & Electrothermal atomic absorption spectrometry & NCS & China National Analysis Centre for Iron and Steel \\
\hline ETV & Electrothermal vaporisation & NDIRS & Non-dispersive infrared spectroscopy \\
\hline \multirow[t]{2}{*}{ EUSAAR } & European Supersites for Atmospheric Aerosol & Nd:YAG & Neodymium doped:yttrium aluminum garnet \\
\hline & Research & $\mathrm{NIOSH}$ & National Institute of Occupational Safety and \\
\hline FAAS & Flame atomic absorption spectrometry & & Health (USA) \\
\hline FFF & Field flow fractionation & NIR & Near infrared \\
\hline FI & Flow injection & NIST & National Institute of Standards and Technology \\
\hline fs & Femto second & & (USA) \\
\hline FTIR & Fourier transform infrared & NMI & National Measurement Institute \\
\hline GC & Gas chromatography & NMIJ & National Metrology Institute of Japan \\
\hline GSJ & Geological Survey of Japan & NP & Nanoparticle \\
\hline HDC & Hydrodynamic chromatography & NRCC & National Research Council of Canada \\
\hline HEN & High efficiency nebuliser & NRCCRM & National Research Centre for Certified Reference \\
\hline HG & Hydride generation & & Materials (China) \\
\hline HILIC & Hydrophilic liquid interaction chromatography & ns & Nano-second \\
\hline HPLC & High performance liquid chromatography & NTIMS & Negative thermal ionisation mass spectrometry \\
\hline HPS & High Purity Standards (USA) & NWRI & National Water Research Institute (Canada) \\
\hline HR & High resolution & OC & Organic carbon \\
\hline IAEA & International Atomic Energy Agency & OES & Optical emission spectrometry \\
\hline IC & Ion chromatography & OREAS & Ore Research and Exploration Pty Ltd Assay \\
\hline ICP & Inductively coupled plasma & & Standards (Australia) \\
\hline \multirow[t]{2}{*}{ ICP-AES } & Inductively coupled plasma atomic emission & PFA & Perfluoroalkyl \\
\hline & spectrometry & PGE & Platinum group element \\
\hline ICP-MS & Inductively coupled plasma mass spectrometry & PIXE & Particle induced X-ray emission \\
\hline ICP-SF-MS & $\begin{array}{l}\text { Inductively coupled plasma sector field mass } \\
\text { spectrometry }\end{array}$ & $\mathrm{PM}_{0.07-0.34}$ & $\begin{array}{l}\text { Particulate matter (with an aerodynamic diameter } \\
\text { of between } 0.07 \text { and } 0.34 \mu \mathrm{m} \text { ) }\end{array}$ \\
\hline ID & Isotope dilution & $\mathrm{PM}_{0.34-1.15}$ & Particulate matter (with an aerodynamic diameter \\
\hline \multirow[t]{2}{*}{ IERM } & Institute for Environmental Reference Materials & & of between 0.34 and $1.15 \mu \mathrm{m})$ \\
\hline & (of Ministry of Environmental Protection, China) & $\mathrm{PM}_{1.15-2.5}$ & Particulate matter (with an aerodynamic diameter \\
\hline \multirow[t]{2}{*}{ IGGE } & Institute of Geophysical and Geochemical & & of between 1.15 and $2.5 \mu \mathrm{m})$ \\
\hline & Exploration (China) & $\mathrm{PM}_{2.5}$ & Particulate matter (with an aerodynamic diameter \\
\hline \multirow[t]{2}{*}{ IMPROVE } & Interagency Monitoring for Protected Visual & & of up to $2.5 \mu \mathrm{m})$ \\
\hline & Environments & ppbv & Part per billion volume \\
\hline INAA & Instrumental neutron activiation analysis & ppm & Part per million \\
\hline \multirow[t]{2}{*}{ INCT } & Institute of Nuclear Chemistry and Technology & PTFE & Poly(tetrafluoroethylene) \\
\hline & (Poland) & PXRF & Portable X-ray fluorescence \\
\hline IR & Infrared & QA & Quality assurance \\
\hline \multirow[t]{2}{*}{ IRMM } & Institute for Reference Materials and & QC & Quality control \\
\hline & Measurements & REE & Rare earth element \\
\hline IRMS & Isotope ratio mass spectrometry & $\mathrm{rf}$ & Radio frequency \\
\hline ISO & International Organisation for Standardization & $\mathrm{RM}$ & Reference material \\
\hline ISS & Instituto Superiore di Sanita (Italy) & $\mathrm{RP}$ & Reversed phase \\
\hline ITU & Institute for Transuranium Elements & RSD & Relative standard deviation \\
\hline LA & Laser ablation & RTC & Resource Techology Corporation (USA) \\
\hline $\mathrm{LC}$ & Liquid chromatography & SBET & Simplified bioaccessibility extraction test \\
\hline LGC & Laboratory of the Government Chemist (UK) & SD & Standard deviation \\
\hline LIBS & Laser induced breakdown spectroscopy & SDME & Single drop microextraction \\
\hline LLE & Liquid liquid extraction & SEC & Size exclusion chromatography \\
\hline LLME & Liquid liquid microextraction & SEM & Scanning electron microscopy \\
\hline LOD & Limit of detection & $\mathrm{SF}$ & Sector field \\
\hline
\end{tabular}


SFE Supercritical fluid extraction

SFODME Solidification of floating organic drop microextraction

SIMS Secondary ion mass spectrometry

SMPS Scanning mobility particle sizer

$S / N \quad$ Signal-to-noise ratio

SPE Solid phase extraction

SPME Solid phase microextraction

SR Synchrotron radiation

SRM Standard reference material

TC Total carbon

TDS Total dissolved solid

TEM Transmission electron microscopy

TEOM Tapered element oscillating microbalance

TGA Thermal gravimetric analysis

TIMS Thermal ionisation mass spectrometry

TOF Time of flight

TOT Thermal optical transmission

TSP Total suspended particles

TXRF Total reflection X-ray fluorescence

USGS United States Geological Survey

USN Ultrasonic nebuliser

UV Ultra violet

VALLME Vortex-assisted liquid liquid microextraction

VG Vapour generation

VOC Volatile organic compound

WDXRF Wavelength dispersive X-ray fluorescence

WHO World Health Organisation

XANES X-ray absorption near edge structure

XAS X-ray absorption spectrometry

XRD X-ray diffraction

XRF X-ray fluorescence

$z \quad$ Atomic number

$\sigma \quad$ Population standard deviation

\section{References}

1 O. T. Butler, W. R. L. Cairns, J. M. Cook and C. M. Davidson, J. Anal. At. Spectrom., 2013, 28(2), 177-216.

2 A. Taylor, M. P. Day, S. Hill, J. Marshall, M. Patriarca and M. White, J. Anal. At. Spectrom., 2013, 28(4), 425-459.

3 E. H. Evans, M. Horstwood, J. Pisonero and C. M. M. Smith, J. Anal. At. Spectrom., 2013, 28(6), 779-800.

4 M. West, A. T. Ellis, P. J. Potts, C. Streli, C. Vanhoof, D. Wegrzynek and P. Wobrauschek, J. Anal. At. Spectrom., 2013, 28(10), 1544-1590.

5 S. Carter, A. S. Fisher, M. W. Hinds and S. Lancaster, J. Anal. At. Spectrom., 2013, 28(12), 1814-1869.

6 P. Negrel, M. Blessing, R. Millot, E. Petelet-Giraud and C. Innocent, TrAC, Trends Anal. Chem., 2012, 38, 143-153.

7 F. Drewnick, Anal. Bioanal. Chem., 2012, 404(8), 2127-2131.

8 B. R. Bzdek, M. R. Pennington and M. V. Johnston, J. Aerosol Sci., 2012, 52, 109-120.

9 P. Kumar, L. Pirjola, M. Ketzel and R. M. Harrison, Atmos. Environ., 2013, 67, 252-277.

10 I. van der Veen and J. de Boer, Chemosphere, 2012, 88(10), 1119-1153.
11 A. Mukhtar and A. Limbeck, Anal. Chim. Acta, 2013, 774, 11-25.

12 E. R. Lennox, N. M. Kreisberg and L. D. Montoya, Aerosol Sci. Technol., 2013, 47(6), 626-633.

13 J. S. Kang, K. S. Lee, K. H. Lee, H. J. Sung and S. S. Kim, Aerosol Sci. Technol., 2012, 46(9), 966-972.

14 B. R'Mili, O. L. C. Le Bihan, C. Dutouquet, O. AguerreCharriol and E. Frejafon, Aerosol Sci. Technol., 2013, 47(7), 767-775.

15 A. L. Miller, P. L. Drake, N. C. Murphy, J. D. Noll and J. C. Volkwein, J. Environ. Monit., 2012, 14(1), 48-55.

16 A. L. Miller, P. L. Drake, N. C. Murphy, E. G. Cauda, R. F. LeBouf and G. Markevicius, Aerosol Sci. Technol., 2013, 47(7), 724-733.

17 C. N. Liu, A. Awasthi, Y. H. Hung and C. J. Tsai, Atmos. Environ., 2013, 69, 325-333.

18 R. Cucciniello, A. Proto, D. Alfano and O. Motta, Atmos. Environ., 2012, 60, 82-87.

19 M. Arashiro and D. Leith, J. Aerosol Sci., 2013, 57, 181-184.

20 S. A. Einstein, C. H. Yu, G. Mainelis, L. C. Chen, C. P. Weisel and P. J. Lioy, J. Environ. Monit., 2012, 14(9), 2411-2420.

21 C. Isaxon, K. Dierschke, J. Pagels, J. Londahl, A. Gudmundsson, I. Hagerman, M. Berglund, A. Wierzbicka, E. Assarsson, U. B. Andersson, B. A. G. Jonsson, M. E. Messing, J. Nielsen and M. Bohgard, Aerosol Sci. Technol., 2013, 47(1), 52-59.

22 C. Isaxon, K. Dierschke, J. H. Pagels, A. Wierzbicka, A. Gudmundsson, J. Londahl, I. Hagerman, M. Berglund, E. Assarsson, U. B. Andersson, B. A. G. Jonsson, J. K. Nojgaard, A. Eriksson, J. Nielsen and M. Bohgard, J. Aerosol Sci., 2013, 60, 55-66.

23 E. Vo and Z. Q. Zhuang, J. Aerosol Sci., 2013, 61, 50-59.

24 B. O. Meuller, M. E. Messing, D. L. J. Engberg, A. M. Jansson, L. I. M. Johansson, S. M. Norlen, N. Tureson and K. Deppert, Aerosol Sci. Technol., 2012, 46(11), 1256-1270.

25 L. Stabile, A. Ruggiero, G. Iannitti and G. Buonanno, J. Aerosol Sci., 2013, 55, 66-77.

26 A. Mamakos, I. Khalek, R. Giannelli and M. Spears, Aerosol Sci. Technol., 2013, 47(8), 927-936.

27 J. Aldabe, C. Santamaria, D. Elustondo, E. Lasheras and J. M. Santamaria, Anal. Methods, 2013, 5(2), 554-559.

28 J. J. Niu, P. E. Rasmussen and M. Chenier, Int. J. Environ. Anal. Chem., 2013, 93(6), 661-678.

29 X. Hu, Y. Zhang, Z. H. Ding, T. J. Wang, H. Z. Lian, Y. Y. Sun and J. C. Wu, Atmos. Environ., 2012, 57, 146152.

30 C. Puls, A. Limbeck and S. Hann, Atmos. Environ., 2012, 55, 213-219.

31 F. Zereini, C. L. S. Wiseman and W. Puttmann, Environ. Sci. Technol., 2012, 46(18), 10326-10333.

32 R. G. O. Araujo, F. Vignola, I. N. B. Castilho, B. Welz, M. G. R. Vale, P. Smichowski, S. L. C. Ferreira and H. Becker-Ross, Microchem. J., 2013, 109, 36-40.

33 S. Atilgan, S. Akman, A. Baysal, Y. Bakircioglu, T. Szigeti, M. Ovari and G. Zaray, Spectrochim. Acta, Part B, 2012, 70, 33-38. 
34 I. Gaona, P. Lucena, J. Moros, F. J. Fortes, S. Guirado, J. Serrano and J. J. Laserna, J. Anal. At. Spectrom., 2013, 28(6), 810-820.

35 C. B. Stipe, A. L. Miller, J. Brown, E. Guevara and E. Cauda, Appl. Spectrosc., 2012, 66(11), 1286-1293.

36 J. H. Kwak, G. Kim, Y. J. Kim and K. Park, Aerosol Sci. Technol., 2012, 46(10), 1079-1089.

37 C. Dutouquet, G. Wattieaux, L. Meyer, E. Frejafon and L. Boufendi, Spectrochim. Acta, Part B, 2013, 83-84, 14-20.

38 T. Tjarnhage, P. A. Gradmark, A. Larsson, A. Mohammed, L. Landstrom, E. Sagerfors, P. Jonsson, F. Kullander and M. Andersson, Opt. Commun., 2013, 296, 106-108.

39 P. Sahay, S. T. Scherrer and C. J. Wang, Rev. Sci. Instrum., 2012, 83(9), 14.

40 N. Spada, A. Bozlaker and S. Chellam, Anal. Chim. Acta, 2012, 735, 1-8.

41 T. Pulles, H. D. van der Gon, W. Appelman and M. Verheul, Atmos. Environ., 2012, 61, 641-651.

42 S. A. Pergantis, T. L. Jones-Lepp and E. M. Heithmar, Anal. Chem., 2012, 84(15), 6454-6462.

43 S. Elzey, D. H. Tsai, L. L. Yu, M. R. Winchester, M. E. Kelley and V. A. Hackley, Anal. Bioanal. Chem., 2013, 405(7), 22792288.

44 Y. Suzuki, H. Sato, K. Hiyoshi and N. Furuta, Spectrochim. Acta, Part B, 2012, 76, 133-139.

45 M. Sakata, T. Ishikawa and S. Mitsunobu, Atmos. Environ., 2013, 67, 296-303.

46 F. Gueguen, P. Stille, V. Dietze and R. Giere, Atmos. Environ., 2012, 62, 631-645.

47 S. Kappel, S. F. Boulyga and T. Prohaska, J. Environ. Radioact., 2012, 113, 8-15.

48 M. Kraiem, S. Richter, N. Erdmann, H. Kuhn, M. Hedberg and Y. Aregbe, Anal. Chim. Acta, 2012, 748, 37-44.

49 H. E. Hocking, L. W. Burggraf, X. F. F. Duan, J. A. Gardella, B. P. Yatzor and W. A. Schuler, Surf. Interface Anal., 2013, 45(1), 545-548.

50 E. Barkan and B. Luz, Rapid Commun. Mass Spectrom., 2012, 26(23), 2733-2738.

51 Z. C. Wu, Y. F. Zhou, N. Xu, L. Tao and H. W. Chen, J. Anal. At. Spectrom., 2013, 28(5), 697-701.

52 E. S. Cross, A. Sappok, E. C. Fortner, J. F. Hunter, J. T. Jayne, W. A. Brooks, T. B. Onasch, V. W. Wong, A. Trimborn, D. R. Worsnop and J. H. Kroll, J. Eng. Gas Turbines Power, 2012, 134(7), 072801.

53 D. Salcedo, A. Laskin, V. Shutthanandan and J. L. Jimenez, Aerosol Sci. Technol., 2012, 46(11), 1187-1200.

54 A. Wastl, F. Stadlbauer, J. Prost, C. Horntrich, P. Kregsamer, P. Wobrauschek and C. Streli, Spectrochim. Acta, Part B, 2013, 82, 71-75.

55 S. Yatkin and M. Gerboles, Atmos. Environ., 2013, 73, 159168.

56 P. Nowinski, V. F. Hodge and S. Gerstenberger, Environ. Chem., 2012, 9(4), 379-388.

57 C. Cantaluppi, M. Natali, F. Ceccotto and A. Fasson, X-Ray Spectrom., 2013, 42(4), 213-219.

58 D. Varrica, F. Bardelli, G. Dongarra and E. Tamburo, Atmos. Environ., 2013, 64, 18-24.
59 J. R. Zeng, G. L. Zhang, L. M. Bao, S. L. Long, M. G. Tan, Y. Li, C. Y. Ma and Y. D. Zhao, J. Environ. Sci., 2013, 25(3), 605-612.

60 L. H. Wang, X. M. Lu, X. J. Wei, Z. Jiang, S. Q. Gu, Q. Gao and Y. Y. Huang, J. Anal. At. Spectrom., 2012, 27(10), 16671673.

61 Z. Kertesz, E. Furu and M. Kavcic, Spectrochim. Acta, Part B, 2013, 79-80, 58-62.

62 J. Noll, S. Janisko and S. E. Mischler, Anal. Methods, 2013, 5(12), 2954-2963.

63 D. Massabo, V. Bernardoni, M. C. Bove, A. Brunengo, E. Cuccia, A. Piazzalunga, P. Prati, G. Valli and R. Vecchi, J. Aerosol Sci., 2013, 60, 34-46.

64 Y. Cheng, K. B. He, F. K. Duan, Z. Y. Du, M. Zheng and Y. L. Ma, Atmos. Environ., 2012, 59, 551-558.

65 V. Bernardoni, G. Calzolai, M. Chiari, M. Fedi, F. Lucarelli, S. Nava, A. Piazzalunga, F. Riccobono, F. Taccetti, G. Valli and R. Vecchi, J. Aerosol Sci., 2013, 56, 88-99.

66 H. Bladt, J. Schmid, E. D. Kireeva, O. B. Popovicheva, N. M. Perseantseva, M. A. Timofeev, K. Heister, J. Uihlein, N. P. Ivleva and R. Niessner, Aerosol Sci. Technol., 2012, 46(12), 1337-1348.

67 S. Verpaele and J. Jouret, Ann. Occup. Hyg., 2013, 57(1), 54-62.

68 M. Harper and K. Ashley, J. Occup. Environ. Hyg., 2013, 10(6), 297-306.

69 M. Chai, M. E. Birch and G. Deye, Ann. Occup. Hyg., 2012, 56(8), 959-967.

70 R. F. LeBouf, A. L. Miller, C. Stipe, J. Brown, N. Murphy and A. B. Stefaniak, Environ. Sci.Processes Impacts, 2013, 15(6), 1191-1198.

71 E. P. Gray, T. A. Bruton, C. P. Higgins, R. U. Halden, P. Westerhoff and J. F. Ranville, J. Anal. At. Spectrom., 2012, 27(9), 1532-1539.

72 S. R. Guevara and M. Horvat, Anal. Methods, 2013, 5(8), 1996-2006.

73 D. Das, U. Gupta and A. K. Das, TrAC, Trends Anal. Chem., 2012, 38, 163-171.

74 C. H. Latorre, J. A. Mendez, J. B. Garcia, S. G. Martin and R. M. P. Crecente, Anal. Chim. Acta, 2012, 749, 16-35.

75 R. Sitko, B. Zawisza and E. Malicka, TrAC, Trends Anal. Chem., 2012, 37, 22-31.

76 V. Andruch, I. S. Balogh, L. Kocurova and J. Sandrejova, J. Anal. At. Spectrom., 2013, 28(1), 19-32.

77 M. Shoaib and H. M. Al-Swaidan, J. Chem. Soc. Pak., 2012, 34(6), 1585-1593.

78 E. Sugar, E. Tatar, G. Zaray and V. G. Mihucz, Microchem. J., 2013, 107, 131-135.

79 S. Doker, L. Uzun and A. Denizli, Talanta, 2013, 103, 123129.

80 K. Pyrzynska, Int. J. Environ. Anal. Chem., 2012, 92(11), 1298-1311.

81 C. J. Zeng, Y. Lin, N. Zhou, J. T. Zheng and W. Zhang, J. Hazard.Mater., 2012, 237, 365-370.

82 R. Karosi, K. Boruzs, A. Beni, J. Posta, J. Balogh and V. Andruch, Anal. Methods, 2012, 4(8), 2361-2364. 
83 J. A. Baig, A. Hol, A. Akdogan, A. A. Kartal, U. Divrikli, T. G. Kazi and L. Elci, J. Anal. At. Spectrom., 2012, 27(9), 1509-1517.

84 Z. W. Qin, D. McNee, H. Gleisner, A. Raab, K. Kyeremeh, M. Jaspars, E. Krupp, H. Deng and J. Feldmann, Anal. Chem., 2012, 84(14), 6213-6219.

85 X. Han, L. H. Cao, H. Y. Cheng, J. H. Liu and Z. G. Xu, Anal. Methods, 2012, 4(10), 3471-3477.

86 A. Spolaor, P. Vallelonga, J. Gabrieli, N. Kehrwald, C. Turetta, G. Cozzi, L. Poto, J. M. C. Plane, C. Boutron and C. Barbante, Anal. Bioanal. Chem., 2013, 405(2-3), 647-654.

87 L. Telgmann, M. Sperling and U. Karst, Anal. Chim. Acta, 2013, 764, 1-16.

88 L. Telgmann, C. A. Wehe, M. Birka, J. Kunnemeyer, S. Nowak, M. Sperling and U. Karst, Environ. Sci. Technol., 2012, 46(21), 11929-11936.

89 U. Lindner, J. Lingott, S. Richter, N. Jakubowski and U. Panne, Anal. Bioanal. Chem., 2013, 405(6), 1865-1873.

90 B. Stolpe, L. D. Guo, A. M. Shiller and G. R. Aiken, Geochim. Cosmochim. Acta, 2013, 105, 221-239.

91 B. Stolpe, L. D. Guo and A. M. Shiller, Geochim. Cosmochim. Acta, 2013, 106, 446-462.

92 N. Garcia-Otero, P. Bermejo-Barrera and A. Moreda-Pineiro, Anal. Chim. Acta, 2013, 760, 83-92.

93 E. Kilinc, S. Bakirdere, F. Aydin and O. Y. Ataman, Spectrochim. Acta, Part B, 2012, 73, 84-88.

94 S. Titretir, A. I. Sik, Y. Arslan and O. Y. Ataman, Spectrochim. Acta, Part B, 2012, 77, 63-68.

95 H. Matusiewicz and M. Krawczyk, Spectrosc. Lett., 2012, 45(7), 487-499.

96 S. Musil, J. Kratzer, M. Vobecky and T. Matousek, J. Anal. At. Spectrom., 2012, 27(9), 1382-1390.

97 O. Acar, O. M. Kalfa, O. Yalcinkaya and A. R. Turker, Anal. Methods, 2013, 5(3), 748-754.

98 T. Limburg and J. W. Einax, Microchem. J., 2013, 107, 31-36.

99 G. I. Bebeshko and Y. A. Karpov, Inorg. Mater., 2012, 48(15), 1341-1348.

100 C. A. Almeida, P. Gonzalez, M. Mallea, L. D. Martinez and R. A. Gil, Talanta, 2012, 97, 273-278.

101 T. Frentiu, A. I. Mihaltan, E. Darvasi, M. Ponta, C. Roman and M. Frentiu, J. Anal. At. Spectrom., 2012, 27(10), 17531760.

102 D. Profrock and A. Prange, Appl. Spectrosc., 2012, 66(8), 843868.

103 S. Caroli, M. Forte, C. Nuccetelli, R. Rusconi and S. Risica, Microchem. J., 2013, 107, 95-100.

104 Z. Long, C. Chen, X. D. Hou and C. B. Zheng, Appl. Spectrosc. Rev., 2012, 47(7), 495-517.

105 J. P. Goulle, E. Saussereau, L. Mahieu, D. Cellier, J. Spiroux and M. Guerbet, Bull. Environ. Contam. Toxicol., 2012, 89(6), 1220-1224.

106 T. D. Saint'Pierre, R. C. C. Rocha and C. B. Duyck, Microchem. J., 2013, 109, 41-45.

107 T. Pfeifer, R. Janzen, T. Steingrobe, M. Sperling, B. Franze, C. Engelhard and W. Buscher, Spectrochim. Acta, Part B, 2012, 76, 48-55.
108 A. C. Fornieles, A. G. de Torres, E. I. V. Alonso and J. M. C. Pavon, J. Anal. At. Spectrom., 2013, 28(3), 364-372.

109 V. Yilmaz, L. Rose, Z. Arslan and M. D. Little, J. Anal. At. Spectrom., 2012, 27(11), 1895-1902.

110 V. Yilmaz, Z. Arslan and L. Rose, Anal. Chim. Acta, 2013, 761, 18-26.

111 S. Y. Ng, A. Zou, L. P. Sim, Y. Ding, K. L. Yuen, R. Y. C. Shin and T. K. Lee, Int. J. Mass Spectrom., 2012, 321, 19-24.

112 J. Zheng and M. Yamada, Appl. Radiat. Isot., 2012, 70(9), 1944-1948.

113 K. F. Huang, J. Blusztajn, D. W. Oppo, W. B. Curry and B. Peucker-Ehrenbrink, J. Anal. At. Spectrom., 2012, 27(9), 1560-1567.

114 A. Das, C. H. Chung, C. F. You and M. L. Shen, J. Anal. At. Spectrom., 2012, 27(12), 2088-2093.

115 G. C. Justen, F. R. Espinoza-Quinones, A. N. Modenes and R. Bergamasco, Water Sci. Technol., 2012, 66(5), 1029-1035.

116 E. de Almeida, V. F. do Nascimento and A. A. Menegario, Spectrochim. Acta, Part B, 2012, 71-72, 70-74.

117 K. Kocot, B. Zawisza and R. Sitko, Spectrochim. Acta, Part B, 2012, 73, 79-83.

118 R. Skorek, E. Turek, B. Zawisza, E. Margui, I. Queralt, M. Stempin, P. Kucharski and R. Sitko, J. Anal. At. Spectrom., 2012, 27(10), 1688-1693.

119 N. Aras, S. U. Yesiller, D. A. Ates and S. Yalcin, Spectrochim. Acta, Part B, 2012, 74-75, 87-94.

120 S. U. Yesiller and S. Yalcin, Anal. Chim. Acta, 2013, 770, 717.

121 H. G. Qian and W. D. Zhou, Spectrosc. Spectral Anal., 2012, 32(10), 2820-2823.

122 Y. Lee, S. W. Oh and S. H. Han, Appl. Spectrosc., 2012, 66(12), 1385-1396.

123 H. Sereshti, Y. E. Heravi and S. Samadi, Talanta, 2012, 97, 235-241.

124 H. Fazelirad and M. A. Taher, Talanta, 2013, 103, 375-383.

125 K. Chandrasekaran, D. Karunasagar and J. Arunachalam, J. Anal. At. Spectrom., 2013, 28(1), 142-149.

126 M. Karimi, H. Sereshti, V. Khojeh and S. Samadi, Int. J. Environ. Anal. Chem., 2013, 93(4), 401-415.

127 Y. Z. Yi, S. Y. Wu, S. J. Jiang and A. C. Sahayam, At. Spectrosc., 2013, 34(2), 39-47.

128 L. L. Zhao, S. X. Zhong, K. M. Fang, Z. S. Qian and J. R. Chen, J. Hazard. Mater., 2012, 239, 206-212.

129 N. N. Meeravali and S. J. Kumar, Anal. Methods, 2012, 4(8), 2435-2440.

130 P. H. Liao, S. J. Jiang and A. C. Sahayam, J. Anal. At. Spectrom., 2012, 27(9), 1518-1524.

131 A. N. Anthemidis, C. Mitani, P. Balkatzopoulou and P. D. Tzanavaras, Anal. Chim. Acta, 2012, 733, 34-37.

132 G. Bauer, M. A. Neouze and A. Limbeck, Talanta, 2013, 103, 145-152.

133 K. Kocot, B. Zawisza, E. Margui, I. Queralt, M. Hidalgo and R. Sitko, J. Anal. At. Spectrom., 2013, 28(5), 736-742.

134 C. K. Su, T. W. Lee and Y. C. Sun, J. Anal. At. Spectrom., 2012, 27(9), 1585-1590.

135 A. N. Anthemidis, S. Xidia and G. Giakisikli, Talanta, 2012, 97, 181-186. 
136 B. Zawisza and R. Sitko, Analyst, 2013, 138(8), 2470-2476.

137 H. Takata, T. Aono, J. Zheng, K. Tagami, J. Shirasaka and S. Uchida, Anal. Methods, 2013, 5(10), 2558-2564.

138 P. R. Aranda, L. Colombo, E. Perino, I. E. De Vito and J. Raba, X-Ray Spectrom., 2013, 42(2), 100-104.

139 M. L. A. Castillo, A. G. de Torres, E. V. Alonso, M. T. S. Cordero and J. M. C. Pavon, Talanta, 2012, 99, 853-858.

140 J. Cho, K. W. Chung, M. S. Choi and H. J. Kim, Talanta, 2012, 99, 369-374.

141 K. L. Shi, J. X. Qiao, W. S. Wu, P. Roos and X. L. Hou, Anal. Chem., 2012, 84(15), 6783-6789.

142 J. Falandysz, Food Chem., 2013, 138(1), 242-250.

143 O. V. Evdokimova, N. V. Pechishcheva and K. Y. Shunyaev, J. Anal. Chem., 2012, 67(9), 741-753.

144 I. A. Bhatti, M. A. Hayat and M. Iqbal, J. Chem. Soc. Pak., 2012, 34(4), 1012-1022.

145 P. Thakur and G. P. Mulholland, Appl. Radiat. Isot., 2012, 70(8), 1747-1778.

146 H. A. Gad, S. H. El-Ahmady, M. I. Abou-Shoer and M. M. AlAzizi, Phytochem. Anal., 2013, 24(1), 1-24.

147 M. Welna, A. Szymczycha-Madeja, E. Stelmach and P. Pohl, Crit. Rev. Anal. Chem., 2012, 42(4), 349-365.

148 R. Djingova, V. Mihaylova, V. Lyubomirova and D. L. Tsalev, Appl. Spectrosc. Rev., 2013, 48(5), 384-424.

149 S. Miyashita, K. Inagaki, T. Narukawa, Y. B. Zhu, T. Kuroiwa, A. Hioki and K. Chiba, Anal. Sci., 2012, 28(12), 1171-1177.

150 I. Rezic, Microchem. J., 2013, 107, 63-69.

151 K. Ivanov, P. Zaprjanova, M. Petkova, V. Stefanova, V. Kmetov, D. Georgieva and V. Angelova, Spectrochim. Acta, Part B, 2012, 71-72, 117-122.

152 R. G. Silva, M. N. Nadagouda, J. Webster, S. Govindaswamy, K. D. Hristovski, R. G. Ford, C. L. Patterson and C. A. Impellitteri, Environ. Sci.Processes Impacts, 2013, 15(3), 645-652.

153 E. J. dos Santos, L. M. Baika, A. B. Herrmann, S. Kulik, C. S. Sato, A. B. dos Santos and A. J. Curtius, Braz. Arch. Biol. Technol., 2012, 55(3), 457-464.

154 M. V. B. Krishna, K. Chandrasekaran, G. Venkateswarlu and D. Karunasagar, Anal. Methods, 2012, 4(10), 3290-3299.

155 S. Oztan and R. A. During, Talanta, 2012, 99, 594-602.

156 N. Fabregat-Cabello, P. Rodriguez-Gonzalez, A. Castillo, J. Malherbe, A. F. Roig-Navarro, S. E. Long and J. I. G. Alonso, Environ. Sci. Technol., 2012, 46(22), 1254212549.

157 A. H. Khan, J. Q. Shang and R. Alam, J. Hazard. Mater., 2012, 235, 376-383.

158 J. Blaskova, V. Vojtekova, J. Novakova, D. Mackovych, Y. Bazel, L. Lapcik, Z. Popernikova and A. M. M. Abusenaina, Cent. Eur. J. Chem., 2013, 11(7), 1201-1212.

159 B. Wang, B. Huang, Y. B. Qi, W. Y. Hu and W. X. Sun, Chin. Chem. Lett., 2012, 23(11), 1287-1290.

160 Z. Y. Huang, D. P. Qin, X. C. Zeng, J. Li, Y. L. Cao and C. Cai, Geoderma, 2012, 189, 243-249.

161 L. Kozak and P. Niedzielski, Int. J. Environ. Anal. Chem., 2012, 92(9), 1093-1105.
162 I. Koch, K. J. Reimer, M. I. Bakker, N. T. Basta, M. R. Cave, S. Denys, M. Dodd, B. A. Hale, R. Irwin, Y. W. Lowney, M. M. Moore, V. Paquin, P. E. Rasmussen, T. RepasoSubang, G. L. Stephenson, S. D. Siciliano, J. Wragg and G. J. Zagury, J. Environ. Sci. Health, Part A: Toxic/Hazard. Subst. Environ. Eng., 2013, 48(6), 641-655.

163 M. Dodd, P. E. Rasmussen and M. Chenier, Hum. Ecol. Risk Assess., 2013, 19(4), 1014-1027.

164 R. Q. Thompson and S. J. Christopher, Anal. Methods, 2013, 5(5), 1346-1351.

165 A. T. Reis, J. P. Coelho, S. M. Rodrigues, R. Rocha, C. M. Davidson, A. C. Duarte and E. Pereira, Talanta, 2012, 99, 363-368.

166 C. Waterlot, A. Pelfrene and F. Douay, Can. J. Chem., 2012, 90(10), 874-879.

167 S. X. Li, F. Y. Zheng, Y. C. Li, T. S. Cai and J. Z. Zheng, J. Agric. Food Chem., 2012, 60(47), 11691-11695.

168 I. Urbanova, L. Husakova and J. Sramkova, Environ. Monit. Assess., 2013, 185(4), 3327-3337.

169 M. A. Alvarez and G. Carrillo, Talanta, 2012, 97, 505-512.

170 F. M. Fortunatoa, J. A. G. Neto and G. P. G. Freschi, At. Spectrosc., 2012, 33(4), 138-142.

171 R. Dobrowolski and M. Otto, J. Food Compos. Anal., 2012, 26(1-2), 58-65.

172 T. Frentiu, M. Ponta and R. Hategan, Chem. Cent. J., 2013, 7, 10.

173 A. Virgilio, J. A. Nobrega, J. F. Rego and J. A. G. Neto, Spectrochim. Acta, Part B, 2012, 78, 58-61.

174 J. F. Rego, A. Virgilio, J. A. Nobrega and J. A. G. Neto, Talanta, 2012, 100, 21-26.

175 M. A. Bechlin, J. A. G. Neto and J. A. Nobrega, Microchem. J., 2013, 109, 134-138.

176 C. D. Pereira, M. A. Aguirre, J. A. Nobrega, M. Hidalgo and A. Canals, J. Anal. At. Spectrom., 2012, 27(12), 21322137.

177 F. Ardini, M. Grotti, R. Sanchez and J. L. Todoli, J. Anal. At. Spectrom., 2012, 27(9), 1400-1404.

178 V. C. G. dos Santos, M. T. Grassi, M. S. de Campos, P. G. Peralta-Zamora and G. Abate, Analyst, 2012, 137(19), 4458-4463.

179 D. Olivares, M. Bravo, J. Feldmann, A. Raab, A. Neaman and W. Quiroz, J. AOAC Int., 2012, 95(4), 1176-1182.

180 G. Leng, L. Feng, S. B. Li, P. Yang and D. Z. Dan, Spectroscopy, 2013, 28(2), 54-67.

181 M. Grotti, F. Ardini and J. L. Todoli, Anal. Chim. Acta, 2013, 767, 14-20.

182 E. Bulska, B. Danko, R. S. Dybczynski, A. Krata, K. Kulisa, Z. Samczynski and M. Wojciechowski, Talanta, 2012, 97, 303-311.

183 F. Claverie, J. Malherbe, N. Bier, J. L. Molloy and S. E. Long, Anal. Bioanal. Chem., 2013, 405(7), 2289-2299.

184 F. Claverie, J. Malherbe, N. Bier, J. L. Molloy and S. E. Long, Anal. Chem., 2013, 85(7), 3584-3591.

185 W. Maher, F. Krikowa, M. Ellwood, S. Foster, R. Jagtap and G. Raber, Microchem. J., 2012, 105, 15-31.

186 X. P. Liu, W. F. Zhang, Y. N. Hu and H. F. Cheng, Microchem. J., 2013, 108, 38-45. 
187 A. Miszczak, M. Roslon, G. Zbroja, K. Brama, E. Szalacha, H. Gawronska and K. Pawlak, Anal. Bioanal. Chem., 2013, 405(14), 4667-4678.

188 F. Aureli, L. Ouerdane, K. Bierla, J. Szpunar, N. T. Prakash and F. Cubadda, Metallomics, 2012, 4(9), 968-978.

189 M. Lenz, G. H. Floor, L. H. E. Winkel, G. Roman-Ross and P. F. X. Corvini, Environ. Sci. Technol., 2012, 46(21), 11988-11994.

190 M. De Cesare, L. K. Fifield, C. Sabbarese, S. G. Tims, N. De Cesare, A. D'Onofrio, A. D'Arco, A. M. Esposito, A. Petraglia, V. Roca and F. Terrasi, Nucl. Instrum. Methods Phys. Res., Sect. B, 2013, 294, 152-159.

191 N. Piotrowska, Nucl. Instrum. Methods Phys. Res., Sect. B, 2013, 294, 176-181.

192 M. Y. Luo, X. L. Hou, W. J. Zhou, C. H. He, N. Chen, Q. Liu and L. Y. Zhang, J. Environ. Radioact., 2013, 118, 30-39.

193 P. Steier, E. Hrnecek, A. Priller, F. Quinto, M. Srncik, A. Wallner, G. Wallner and S. Winkler, Nucl. Instrum. Methods Phys. Res., Sect. B, 2013, 294, 160-164.

194 F. J. Fortes, J. Moros, P. Lucena, L. M. Cabalin and J. J. Laserna, Anal. Chem., 2013, 85(2), 640-669.

195 D. Santos, L. C. Nunes, G. G. A. de Carvalho, M. D. Gomes, P. F. de Souza, F. D. Leme, L. G. C. dos Santos and F. J. Krug, Spectrochim. Acta, Part B, 2012, 71-72, 3-13.

196 J. Kaiser, K. Novotny, M. Z. Martin, A. Hrdlicka, R. Malina, M. Hartl, V. Adam and R. Kizek, Surf. Sci. Rep., 2012, 67(1112), 233-243.

197 J. Pareja, S. Lopez, D. Jaramillo, D. W. Hahn and A. Molina, Appl. Opt., 2013, 52(11), 2470-2477.

198 Y. Liu, B. Bousquet, M. Baudelet and M. Richardson, Spectrochim. Acta, Part B, 2012, 73, 89-92.

199 M. Garcimuno, D. M. D. Pace and G. Bertuccelli, Opt. Laser Technol., 2013, 47, 26-30.

200 G. G. A. de Carvalho, D. Santos, L. C. Nunes, M. D. Gomes, F. D. Leme and F. J. Krug, Spectrochim. Acta, Part B, 2012, 74-75, 162-168.

201 J. Kwak, K. W. Kim, M. Park, J. Kim and K. Park, Environ. Technol., 2012, 33(18), 2177-2184.

202 A. M. Popov, M. O. Kozhnov, T. A. Labutin, S. M. Zaytsev, A. N. Drozdova and N. A. Mityurev, Tech. Phys. Lett., 2013, 39(1), 81-83.

203 V. K. Unnikrishnan, R. Nayak, K. Aithal, V. B. Kartha, C. Santhosh, G. P. Gupta and B. M. Suri, Anal. Methods, 2013, 5(5), 1294-1300.

204 J. Z. Chen, Z. Y. Chen, J. Sun, X. Li, Z. C. Deng and Y. L. Wang, Appl. Opt., 2012, 51(34), 8141-8146.

205 J. Frydenvang, K. M. Kinch, S. Husted and M. B. Madsen, Anal. Chem., 2013, 85(3), 1492-1500.

206 J. El Haddad, M. Villot-Kadri, A. Ismael, G. Gallou, K. Michel, D. Bruyere, V. Laperche, L. Canioni and B. Bousquet, Spectrochim. Acta, Part B, 2013, 79-80, 51-57.

207 S. Majumdar, J. R. Peralta-Videa, H. Castillo-Michel, J. Hong, C. M. Rico and J. L. Gardea-Torresdey, Anal. Chim. Acta, 2012, 755, 1-16.

208 A. Plessow, X-Ray Spectrom., 2013, 42(1), 19-32.

209 I. M. Ismail and M. S. Rihawy, Nucl. Instrum. Methods Phys. Res., Sect. B, 2013, 296, 50-53.
210 K. Wovkulich, B. J. Mailloux, B. C. Bostick, H. L. Dong, M. E. Bishop and S. N. Chillrud, Geochim. Cosmochim. Acta, 2012, 91, 254-270.

211 J. Malherbe and F. Claverie, Anal. Chim. Acta, 2013, 773, 37-44.

212 N. G. Paltridge, L. J. Palmer, P. J. Milham, G. E. Guild and J. C. R. Stangoulis, Plant Soil, 2012, 361(1-2), 251-260.

213 N. G. Paltridge, P. J. Milham, J. I. Ortiz-Monasterio, G. Velu, Z. Yasmin, L. J. Palmer, G. E. Guild and J. C. R. Stangoulis, Plant Soil, 2012, 361(1-2), 261-269.

214 R. Terzano, M. Alfeld, K. Janssens, B. Vekemans, T. Schoonjans, L. Vincze, N. Tomasi, R. Pinton and S. Cesco, Anal. Bioanal. Chem., 2013, 405(10), 3341-3350.

215 T. Ducic, M. Borchert, A. Savic, A. Kalauzi, A. Mitrovic and K. Radotic, J. Synchrotron Radiat., 2013, 20, 339-346.

216 I. De La Calle, M. Costas, N. Cabaleiro, I. Lavilla and C. Bendicho, Food Chem., 2013, 138(1), 234-241.

217 G. L. Bosco, TrAC, Trends Anal. Chem., 2013, 45, 121-134.

218 R. O. Bastos, F. L. Melquiades and G. E. V. Biasi, X-Ray Spectrom., 2012, 41(5), 304-307.

219 T. I. McLaren, C. N. Guppy and M. K. Tighe, Soil Sci. Soc. Am. J., 2012, 76(4), 1446-1453.

220 S. Reidinger, M. H. Ramsey and S. E. Hartley, New Phytol., 2012, 195(3), 699-706.

221 Y. P. Lian, W. Zhen, Z. G. Tai, Y. L. Yang, J. Song and Z. H. Li, Rare Met., 2012, 31(5), 512-516.

222 M. M. Hasssanien and A. A. Z. Ali, Arabian J. Sci. Eng., 2012, 37(5), 1271-1282.

223 E. D. Silva, L. O. Correia, L. O. dos Santos, E. V. D. Vieira and V. A. Lemos, Microchim. Acta, 2012, 178(3-4), 269-275.

224 G. Leng, H. Yin, S. B. Li, Y. Chen and D. Z. Dan, Talanta, 2012, 99, 631-636.

225 V. A. Lemos and U. S. Vieira, Microchim. Acta, 2013, 180(56), 501-507.

226 D. Bakircioglu, Environ. Sci. Pollut. Res., 2012, 19(6), 24282437.

227 S. Sacmaci, S. Kartal and S. Dural, J. Braz. Chem. Soc., 2012, 23(6), 1033-1040.

228 S. Sacmaci, S. Kartal and M. Sacmaci, Int. J. Environ. Anal. Chem., 2012, 92(14), 1626-1637.

229 S. Saracoglu, M. Soylak, D. Cabuk, Z. Topalak and Y. Karagozlu, J. AOAC Int., 2012, 95(3), 892-896.

230 M. Tufekci, V. N. Bulut, H. Elvan, D. Ozdes, M. Soylak and C. Duran, Environ. Monit. Assess., 2013, 185(2), 11071115.

231 S. Saracoglu, E. Yilmaz and M. Soylak, Curr. Anal. Chem., 2012, 8(3), 358-364.

232 M. Karimi, V. Amani, F. Aboufazeli, H. Zhad, O. Sadeghi and E. Najafi, J. Chem., 2013, 142845.

233 S. Turan, S. Tokalioglu, A. Sahan and C. Soykan, React. Funct. Polym., 2012, 72(10), 722-728.

234 M. Soylak and I. Murat, Food Analytical Methods, 2012, 5(5), 1003-1009.

235 E. Yilmaz, Z. A. Alothman, H. M. T. Sumayli, M. Ibrahim and M. Soylak, J. AOAC Int., 2012, 95(4), 1205-1210.

236 Y. H. Zhai, Q. He, Q. Han and S. E. Duan, Microchim. Acta, 2012, 178(3-4), 405-412. 
237 M. Soylak and Y. E. Unsal, J. AOAC Int., 2012, 95(4), 11831188.

238 Y. Jiang, H. T. Zhang, Q. He, Z. Hu and X. J. Chang, Microchim. Acta, 2012, 178(3-4), 421-428.

239 F. Tajabadi, Y. Yamini and M. R. Sovizi, Microchim. Acta, 2013, 180(1-2), 65-73.

240 R. K. Sharma, A. Pandey, S. Gulati and A. Adholeya, Chem. Eng. J., 2012, 210, 490-499.

241 H. Ebrahimzadeh, N. Tavassoli, O. Sadeghi, M. M. Amini, S. Vahidi, S. Aghigh and E. Moazzen, Food Analytical Methods, 2012, 5(5), 1070-1078.

242 M. Behbahani, M. Taghizadeh, A. Bagheri, H. Hosseini, M. Salarian and A. Tootoonchi, Microchim. Acta, 2012, 178(3-4), 429-437.

243 B. F. Somera, M. Z. Corazza, M. J. S. Yabe, M. G. Segatelli, E. Galunin and C. R. T. Tarley, Water, Air, Soil Pollut., 2012, 223(9), 6069-6081.

244 A. Bagheri, M. Taghizadeh, M. Behbahani, A. A. Asgharinezhad, M. Salarian, A. Dehghani, H. Ebrahimzadeh and M. M. Amini, Talanta, 2012, 99, 132-139.

245 A. Bagheri, M. Behbahani, M. M. Amini, O. Sadeghi, A. Tootoonchi and Z. Dahaghin, Microchim. Acta, 2012, 178(3-4), 261-268.

246 E. Herincs, M. Puschenreiter, W. Wenzel and A. Limbeck, J. Anal. At. Spectrom., 2013, 28(3), 354-363.

247 K. P. Jochum, U. Nohl, N. Rothbarth, B. Schwager, B. Stoll and U. Weis, Geostand. Geoanal. Res., 2012, 36(4), 415-419.

248 Z. Cheng, H. Huang, M. Liu, T. Gu, W. Yan and M. Yan, Geostand. Geoanal. Res., 2013, 37(1), 95-101.

249 Q. C. Yang, K. P. Jochum, B. Stoll, U. Weis, D. Kuzmin, M. Wiedenbeck, H. Traub and M. O. Andreae, Geostand. Geoanal. Res., 2012, 36(3), 301-313.

250 S. Gilbert, L. Danyushevsky, P. Robinson, C. WohlgemuthUeberwasser, N. Pearson, D. Savard, M. Norman and J. Hanley, Geostand. Geoanal. Res., 2013, 37(1), 51-64.

251 W. Abouchami, S. J. G. Galer, T. J. Horner, M. Rehkamper, F. Wombacher, Z. C. Xue, M. Lambelet, M. Gault-Ringold, C. H. Stirling, M. Schonbachler, A. E. Shiel, D. Weis and P. F. Holdship, Geostand. Geoanal. Res., 2013, 37(1), 5-17.

252 T. Goldberg, G. Gordon, G. Izon, C. Archer, C. R. Pearce, J. McManus, A. D. Anbar and M. Rehkamper, J. Anal. At. Spectrom., 2013, 28(5), 724-735.

253 N. D. Greber, C. Siebert, T. F. Nagler and T. Pettke, Geostand. Geoanal. Res., 2012, 36(3), 291-300.

254 J. R. Darling, C. D. Storey, C. J. Hawkesworth and P. C. Lightfoot, Geochim. Cosmochim. Acta, 2012, 99, 1-17.

255 Z. C. Liu, F. Y. Wu, Y. H. Yang, J. H. Yang and S. A. Wilde, Chem. Geol., 2012, 334, 221-239.

256 M. Wiedenbeck, R. Bugoi, M. J. M. Duke, T. Dunai, J. Enzweiler, M. Horan, K. P. Jochum, K. Linge, J. Kosler, S. Merchel, L. F. G. Morales, L. Nasdala, R. Stalder, P. Sylvester, U. Weis and A. Zoubir, Geostand. Geoanal. Res., 2012, 36(4), 337-398.

257 M. E. Shaheen, J. E. Gagnon and B. J. Fryer, Chem. Geol., 2012, 330, 260-273.
258 J. I. Kimura and Q. Chang, J. Anal. At. Spectrom., 2012, 27(9), 1549-1559.

259 G. Velasquez, A. Y. Borisova, S. Salvi and D. Beziat, Geostand. Geoanal. Res., 2012, 36(3), 315-324.

260 J. M. Koornneef, L. Dorta, B. Hattendorf, G. H. Fontaine, B. Bourdon, A. Stracke, P. Ulmer and D. Gunther, J. Anal. At. Spectrom., 2012, 27(11), 1863-1874.

261 M. W. Loewen and A. J. R. Kent, J. Anal. At. Spectrom., 2012, 27(9), 1502-1508.

262 L. Flamigni, J. Koch and D. Gunther, Spectrochim. Acta, Part $B, 2012,76,70-76$.

263 Z. C. Hu, Y. S. Liu, S. Gao, S. Q. Xiao, L. S. Zhao, D. Gunther, M. Li, W. Zhang and K. Q. Zong, Spectrochim. Acta, Part B, 2012, 78, 50-57.

264 Z. C. Hu, Y. S. Liu, S. Gao, W. G. Liu, W. Zhang, X. R. Tong, L. Lin, K. Q. Zong, M. Li, H. H. Chen, L. Zhou and L. Yang, J. Anal. At. Spectrom., 2012, 27(9), 1391-1399.

265 J. Hammerli, B. Rusk, C. Spandler, P. Emsbo and N. H. S. Oliver, Chem. Geol., 2013, 337, 75-87.

266 T. U. Schlegel, M. Walle, M. Steele-MacInnis and C. A. Heinrich, Chem. Geol., 2012, 334, 144-153.

267 M. Leisen, J. Dubessy, M. C. Boiron and P. Lach, Geochim. Cosmochim. Acta, 2012, 90, 110-125.

268 M. Leisen, M. C. Boiron, A. Richard and J. Dubessy, Chem. Geol., 2012, 330, 197-206.

269 A. A. Nemchin, M. S. A. Horstwood and M. J. Whitehouse, Elements, 2013, 9(1), 31-37.

270 C. R. M. McFarlane and Y. Luo, Geosci. Can., 2012, 39(3), 158-172.

271 J. A. Petrus and B. S. Kamber, Geostand. Geoanal. Res., 2012, 36(3), 247-270.

272 C. M. Allen and I. H. Campbell, Chem. Geol., 2012, 332, 157165.

273 J. M. Cottle, A. R. Kylander-Clark and J. C. Vrijmoed, Chem. Geol., 2012, 332, 136-147.

274 J. F. Sun, J. H. Yang, F. Y. Wu, L. W. Xie, Y. H. Yang, Z. C. Liu and X. H. Li, Chin. Sci. Bull., 2012, 57(20), 2506-2516.

275 M. Bertini, A. Izmer, F. Vanhaecke and E. M. Krupp, J. Anal. At. Spectrom., 2013, 28(1), 77-91.

276 T. Ulrich and B. S. Kamber, Geostand. Geoanal. Res., 2013, 37(2), 169-188.

277 D. A. Frick and D. Gunther, J. Anal. At. Spectrom., 2012, 27(8), 1294-1303.

278 R. B. Anderson, J. F. Bell, R. C. Wiens, R. V. Morris and S. M. Clegg, Spectrochim. Acta, Part B, 2012, 70, 24-32.

279 M. D. Dyar, M. L. Carmosino, E. A. Breves, M. V. Ozanne, S. M. Clegg and R. C. Wiens, Spectrochim. Acta, Part B, 2012, 70, 51-67.

280 C. B. Stipe, E. Guevara, J. Brown and G. R. Rossman, Spectrochim. Acta, Part B, 2012, 70, 45-50.

281 J. Rakovsky, O. Musset, J. Buoncristiani, V. Bichet, F. Monna, P. Neige and P. Veis, Spectrochim. Acta, Part B, 2012, 74-75, 57-65.

282 C. Bendicho, I. Lavilla, F. Pena-Pereira and V. Romero, J. Anal. At. Spectrom., 2012, 27(11), 1831-1857.

283 W. Zhang, Z. C. Hu, Y. S. Liu, H. H. Chen, S. Gao and R. M. Gaschnig, Anal. Chem., 2012, 84(24), 10686-10693. 
284 K. Gopalan, Geostand. Geoanal. Res., 2012, 36(4), 399-405. 285 W. Zhang, Z. C. Hu, Y. S. Liu, L. Chen, H. H. Chen, M. Li, L. S. Zhao, S. H. Hu and S. Gao, Geostand. Geoanal. Res., 2012, 36(3), 271-289.

286 F. G. Pinto, R. Escalfoni and T. D. Saint'Pierre, Anal. Lett., 2012, 45(12), 1537-1556.

287 A. K. Singh, V. Padmasubashini and L. Gopal, J. Radioanal. Nucl. Chem., 2012, 294(1), 19-25.

288 Y. L. Sun, S. L. Sun, C. Y. Wang and P. Xu, Geostand. Geoanal. Res., 2013, 37(1), 65-76.

289 N. N. Fedyunina, K. B. Ossipov, I. F. Seregina, M. A. Bolshov, M. A. Statkus and G. I. Tsysin, Talanta, 2012, 102, 128-131.

290 A. Asfaw, W. R. MacFarlane and D. Beauchemin, J. Anal. At. Spectrom., 2012, 27(8), 1254-1263.

291 D. C. Baxter, I. Rodushkin and E. Engstrom, J. Anal. At. Spectrom., 2012, 27(9), 1355-1381.

292 H. P. Longerich, J. Anal. At. Spectrom., 2012, 27(8), 11811184.

293 M. S. Choi, J. S. Ryu, S. W. Lee, H. S. Shin and K. S. Lee, J. Anal. At. Spectrom., 2012, 27(11), 1955-1959.

294 L. Lobo, V. Devulder, P. Degryse and F. Vanhaecke, J. Anal. At. Spectrom., 2012, 27(8), 1304-1310.

295 S. H. Tian, Z. Q. Hou, A. N. Su, K. J. Hou, W. J. Hu, Z. Z. Li, Y. Zhao, Y. G. Gao, Y. H. Li, D. Yang and Z. S. Yang, Acta Geol. Sin., 2012, 86(5), 1297-1305.

296 T. Nozaki, K. Suzuki, G. Ravizza, J. I. Kimura and Q. Chang, Geostand. Geoanal. Res., 2012, 36(2), 131-148.

297 C. J. M. Lawley and D. Selby, Econ. Geol., 2012, 107(7), 14991505.

298 A. Y. Kramchaninov, I. V. Chernyshev and K. N. Shatagin, J. Anal. Chem., 2012, 67(14), 1084-1092.

299 E. Paredes, D. G. Asfaha and C. R. Quetel, J. Anal. At. Spectrom., 2013, 28(3), 320-326.

300 M. E. Sanchez-Lorda, S. G. de Madinabeitia, C. Pin and J. I. G. Ibarguchi, Int. J. Mass Spectrom., 2013, 333, 34-43.

301 T. Ohno and T. Hirata, Anal. Sci., 2013, 29(1), 47-53.

302 F. Corfu, Geol. Soc. Am. Bull., 2013, 125(1-2), 33-47.

303 F. E. Stanley, J. Anal. At. Spectrom., 2012, 27(11), 1821-1830.

304 M. D. Schmitz and K. F. Kuiper, Elements, 2013, 9(1), 25-30.

305 J. Woodhead and R. Pickering, Chem. Geol., 2012, 322, 290299.

306 J. Woodhead, J. Hellstrom, R. Pickering, R. Drysdale, B. Paul and P. Bajo, Quaternary Geochronology, 2012, 14, 105-113.

307 S. Wakaki and T. Tanaka, Int. J. Mass Spectrom., 2012, 323, 45-54.

308 J. M. Koornneef, C. Bouman, J. B. Schwieters and G. R. Davies, J. Anal. At. Spectrom., 2013, 28(5), 749-754.

309 C. F. Li, X. H. Li, Q. L. Li, J. H. Guo, L. J. Feng and Z. Y. Chu, Anal. Chem., 2012, 84(14), 6040-6047.

310 H. P. Wu, S. Y. Jiang, H. Z. Wei and X. Yan, Int. J. Mass Spectrom., 2012, 328, 67-77.

311 X. Yan, S. Y. Jiang, H. Z. Wei, Y. Yan, H. P. Wu and W. Pu, Chin. J. Inorg. Anal. Chem., 2012, 40(11), 1654-1659.

312 E. M. Peterman, J. M. Mattinson and B. R. Hacker, Chem. Geol., 2012, 312, 58-73.
313 M. H. Huyskens, T. Iizuka and Y. Amelin, J. Anal. At. Spectrom., 2012, 27(9), 1439-1446.

314 P. Hoppe, S. Cohen and A. Meibom, Geostand. Geoanal. Res., 2013, 37(2), 111-154.

315 L. Vetter, R. Kozdon, C. I. Mora, S. M. Eggins, J. W. Valley, B. Honisch and H. J. Spero, Geochim. Cosmochim. Acta, 2013, 107, 267-278.

316 C. Brahmi, I. Domart-Coulon, L. Rougee, D. G. Pyle, J. Stolarski, J. J. Mahoney, R. H. Richmond, G. K. Ostrander and A. Meibom, Coral Reefs, 2012, 31(3), 741-752.

317 A. K. Schmitt and T. Zack, Chem. Geol., 2012, 332, 65-73.

318 A. K. Ault, R. M. Flowers and K. H. Mahan, Earth Planet. Sci. Lett., 2012, 339, 57-66.

319 T. H. Luu, M. Chaussidon, R. K. Mishra, C. Rollion-Bard, J. Villeneuve, G. Srinivasan and J. L. Birck, J. Anal. At. Spectrom., 2013, 28(1), 67-76.

320 M. E. Hartley, T. Thordarson, C. Taylor, J. G. Fitton and EIMF, Chem. Geol., 2012, 334, 312-323.

321 J. W. Boyce, J. M. Eiler and M. B. Channon, Am. Mineral., 2012, 97(7), 1116-1128.

322 M. J. Whitehouse, Geostand. Geoanal. Res., 2013, 37(1), 1933.

323 A. F. A. Marques, S. D. Scott and R. N. S. Sodhi, Can. Mineral., 2012, 50(5), 1305-1320.

324 L. Zimmermann, P. H. Blard, P. Burnard, S. Medynski, R. Pik and N. Puchol, Geostand. Geoanal. Res., 2012, 36(2), 121-129.

325 K. M. Wilcken, S. Freeman, C. Schnabel, S. A. Binnie, S. Xu and R. J. Phillips, Nucl. Instrum. Methods Phys. Res., Sect. B, 2013, 294, 107-114.

326 A. Wallner, K. Melber, S. Merchel, U. Otte, O. Forstner, R. Golser, W. Kutschera, A. Priller and P. Steier, Nucl. Instrum. Methods Phys. Res., Sect. B, 2013, 294, 496502.

327 S. Merchel, W. Bremser, S. Akhmadaliev, M. Arnold, G. Aumaitre, D. L. Bourles, R. Braucher, M. Caffee, M. Christl, L. K. Fifield, R. C. Finkel, S. Freeman, A. RuizGomez, P. W. Kubik, M. Martschini, D. H. Rood, S. G. Tims, A. Wallner, K. M. Wilcken and S. Xu, Nucl. Instrum. Methods Phys. Res., Sect. B, 2012, 289, 68-73.

328 J. Lachner, M. Christl, H. A. Synal, M. Frank and M. Jakobsson, Nucl. Instrum. Methods Phys. Res., Sect. B, 294, 67-71.

329 K. Horiuchi, I. Oniyanagi, H. Wasada and H. Matsuzaki, Nucl. Instrum. Methods Phys. Res., Sect. B, 2013, 294, 72-76.

330 C. Mifsud, T. Fujioka and D. Fink, Nucl. Instrum. Methods Phys. Res., Sect. B, 2013, 294, 203-207.

331 L. Bertrand, M. Cotte, M. Stampanoni, M. Thoury, F. Marone and S. Schoder, Phys. Rep., 2012, 519(2), 51-96.

332 U. Cevik, S. Akbulut, Y. Makarovska and R. Van Grieken, Spectrosc. Lett., 2013, 46(1), 36-46.

333 G. Gauthier, A. L. Burke and M. Leclerc, J. Archaeol. Sci., 2012, 39(7), 2436-2451.

334 R. Redus and A. Huber, X-Ray Spectrom., 2012, 41(6), 401-409. 
335 R. Redus, A. Huber, T. Pantazis, J. Pantazis and B. Cross, X-Ray Spectrom., 2012, 41(6), 393-400.

336 D. Wilhelms-Dick, T. Westerhold, U. Rohl, F. Wilhelms, C. Vogt, T. J. J. Hanebuth, H. Rommermann, M. Kriews and S. Kasten, J. Anal. At. Spectrom., 2012, 27(9), 1574-1584. 337 R. Hennekam and G. de Lange, Limnol. Oceanogr., 2012, 10, 991-1003.
338 H. Rowe, N. Hughes and K. Robinson, Chem. Geol., 2012, 324, 122-131.

339 D. Mitchell, P. Grave, M. Maccheroni and E. Gelman, J. Archaeol. Sci., 2012, 39(9), 2921-2933.

340 S. Liu, Q. H. Li, F. Gan, P. Zhang and J. W. Lankton, J. Archaeol. Sci., 2012, 39(7), 2128-2142.

341 M. Wiedenbeck, Elements, 2013, 9(1), 7-8. 